
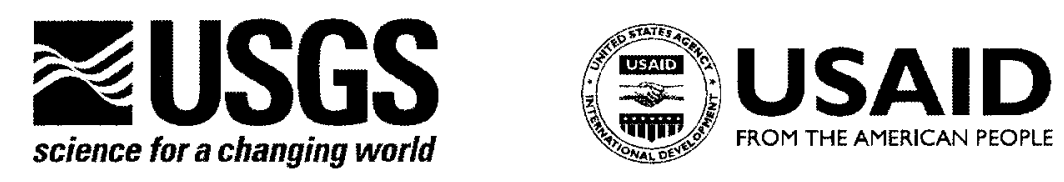

\title{
Seismicity of Afghanistan and Vicinity
}

Edited by James W. Dewey

15088

U.S. Geological Survey Open-File Report 2006-1185

This report is USGS Afghanistan Project Product No. 28

U.S. Department of the Interior

U.S. Geological Survey 


\section{U.S. Department of the Interior \\ DIRK KEMPTHORNE, Secretary}

\section{U.S. Geological Survey \\ P. Patrick Leahy, Acting Director}

U.S. Geological Survey, Reston, Virginia 2006

For product and ordering information:

World Wide Web: http://www.usgs.gov/pubprod

Telephone: 1-888-ASK-USGS

For more information on the USGS-the Federal source for science about the Earth,

its natural and living resources, natural hazards, and the environment:

World Wide Web: http://www.usgs.gov

Telephone: 1-888-ASK-USGS

Suggested citation:

Dewey, James W. (ed.), 2006, Seismicity of Afghanistan and Vicinity, U.S. Geological Survey Open-File Report 2006-1185, 2 Chapters, 2 plates, and accompanying data.

Any use of trade, firm, or product names is for descriptive purposes only and does not imply endorsement by the U.S. Government.

Although this report is in the public domain, permission must be secured from the individual copyright owners to reproduce any copyrighted material contained within this report. 


\section{Contents}

(A) Overview of the Seismicity of Afghanistan, by James W. Dewey, Eric A. Bergman, Margaret G. Hopper, and Stuart A. Sipkin

(B) A Comprehensive Earthquake Catalog for the Afghanistan Region, by Eric A. Bergman

(Plate 1) Instrumental Seismicity (1964-2004) of the Afghanistan Region, by Stuart A. Sipkin, Eric A.

Bergman, Margo L. Johnson, Kenneth S. Rukstales, and James W. Dewey

(Plate 2) Damaging Historic Earthquakes of the Afghanistan Region, by Margaret G. Hopper, Kenneth S.

Rukstales, Margo L. Johnson, James W. Dewey, Eric A. Bergman, and Stuart A. Sipkin 


\section{Overview of the Seismicity of Afghanistan and Vicinity}

By James W. Dewey, Eric A. Bergman, Margaret G. Hopper, Stuart A. Sipkin

Chapter A of Seismicity of Afghanistan and Vicinity

Edited by James W. Dewey

Prepared under the auspices of the U.S. Agency for International Development

Open-File Report 2006-1185-A

This report is USGS Afghanistan Project Product No. 28A

U.S. Department of the Interior

U.S. Geological Survey 


\section{Contents}

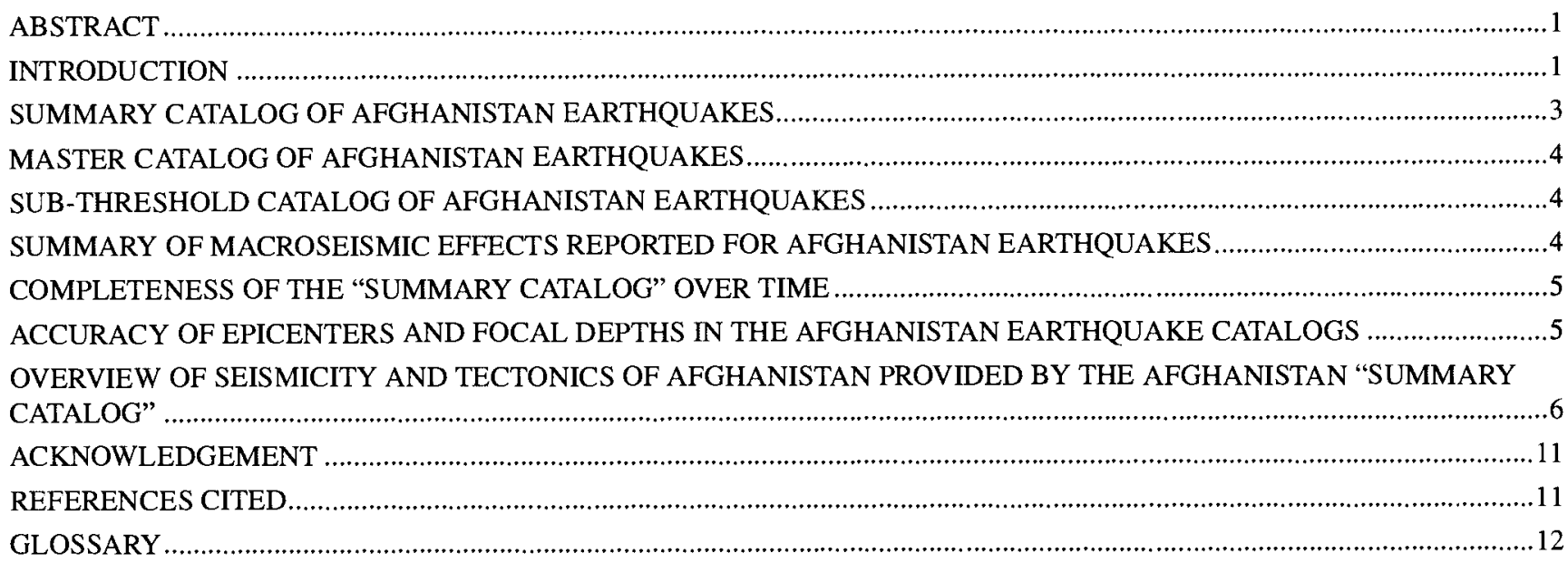

\section{Figures}

Figure 1. Epicenters from the "Summary Catalog of Afghanistan Earthquakes" for the study area

Figure 2. Locations of quality A and quality B epicenters from the "Summary Catalog of Afghanistan Earthquakes" for Afghanistan and immediately adjacent regions

Figure 3. Locations of quality C epicenters from the "Summary Catalog of Afghanistan Earthquakes" for Afghanistan and immediately adjacent regions

Figure 4. Locations of quality M epicenters from the "Summary Catalog of Afghanistan Earthquakes" for Afghanistan and immediately adjacent regions

Figure 5. Epicenters of earthquakes having focal-depths less than $50 \mathrm{~km}$, distinguished by the type of faulting that caused the earthquakes, for Afghanistan and immediately adjacent regions 


\title{
Overview of the Seismicity of Afghanistan and Vicinity
}

\author{
By James W. Dewey', Eric A. Bergman², Margaret G. Hopper', Stuart A. Sipkin'
}

\section{ABSTRACT}

We have prepared a catalog of 12,728 earthquakes that have been recorded in Afghanistan and the surrounding vicinity through mid-December 2004. The catalog is compiled from a number of preexisting source catalogs, and it also includes earthquake epicenters and focal-depths that have been computed especially for this project. The catalog includes historically documented earthquakes from before 1900 , earthquakes of magnitude 5.5 and larger during 1900-63, and earthquakes of magnitude 4.0 and larger since 1964 . The catalog is presented in three formats. One format is a "Summary Catalog of Afghanistan Earthquakes" which contains only our best estimates of the location and magnitude of each earthquake and which will be the version of the catalog used in almost all applications. A second format is a "Master Catalog of Afghanistan Earthquakes" which gives the entire range of locations and magnitudes estimated for each earthquake from the preexisting catalogs and which will be of interest primarily to research seismologists. The third format is a "Summary of Macroseismic Effects Reported for Afghanistan Earthquakes" which provides users with an overview of the effects on humans of past Afghanistan earthquakes, including those that occurred prior to instrumental recording of earthquakes. Included also with this report is a file entitled "SubThreshold Catalog of Afghanistan Earthquakes" which includes seismic events from various source catalogs that did not meet the magnitude criteria for being included in the "Summary Catalog" and "Master Catalog."

The earthquake catalog is most complete and accurate in recent decades, a reflection of the progressive improvement of the global seismographic network with time. The catalog should completely document shocks of magnitude 7 and larger throughout the twentieth century, but some earthquakes with magnitudes between 5.5 and 6.9 are probably missing from the early decades of the twentieth century. For the period before 1900 , the catalog is based entirely on observations of felt reports and damage, and it likely includes only a small fraction of the large earthquakes that actually occurred. However, the pre- 1900 part of the catalog is important to demonstrate the occurrence of

\footnotetext{
${ }^{1}$ U.S. Geological Survey, MS 966

Denver, Colorado 80225

${ }^{2}$ Global Seismological Services

Golden, Colorado 80401
}

large earthquakes in areas within which only small and moderate earthquakes have been recorded since 1900 .

Throughout the time covered by the catalog, shallow-focus earthquake activity has been most intense in the eastern part of Afghanistan, which is one of the principal locations where deformation is occurring as a result of collision between the Indian plate and the Eurasian plate. Significant shallow-focus earthquake activity also occurs in northern Afghanistan. In addition to shallow-focus earthquakes, northeastern Afghanistan has been affected by frequent intermediate-depth (focal depths greater than $70 \mathrm{~km}$ ) earthquakes. The rate of earthquake activity in southwestern Afghanistan is low.

This chapter is an overview that defines the earthquake parameters included in the "Summary Catalog" and the "Summary of Macroseismic Effects." Chapter B summarizes compilation of the "Master Catalog" and "Sub-Threshold Catalog" and documents their formats. The "Summary Catalog" itself is presented as a comma-delimited ASCII file, the "Summary of Macroseismic Effects" is presented as an html file, and the "Master Catalog" and "Sub-Threshold Catalog" are presented as flat ASCII files. Finally, this report includes as separate plates a digital image of a map of epicenters of earthquakes occurring since 1964 (plate 1) and a representation of areas of damage or strong shaking from selected past earthquakes in Afghanistan and vicinity (plate 2).

\section{INTRODUCTION}

The Afghanistan earthquake catalog is designed to help evaluate the seismic hazards of the country, which in turn will support the development and reconstruction of Afghanistan's infrastructure. The catalog will be used in the seismic hazards study to help define earthquake sources in and near Afghanistan on the basis of the distribution and focal mechanisms of the catalogued earthquakes and on the basis of the locations of the earthquakes with respect to mapped geologic faults and boundaries of major tectonic plates (Wheeler and others, 2005). The catalog will also be used to derive estimates of the frequency of strong earthquakes for most source zones.

We compiled the Afghanistan earthquake catalog from 26 preexisting source catalogs, which was necessary because no single preexisting catalog listed all earthquakes that could influence the hazard calculation. Since a particular significant earthquake might be listed in multiple catalogs, some with different epicenters and magnitudes, we formalized a scheme to 

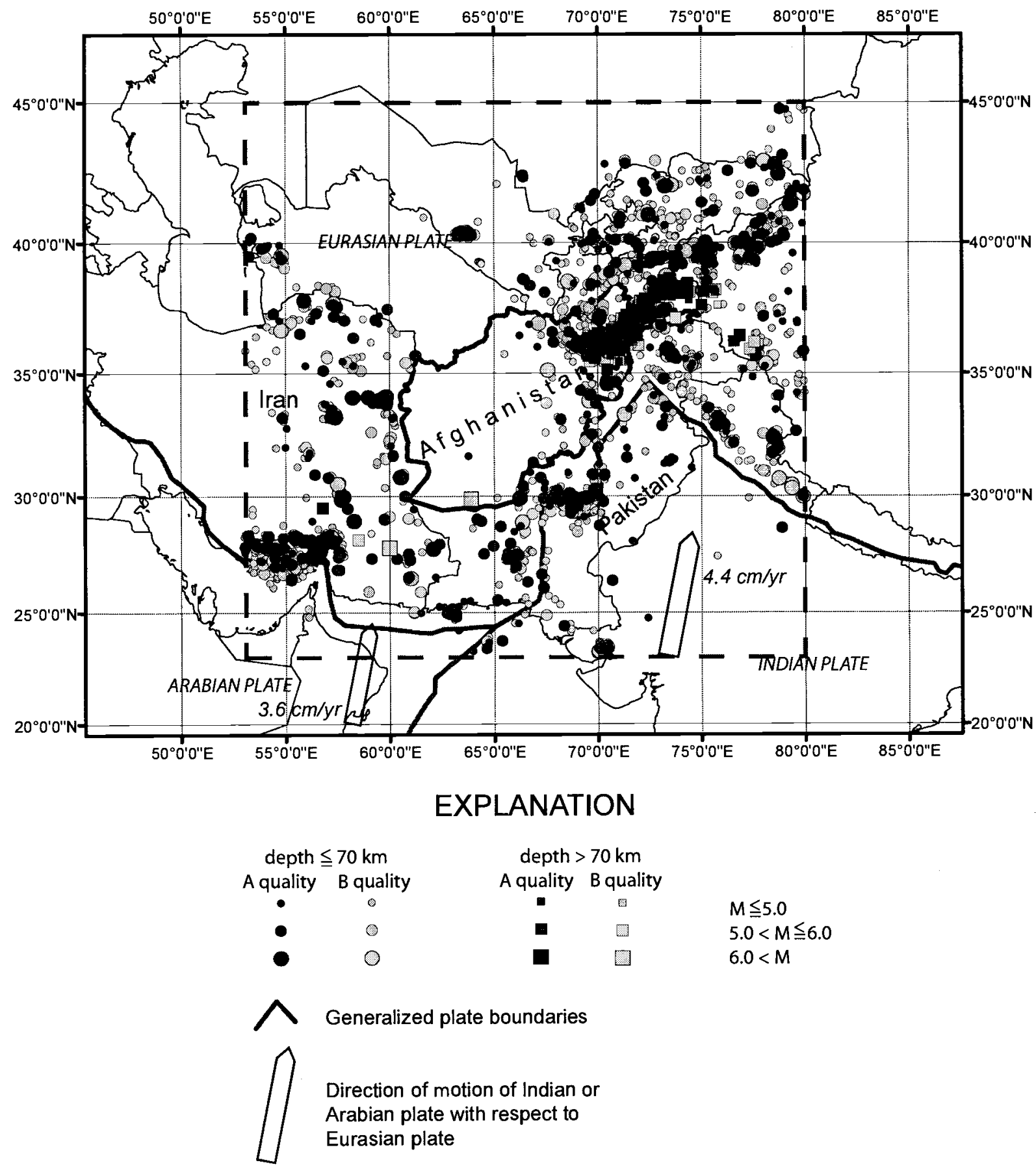

Figure 1. Epicenters from the "Summary Catalog of Afghanistan Earthquakes" for the study area (within dashed rectangle). "A" quality symbols identify earthquakes whose epicenters and focal depths are determined with good accuracy and "B" quality symbols identify earthquakes whose epicenters are determined with good accuracy but whose focal-depths are not reliably determined. Plate velocities shown by the plate-motion vectors are those implied by the model of Demets and others (1994; see discussion in Wheeler and others, 2005). M, magnitude. 
select our preferred epicenter and magnitude. We also used an up-to-date location procedure to relocate the epicenters for the vast majority of the earthquakes listed in the 26 source catalogs. E. A. Bergman (Chapter B) describes in detail the procedures for compiling the catalog and recalculating earthquake locations.

The Afghanistan earthquake catalog covers the region of central Asia between lat. $23^{\circ} \mathrm{N}$. and $45^{\circ} \mathrm{N}$. and between long. $53^{\circ} \mathrm{E}$. and $80^{\circ} \mathrm{E}$. (fig. 1). The catalog's coverage extends well beyond the boundaries of Afghanistan proper because some faults and seismic source zones extend beyond the national boundaries, and the ability to properly characterize a fault or seismic source zone may require information about seismic events outside of Afghanistan. In addition, large earthquakes that are centered outside of the country could cause damaging or alarming shaking within the country.

In compiling the catalog, we have devoted our efforts to earthquakes large enough to influence seismic hazards estimates. For the period 1964 to mid-December 2004, the Afghanistan earthquake catalog includes all previously cataloged shocks from the Afghanistan region that had magnitudes of 4.0 or greater. For the period 1900-63, the Afghanistan earthquake catalog includes all previously cataloged shocks from the Afghanistan region that had magnitudes of 5.5 or larger. For the period before 1900 , all previously cataloged shocks are included in the Afghanistan earthquake catalog. The vast majority of shocks smaller than these thresholds are unlikely to be located with sufficient precision to be useful for seismic hazards estimates.

We present the Afghanistan catalog in three formats. The "Summary Catalog of Afghanistan Earthquakes" presents, for each earthquake, the location (epicenter and focal-depth) and magnitude that we think best represents the earthquake. For most users, the "Summary Catalog" will contain all of the information that they need for their own study of Afghanistan earthquakes. The "Master Catalog of Afghanistan Earthquakes" presents, for each earthquake, the epicenters, focal-depths, and magnitudes that are listed for the earthquake in any of the 26 preexisting source catalogs used in this study. The "Master Catalog" could be confusing to non-specialists because of the multiplicity of epicenters, focal-depths, and magnitudes and because the entries from different source catalogs include supplementary data that differ from one source catalog to another. Nonetheless, the "Master Catalog" will be useful to seismologists who need the in-depth data to resolve uncertainties about specific earthquakes. The "Summary of Macroseismic Effects Reported for Afghanistan Earthquakes" contains written descriptions of the effects of the larger earthquakes on people, human-structures, and natural landscape. The "Summary Catalog," the "Master Catalog," and the "Summary of Macroseismic Effects" are all included with this report. The report also includes a "SubThreshold Catalog of Afghanistan Earthquakes," a catalog of seismic events that were listed in the 26 source catalogs but that were too small to include in the "Master Catalog,"

\section{SUMMARY CATALOG OF AFGHANISTAN EARTHQUAKES}

The "Summary Catalog of Afghanistan earthquakes" lists 12,728 earthquakes that occurred from the second millennium B.C. to December 2004, formatted in one line per earthquake. Commonly, the preferred location and magnitude have been selected from among several different estimates of both location and magnitude. Rationales for selecting the listed locations and magnitudes are given in Chapter B. The following characteristics of the earthquakes are listed:

Year, month, day: The date on which the earthquake occurred. For some earthquakes that occurred prior to the middle of the nineteenth century, the date may be uncertain by days, months, or (for the earliest earthquakes) years. Entries of ' 0 ' for "month" or "day" indicate that the month or day of the earthquake is unknown.

Hour, minute and second of the origin time: The time at which the earthquake occurred in hours, minutes, and seconds. For earthquakes occurring after 1900 , the origin time is given in Universal, or "Greenwich," time, which is $4 \frac{1}{2}$ hours behind the local time in Afghanistan. The origin times of many earlier earthquakes are given in local time rather than Universal time. If the source catalog did not specify origin time to the full precision allowed by the format of the "Summary Catalog," fields that are blank in the source catalog are represented as " 0 " in the "Summary Catalog."

Latitude, longitude: The geographic coordinates of the epicenter of the earthquake.

Depth: The depth (in kilometers) of the earthquake hypocenter below the Earth's surface.

Magnitude (abbreviated “M"): The preferred magnitude of the earthquake, commonly selected from among several slightly different magnitude estimates. If more than one type of magnitude has been assigned to a single earthquake, the order of preference is moment-magnitude $\left(\mathrm{M}_{\mathrm{W}}\right)$, surface-wave magnitude $\left(\mathrm{M}_{\mathrm{S}}\right)$, broadband body wave $\left(\mathrm{M}_{\mathrm{B}}\right)$, short-period body-wave magnitude $\left(\mathrm{m}_{\mathrm{b}}\right)$, and unknown magnitude type. Explanations of these different magnitude types may be found in Utsu (2002).

Magnitude type (abbreviated "mtype"): The type of magnitude corresponding to the preferred magnitude. "W" denotes moment magnitude, " $S$ " denotes surface-wave magnitude, " $B$ " denotes broadband body-wave magnitude, " $b$ " denotes body-wave magnitude, and blank is used for unknown magnitude types.

Descriptor of the quality of epicenter and focal-depth determination (abbreviated "Q"):

A - Good accuracy of both epicenter and focal depth. 
B - Good accuracy of epicenter; focal depth poorly constrained or fixed to values similar to those of nearby earthquakes for which the focal-depth is well determined.

C - Less reliable epicenter and focal depth, 1900-2004. The vast majority of C-quality epicenters are estimated from instrumental observations, but a few are estimated from noninstrumental observations.

M - Earthquake occurred prior to 1900 , and the epicenter and focal-depth of the earthquake are estimated from noninstrumental, "macroseismic" observations.

Epsource: Source of the origin-time, latitude, longitude, and focal depth given in the table. The following abbreviations are used, as discussed in more detail in Chapter B:

$\mathrm{ABE}-\mathrm{Abe}(1981,1984)$ or Abe and Noguchi (1983a,b)

AB 1 - Ambraseys and Bilham (2003a)

AM - Ambraseys and Melville (1982)

CEN - “Centennial Catalog," Engdahl and Villaseñor (2002)

CHI - "China" catalog, U.S. Geological Survey (2005a)

EHB, EHBI, EHBS - Computed with the methodology of Engdahl and others (1998). See Chapter B for explanation of the distinction between these abbreviations.

GR - Gutenberg and Richter (1954)

IND - "India" catalog, U.S. Geological Survey (2005b)

ISC - Published by the International Seismological Centre (2005)

ISS - Published in the International Seismological Summary, under the auspices of the International Union of Geodesy and Geophysics (Adams, 2002).

NOAA - Dunbar and others (1992)

PDE - Published in the "Preliminary Determination of Epicenters" seismic bulletin by the U.S. Geological Survey or its predecessors.

ROTH - Rothé (1969)

SSR - "USSR" catalog, Kondorskaya and Shebalin (1982)

EB, EBS - Specially computed for this study by E. A. Bergman (Chapter B).

As noted in Chapter B, for 82 of the events, the "Epsource" is flagged with a " + ," indicating that the preferred origin is in some respect a compromise between the origin given by "Epsource" and the origin given in another source catalog.

Magsource: Source of the magnitudes given above. In addition to the abbreviations for "Epsource" (above), the following abbreviations are used: GS - U.S. Geological Survey Moment Tensor
(Mw)

HRV - Harvard University Centroid Moment Tensor (Mw)

OMT - Moment tensor from other source (Mw).

\section{MASTER CATALOG OF AFGHANISTAN EARTHQUAKES}

The "Master Catalog of Afghanistan Earthquakes" is a compilation of earthquake information contained in all of the 26 source catalogs from which preferred epicenters and magnitudes were extracted to obtain the "Summary Catalog of Afghanistan Earthquakes." Refer to Chapter B for an explanation of the compilation of the catalog and parameters listed in the catalog. The catalog is intended for use by specialists who seek the full range of data from which preferred parameters were taken for the "Summary Catalog."

\section{SUB-THRESHOLD CATALOG OF AFGHANISTAN EARTHQUAKES}

The "Sub-Threshold Catalog of Afghanistan Earthquakes" contains seismic events from the 26 source catalogs that did not meet the magnitude criteria for being included in the "Summary Catalog" and the "Master Catalog," As with the "Master Catalog," there may be multiple entries for the same earthquake. Refer to Chapter B for explanation of the compilation of the catalog and parameters listed in the catalog. There are 9,736 earthquakes listed in the "Sub-Threshold Catalog."

\section{SUMMARY OF MACROSEISMIC EFFECTS REPORTED FOR AFGHANISTAN EARTHQUAKES}

The "Summary Of Macroseismic Effects Reported For Afghanistan Earthquakes" contains narrative descriptions of the effects of earthquakes in Afghanistan and the surrounding region on people, human structures, and the natural landscape. The entry for each earthquake references the source for the entry. Included with the narrative descriptions are the following descriptors from the "Summary Catalog" (see section above entitled "Summary Catalog of Afghanistan Earthquakes"):

Year, month, day ("month" and "day" are abbreviated "Mo" and "Dy," respectively).

Hour and minute of origin time (abbreviated " $\mathrm{Hr}$ " and "Mi," respectively).

Latitude, longitude (abbreviated "Lat" and "Lon,"

respectively).

Depth (abbreviated "Dep"),

Magnitude (abbreviated "M").

The vast majority of the narrative descriptions are extracted verbatim from Ambraseys and Melville (1982), Ambraseys and Bilham (2003a), or Ambraseys and Bilham (2003b). Yeats 
and Madden (2006) provide a detailed description of damage due to the earthquake of 25 March 2002, from which we extract a summary paragraph. Additional observations come from international seismological bulletins: the "International Seismological Summary," Seismological Bulletins of the U.S. Coast and Geodetic Survey, Bulletins of the Bureau Central International de Séismologie, and the Preliminary Determination of Epicenters bulletin of the U.S. Geological Survey. For some earthquakes, the macroseismic observations have been interpreted in terms of a Modified Mercalli Intensity (see Plate 2) and the earthquake's maximum Modified Mercalli Intensity listed as an Arabic numeral in the column headed by the abbreviation "MMIo."

We include the "Summary of Macroseismic Effects" because we think it is valuable for those concerned with the seismic hazards of Afghanistan to have these descriptions available along with the earthquake catalogs. If, however, readers of the "Summary of Macroseismic Effects" wish to cite some of the narratives, they should cite the original sources.

Plate 2 provides map representations of felt areas and sites of damage associated with major earthquakes in and near Afghanistan. These maps are based on the data that are in the "Sumnary of Macroseismic Effects." Maps such as these are valuable for showing the sizes of the areas in which Afghanistan earthquakes have been felt or have caused damage.

\section{COMPLETENESS OF THE "SUMMARY CATALOG" OVER TIME}

For most of the four millennia spanned by the catalog, the earthquake epicenters and magnitudes are inferred from the distribution of damage caused by the earthquakes. The documentation of these earthquakes is necessarily incomplete, and the accuracy of the inferred epicenters and magnitudes varies in quality and may be poor. Comparing the numbers of large $(M>7)$ earthquakes in the twentieth century with those reported in previous centuries, we may infer that the catalog documents fewer than 10 percent of such earthquakes that actually occurred in the ninth through the nineteenth century. Most of the undocumented earthquakes would have occurred in regions that were then not populated by literate people or during times of civil instability when records of natural disasters were not kept. In spite of its incompleteness, the existing record of pre-twentieth century earthquakes adds important knowledge of Afghan seismicity. For example, some of the largest earthquakes in the region of Kabul and southwest of Mazar-e Sharif occurred prior to the twentieth century.

The pre-1900 part of the catalog is based for the most part on work of Ambraseys and Bilham (2003a,b) and Ambraseys and Melville (1982), whose estimates of epicenters and magnitudes are given priority. Additional entries in the pre-1900 part of the "Master Catalog" come from the catalogs of Kondorskaya and Shebalin (1982) and Dunbar and others (1992). In 29 cases, earthquakes are listed in Kondorskaya and Shebalin (1982) or Dunbar and others (1992) as occurring within regions covered by the more recent studies of Ambraseys and Bilham (2003a,b), but these earthquakes are not listed by Ambraseys and Bilham $(2003 \mathrm{a}, \mathrm{b})$ at similar locations and date. We assume in these cases that the earthquakes in question listed by Kondorskaya and Shebalin (1982) or Dunbar and others (1992) were, in fact, considered by Ambraseys and Bilham $(2003 \mathrm{a}, \mathrm{b})$ and rejected by them as being unreliably determined or as corresponding to earthquakes that they cataloged at different locations or dates. The entries of Kondorskaya and Shebalin (1982) or Dunbar and others (1992) for the earthquakes in question are excluded from the "Summary Catalog," but they are included in the "Master Catalog."

For 1900-63, our Afghanistan earthquake catalog lists all previously cataloged earthquakes of magnitude 5.5 and higher and is probably complete at the level of magnitude 7 and larger. Some shocks in the magnitude range 5.5-6.9 that occurred in the first $2 \frac{1}{2}$ decades of the twentieth century would not have been detected by the seismograph networks of the time and would be absent from the catalog.

The Afghanistan catalog is substantially more complete and accurate in the last few decades than in earlier decades and centuries. In the 1960s, the completeness of global earthquake catalogs increased dramatically due to the installation of many new seismographic stations and the development of computerbased procedures to process the increased number of data. For 1964-2004, our catalog lists all previously cataloged earthquakes of magnitude 4.0 and larger. Preliminary analysis suggests that the catalog is complete for magnitude 5.0 and larger earthquakes in the nation of Afghanistan. Although the thousands of shocks in the magnitude range 4.0-4.9 that occurred in 1964-2004 represent an incomplete sample of all Afghanistan shocks of that size, they nonetheless provide important information on active source regions that might produce large future shocks.

\section{ACCURACY OF EPICENTERS AND FOCAL DEPTHS IN THE AFGHANISTAN EARTHQUAKE CATALOGS}

In this section, we use the term "relative accuracy" to describe the precision of the location of an earthquake with respect to the locations of other nearby earthquakes, and we use the term "absolute accuracy" to describe the precision of the location of an earthquake with respect to geographic or geologic features mapped on land. The distinction between relative accuracy and absolute accuracy is scientifically relevant to Afghanistan. A group of earthquakes may be located with good relative accuracy by using data from distant seismographic stations, but because of the scarcity of data from local seismographs the calculated epicenters for the entire group of earthquakes may be biased and shifted with respect to their true positions. For continental regions worldwide, including Central Asia, location biases of as much as $15 \mathrm{~km}$ are not uncommon in the absence of a local seismographic network (Engdahl and others, 1998). We recommend that users of both the "Summary Catalog" and the "Master Catalog" keep 
in mind that the locations of even widely recorded earthquakes could be biased by $15-20 \mathrm{~km}$. A probabilistic seismic-hazard study that is planned for the next phase of this project can easily accommodate the possibility of location biases of this size. Future detailed studies of the mechanics of individual faults in Afghanistan would, however, require the installation of more seismographic stations in the country to improve the absolute accuracy of epicenters.

In the "Summary Catalog," the descriptors of the quality of epicenter and focal-depth determination refer to the relative accuracy with which these events are determined with respect to nearby events of similar quality; the descriptors do not account for systematic bias as previously described. The descriptors for quality (A, B, or C) are based on the distance and azimuth distribution of recording seismographic stations with respect to the epicenter, on the standard errors of observed arrival-times with respect to the epicenters, and on the consistency between the epicenters and focal'depths computed by the method of Engdahl and others (1998) and by the method of E.A. Bergman (see Chapter B). Criteria used to define the descriptors are defined in detail in Chapter $\mathrm{B}$. The descriptor $\mathrm{M}$ is used for all events occurring before 1900 . These earthquakes occurred before seismographic instruments were sufficiently developed to permit reliable location of earthquakes with seismographic data. Epicenters of pre-1900 earthquakes are determined from macroseismic observations, such as the strength of shaking at different locations inferred from the effects of the earthquake on people, buildings, and the natural environment.

Most quality A earthquakes in the "Summary Catalog" should have epicenters and focal-depths that are accurate, in a relative but not absolute sense, to within $15 \mathrm{~km}$. The defining characteristic of these events is that two independent location studies, using the methods of Engdahl and others (1998) and E.A. Bergman (see Chapter B) both achieved high-quality hypocentral estimates that agree with each other within $10 \mathrm{~km}$ in epicenter and depth. The quality A earthquakes are those that are most suitable for discriminating source regions of Afghanistan that produce intermediate-focus shocks (focal depths greater than $70 \mathrm{~km}$ ) from the source regions that produce only shallow shocks. This discrimination is important for seismic hazard evaluation: the large intermediate-focus earthquakes may be felt over a broad area on the Earth's surface, but they do not cause shaking near their epicenters as strong as shallow-focus earthquakes of similar magnitude.

Most quality B earthquakes should also have epicenters that are accurate in a relative sense to within $15 \mathrm{~km}$, but the focal depths of the quality $B$ earthquakes are less reliable than those of quality A events. The defining characteristic of quality B events is that they meet the criteria of quality A events except for focal depth; that is, one or both of the independent studies using the methods of Engdahl and others (1998) and E. A. Bergman (see Chapter B) failed to determine a reliable free-depth solution, or the two solutions differed in depth by more than $10 \mathrm{~km}$.

Most quality $\mathrm{C}$ locations are probably accurate to within $30 \mathrm{~km}$ in a relative sense, but a significant fraction are likely to be mislocated by more than $30 \mathrm{~km}$. Either these earthquakes were recorded from too limited a range of azimuths for us to be confident of their calculated epicenters and focal-depths, or the statistics of the arrival-time observations suggest that the data are insufficiently consistent to guarantee high confidence in the calculated location, or there is no basis for deciding between significantly different independent estimates of the earthquakes' locations. Earthquakes that are located to quality $\mathrm{C}$ may still be important for estimating the frequency of strong earthquakes in areas that are large enough that the poor location accuracy is not important

Quality $\mathrm{M}$ epicenters and focal-depths will generally be the least accurate among the cataloged epicenters because the macroseismic observations on which they depend commonly are obtained from only a few widely scattered locations. Location errors of $50 \mathrm{~km}$ or more would not be surprising for many of these shocks. These earthquakes are still reliably enough located that they can be placed within broad tectonic provinces, such as those discussed by Wheeler and others (2005).

\section{OVERVIEW OF SEISMICITY AND TECTONICS OF AFGHANISTAN PROVIDED BY THE AFGHANISTAN "SUMMARY CATALOG"}

Afghanistan lies within the tectonically deforming southern part of the Eurasian plate. The deformation of the Earth's crust and uppermost mantle is responsible for Afghanistan's mountains and earthquakes and is primarily caused by the northward motion of the Indian plate and Arabian plate against the Eurasian plate, at velocities of 3-4 cm/yr (see, for example, Wheeler and others, 2005). High levels of earthquake activity within the Eurasian plate, due to the northward motion of the Arabian and Indian plates, occur well over $1,000 \mathrm{~km}$ from the southern boundary of the Eurasian plate. The deformation of the southern part of the Eurasian plate is commonly described in terms of the motion of "blocks," or sub-units, of the Eurasian plate with respect to each other. The region underlying southwestern Afghanistan, for example, has been termed the "Sistan" block by Ambraseys and Bilham (2003a).

Plate 1 depicts the post-1963 seismicity of Afghanistan, superimposed on the topography of Afghanistan. In this chapter, we have figures showing separately the well-located (quality A and B, fig. 2) and less well-located (quality C, fig. 3) earthquakes from the era of instrumental seismology and the distribution of pre-instrumental epicenters (quality M, fig. 4). From these maps and figures, it is clear that earthquake activity within Afghanistan and the southern Eurasian plate in general is not uniform. Northern and eastern Afghanistan are situated on belts of intense earthquake activity. Southwestern Afghanistan lies within a relatively undeformed promontory of the Eurasian plate (Wheeler and others, 2005). 


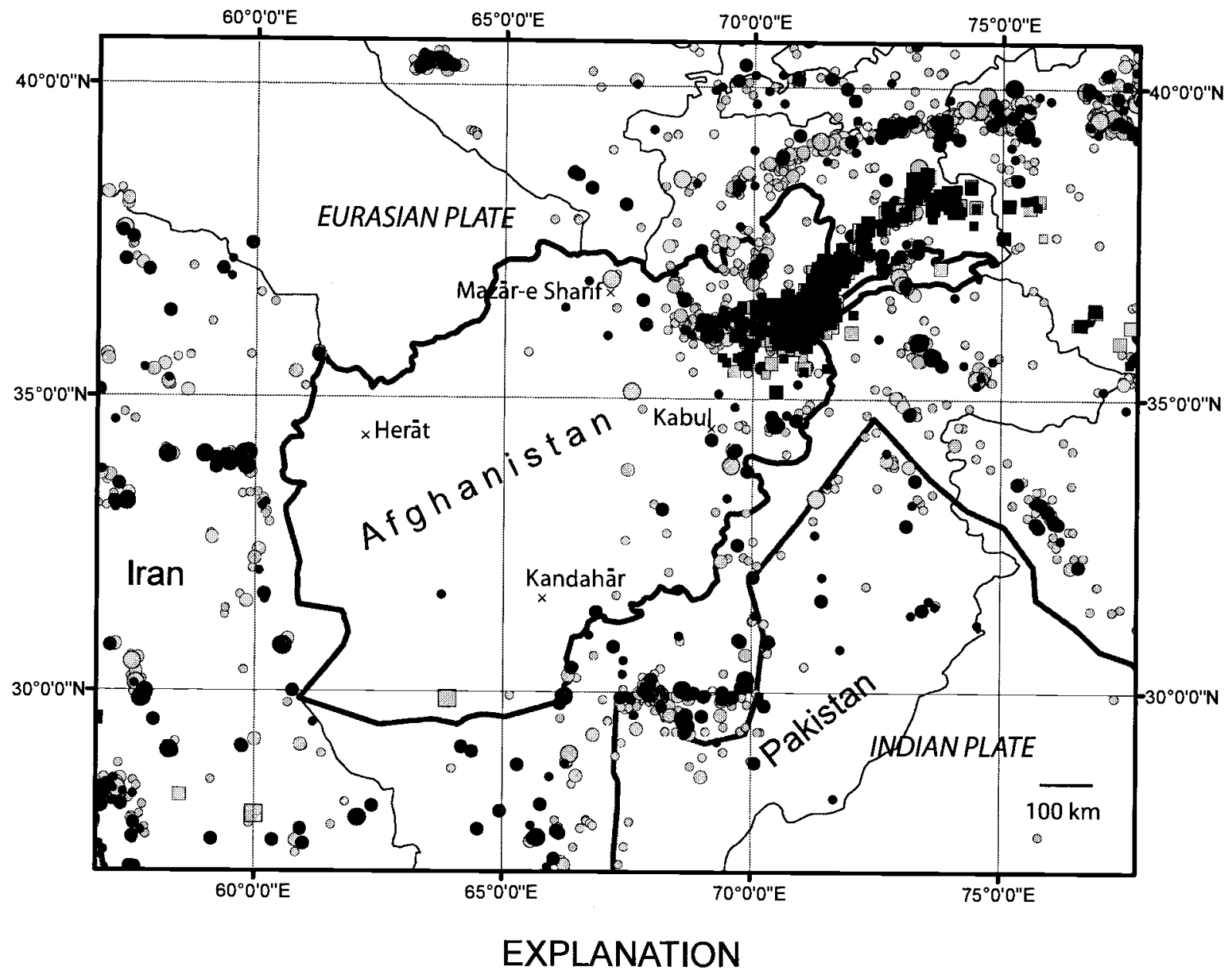

depth $\leqq 70 \mathrm{~km}$

A quality $B$ quality

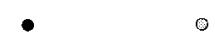

-

$\checkmark$ depth $>70 \mathrm{~km}$

A quality $B$ quality

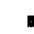

.

-

줎

$M \leqq 5.0$

$5.0<M \leqq 6.0$

$6.0<M$

\section{Generalized boundary, Indian/Eurasian plates}

Figure 2. Locations of quality A and quality B epicenters from the "Summary Catalog of Afghanistan Earthquakes" for Afghanistan and immediately adjacent regions. Note the concentration of deeper earthquakes in northeastern Afghanistan, which result from the subduction beneath Eurasia of oceanic lithosphere that is attached to the Indian plate. M, magnitude. 

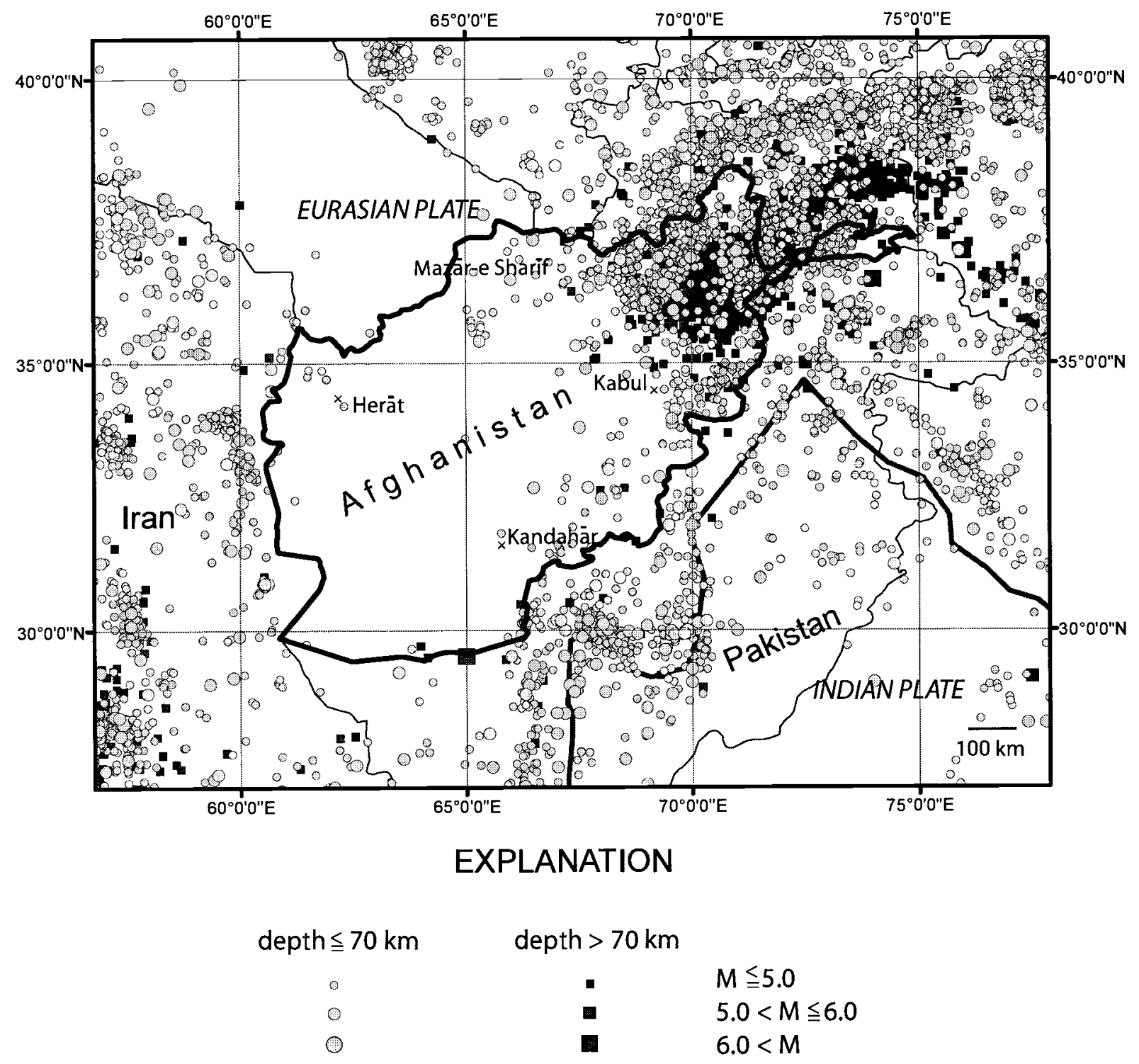

Generalized boundary, Indian/Eurasian plates

Figure 3. Locations of quality C epicenters from the "Summary Catalog of Afghanistan Earthquakes" for Afghanistan and immediately adjacent regions. $M$, magnitude. 


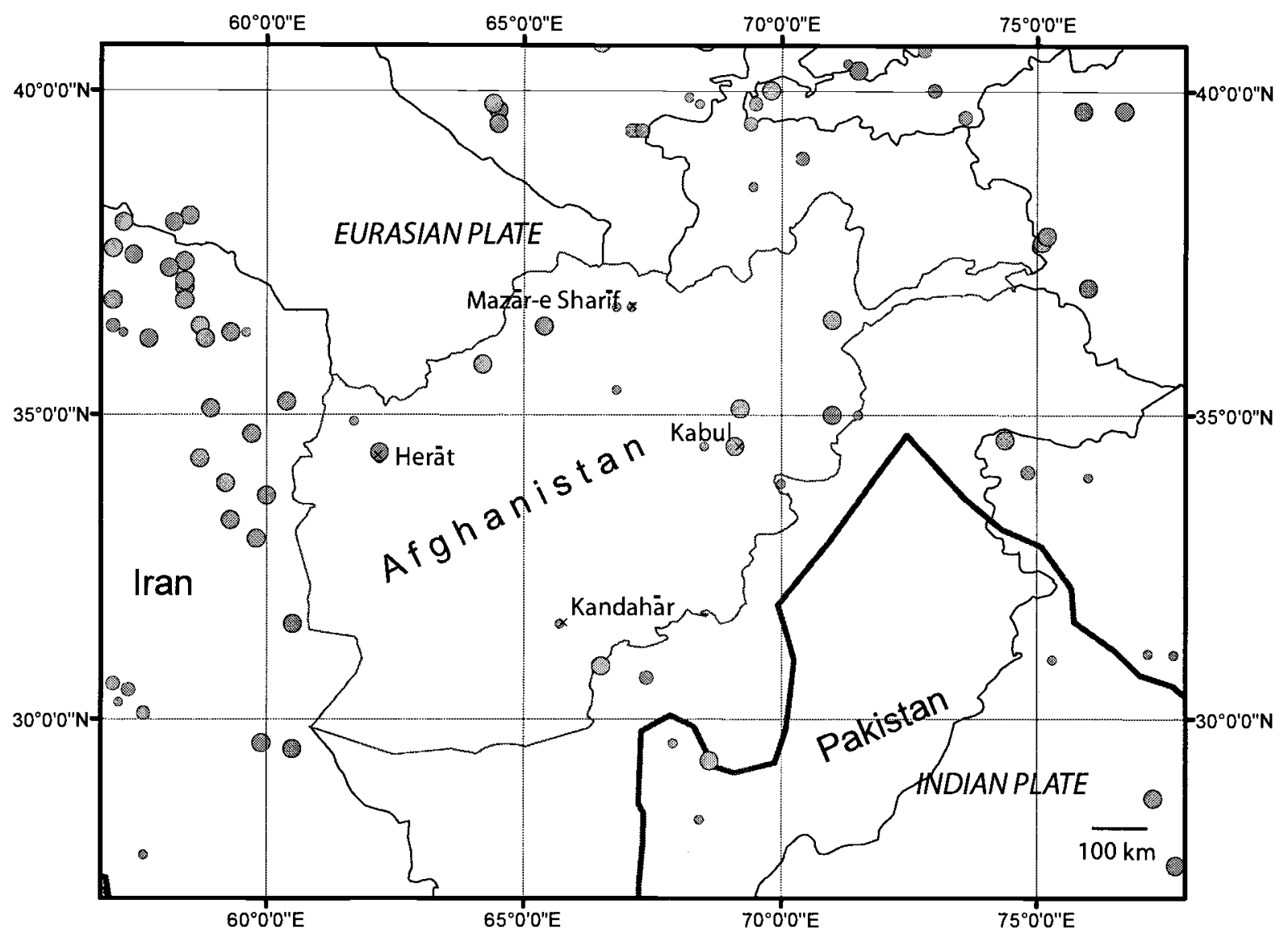

EXPLANATION

- $M \leqq 5.0$

- $5.0<M \leqq 6.0$

- $6.0<M$

Generalized boundary, Indian/Eurasian plates

Figure 4. Locations of quality M epicenters from the "Summary Catalog of Afghanistan Earthquakes" for Afghanistan and immediately adjacent regions. All the events plotted here occurred before 1900 , and their epicenters and magnitudes were estimated from macroseismic data. $M$, magnitude. 


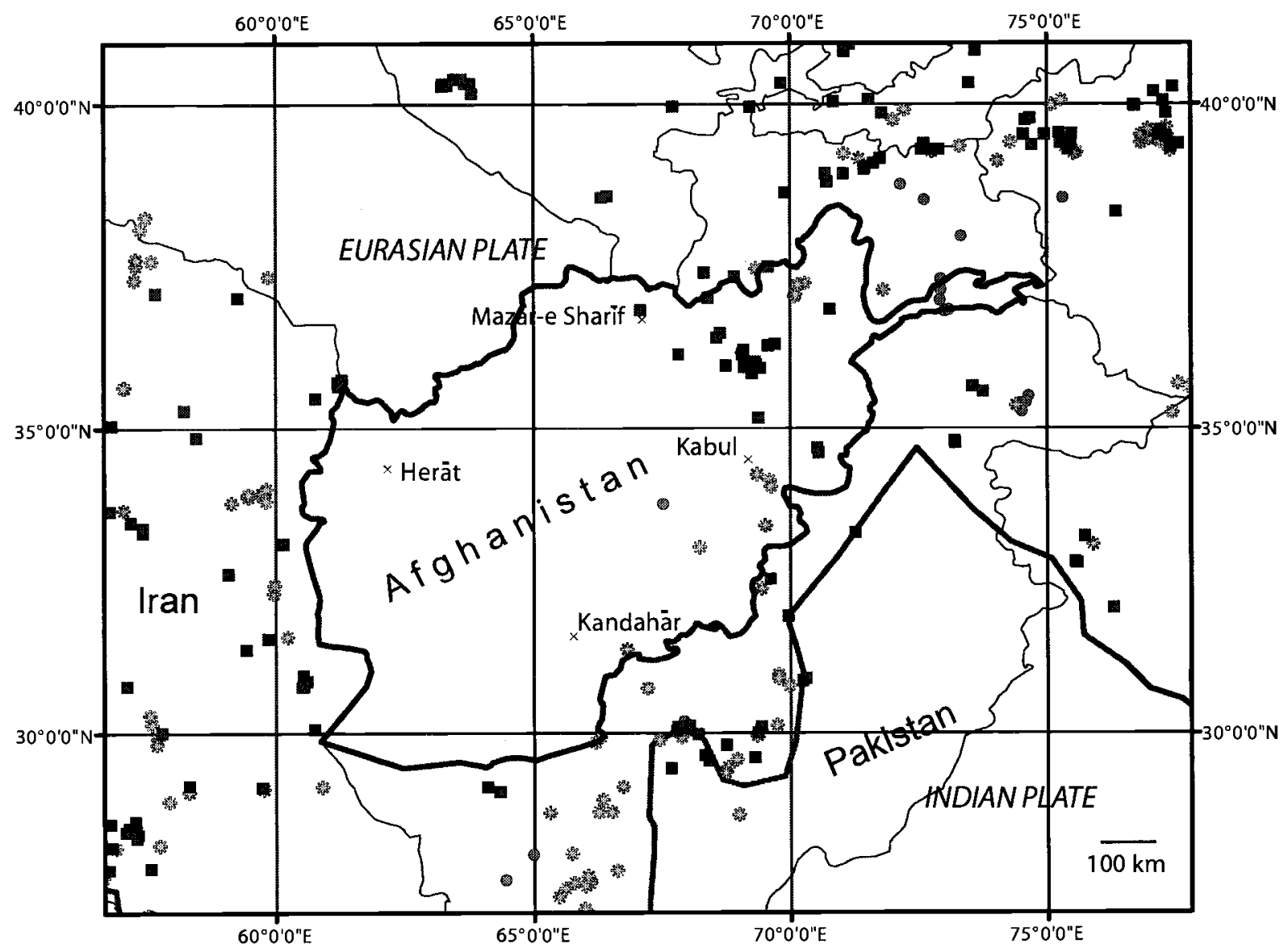

EXPLANATION

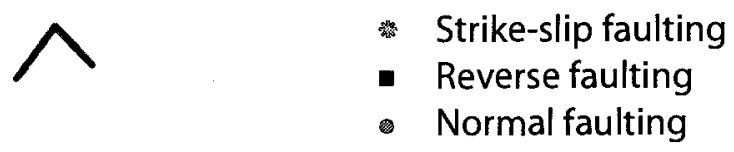

Generalized boundary, Indian/Eurasian plates

Figure 5. Epicenters of earthquakes having focal-depths less than $50 \mathrm{~km}$, distinguished by the type of faulting that caused the earthquakes, for Afghanistan and immediately adjacent regions. The earthquakes are those for which Harvard Moment Tensor focal mechanisms (Dziewonski and others, 1980) were determined and for which the moment-tensor methodology determined a depth of less than $50 \mathrm{~km}$. The shocks occurred in the period from 1976 through October 2004. 
Shallow-focus earthquakes in most of eastern Afghanistan reflect the northward motion of the Earth's crust and mantle beneath Pakistan and India with respect to the promontory of Eurasia to the west. The orientation of the plate-boundary with respect to the direction of plate motion is such that shallow-focus deformation occurs as both left-lateral strike-slip faulting and reverse faulting (Wheeler and others, 2005; fig. 5, this chapter). Eastern Afghanistan is traversed by major conspicuous, young, left-lateral strike-slip faults that approximately parallel the plate boundary, including the Chaman and Darvaz faults (see Wheeler and others for maps showing the position of these faults). Wheeler and others (2005) noted that previous studies have estimated a long-term slip rate of $1-2 \mathrm{~cm} / \mathrm{yr}$ on the Chaman fault. If correct, such a slip rate ranks the Chaman fault as one of the most active continental strike-slip faults in the world and implies a substantial risk of large earthquakes. And, in fact, a section of the fault southeast of Kandahar did produce a significant earthquake in 1892 that caused surface rupture (Wheeler and others, 2005). As is true of plate boundaries in other continental regions of the world, however, seismicity in southeastern Afghanistan and adjacent Pakistan is not restricted exclusively to a single fault such as the Chaman fault but is distributed across a belt that is several hundred kilometers wide (fig. 2).

Northernmost Afghanistan near and west of Mazar-e Sharif has had a moderately high level of earthquake activity since 1900 , and several large, pre-instrumental earthquakes are documented for the region. Ambraseys and Bilham (2003a) proposed that these earthquakes reflect convergence between their Sistan block of southwestern Afghanistan and the rest of the Eurasian plate. It is not clear if the moderate level of seismicity near Herat (figs. 24 ), including one damaging shock in 1102, is to be related to the seismicity near Mazar-e Sharif. The seismicity near Herat may instead be more directly related to a major north-south seismic zone in eastern Iran (figs. 1-4), which reflects the relative motion of the interior of Iran northward with respect to the interior of southwestern Afghanistan (Sistan block).

An intensely active zone of earthquakes having focal-depths greater than $70 \mathrm{~km}$ is present beneath northeastern Afghanistan. These shocks are well-known in seismological literature as the "Hindu Kush" source and probably occur in a remnant or remnants of oceanic crust and upper-mantle that were formerly at the Earth's surface and have been subducted to great depths by the convergence of the Indian and Eurasian plates (see, for example, Pegler and Das, 1998). The largest of the Hindu Kush intermediate-depth earthquakes have magnitudes of more than 7.0. Because of their great depth, they produce less severe shaking near their epicenters than do shallow-focus earthquakes of similar magnitude. Nonetheless, the larger of these earthquakes have caused severe damage and fatalities (see the "Summary of Macroseismic Effects Reported for Afghanistan Earthquakes"). Some intermediate-depth activity also occurs in southernmost Afghanistan as a result of subduction of the Arabian plate (fig. 1) and is represented by a quality B epicenter in figure 2 .

\section{ACKNOWLEDGEMENT}

This report is based on research conducted under Interagency Agreement 306-P-00-04-00566-00 between the U.S. Agency for International Development (USAID) and the USGS.

\section{REFERENCES CITED}

Abe, Katsuyuki, 1981, Magnitudes of large shallow earthquakes from 1904 to 1980: Physics of the Earth and Planetary Interiors, v. 27, p. 72-92.

Abe, Katsuyuki, 1984, Complements to "magnitudes of large shallow earthquakes from 1904 to 1980 ": Physics of the Earth and Planetary Interiors, v. 34, p. 17-23.

Abe, Katsuyuki, and Noguchi, Shin'ichi, 1983a, Determination of magnitude for large shallow earthquakes, 1898-1917: Physics of the Earth and Planetary Interiors, v. 32, p. 45-59.

Abe, Katsuyuki, and Noguchi, Shin' ichi, 1983b, Revision of magnitudes of large shallow earthquakes, 1897-1912: Physics of the Earth and Planetary Interiors, v. 33, p. 1-11.

Adams, R.D., 2002, International seismology, in Lee, W.H.K., Kanamori, Hiroo, Jennings, P.C., and Kisslinger, Carl, eds., International handbook of earthquake and engineering seismology, pt. A: Amsterdam, Academic Press, p. 29-37.

Aki, Keiiti, and Lee, W.H.K., 2002, Glossary of interest to earthquake and engineering seismologists, in Lee, W.H.K, Kanamori, H., Jennings, P.C., and Kisslinger, C., eds., International handbook of earthquake and engineering seismology, pt. A: Amsterdam, Academic Press, p. 17931856.

Ambraseys, Nicholas, and Bilham, Roger, 2003a, Earthquakes in Afghanistan: Seismological Research Letters, v. 74, p. 107 123 (includes electronic supplement on the web site of the Seismological Society of America, http://www.seismosoc. org/publications/SRL/SRL_74/srl_74-2_ambraseys_esupp1. html; last accessed September 19, 2005).

Ambraseys, Nicholas, and Bilham, Roger, 2003b, Earthquakes and associated deformation in northern Baluchistan: Bulletin Seismological Society America, v. 93, p. 1573-1605.

Ambraseys, N. N., and Melville, C. P., 1982, A History of Persian Earthquakes: Cambridge, Cambridge University Press, $219 \mathrm{p}$.

Demets, Charles, Gordon, R.G., Argus, D.F., and Stein, Seth, 1994, Effect of recent revisions to the geomagnetic reversal time scale on estimates of current plate motions: Geophysical Research Letters, v. 21, no. 20, p. 2191-2194.

Dunbar, P.K., Lockridge, P.A., and Whiteside, L.S., 1992, Catalog of significant earthquakes, including quantitative casualties and damage: National Oceanic and Atmospheric Administration, National Environment Satellite Data and Information Service, National Geophysical Data Center, Report SE-49, $320 \mathrm{p}$.

Dziewonski, A.M., Chou, T.A., and Woodhouse, J.H., 1980, Determination of earthquake source parameters from waveform data for studies of global and regional seismicity: Journal of Geophysical Research, v. 86, p. 2825-2852. 
Engdahl, E. R., Van der Hilst, R.D., and Buland, R.P., 1998, Global teleseismic earthquake location with improved travel times and procedures for depth determination: Bulletin Seismological Society of America, v. 88, p. 722-743.

Engdahl, E. R., and Villaseñor, Antonio, 2002, Global Seismicity: 1900-1999, in Lee, W.H.K., Kanamori, Hiroo, Jennings, P.C., and Kisslinger, Carl, eds., International handbook of earthquake and engineering seismology, pt. A: Amsterdam, Academic Press, p. 665-690.

Gutenberg, Beno, and Richter, C.F., 1954, Seismicity of the Earth and Associated Phenomena: Princeton, N.J., Princeton University Press, 310 p.

International Seismological Centre, 2005, On-line Bulletin, http://www.isc.ac.uk/Bull: Thatcham, United Kingdom, International Seismological Centre (last accessed February 14, 2006).

Kondorskaya, N.V. and Shebalin, N.V., eds., 1982, New Catalog of Strong Earthquakes in the U.S.S.R. from Ancient Times through 1977: National Oceanic and Atmospheric Administration, National Environment Satellite Data and Information Service, National Geophysical Data Center, Report SE-31, 601 p.

Pegler, G., and Das, S., 1998, An enhanced image of the Pamir-Hindu Kush seismic zone from relocated earthquake hypocenters: Geophysical Journal International, v. 134, p. 573-595.

Rothé, J. P., 1969, The seismicity of the Earth, 1953-1965: Paris, United Nations Educational, Scientific, and Cultural Organization (UNESCO), $336 \mathrm{p}$.

U.S. Geological Survey, 2005a, Database of Chinese earthquakes, maintained in the National Earthquake Information Center's computerized hypocenter data-base, ultimately compiled by World Data Center D for Seismology, State Seismological Bureau, Beijing, China, in 1993.

U.S. Geological Survey, 2005b, NEIC Earthquake Search, "India" database, http://neic.usgs.gov/neis/epic/ (last accessed September 19, 2005).

Utsu, Tokuji, 2002, Relationships between magnitude scales, in Lee, W.H.K., Kanamori, Hiroo, Jennings, P.C., and Kisslinger, Carl, eds., International handbook of earthquake and engineering seismology, pt. A: Amsterdam, Academic Press, p. 733-746.

Wheeler, R.L., Bufe, C.G., Johnson, M.L., and Dart, R.L., 2005, Seismotectonic map of Afghanistan, with annotated bibliography: U.S. Geological Survey Open-File Report 2005-1264, $31 \mathrm{p}$.

Yeats, R.S., and Madden, Christopher, 2003, Damage from the Nahrin, Afghanistan, earthquake of 25 March 2002, Seismological Research Letters, v. 74, p. 305-311.

\section{GLOSSARY}

arrival-time The time at which elastic-waves from an earthquake arrive at a recording seismograph. The interpreted arrival-times from a minimum of four seismographs are used to calculate an earthquake's epicenter and focal-depth. crust The outermost layer of the earth. The crust in most continental regions is between 25 and $75 \mathrm{~km}$ thick and that in most oceanic areas is between 5 and $10 \mathrm{~km}$ thick (see, for example, Aki and Lee, 2002).

epicenter The location on the earth's surface above the earthquake origin (see also "hypocenter").

focal depth The depth of the earthquake origin beneath the Earth's surface. The deepest reliably located earthquake from the region of this study had a focal depth of about $280 \mathrm{~km}$.

hypocenter The location of the earthquake origin in three dimensions: latitude, longitude, and depth. Synonymous with "epicenter and focal-depth."

intermediate-focus earthquake An earthquake having a focal depth greater than $70 \mathrm{~km}$ and less than $300 \mathrm{~km}$. Such earthquakes are characteristic of regions where oceanic lithosphere is being subducted (see "subduction") into the Earth's mantle.

lithosphere The Earth's crust and that part of the Earth's uppermost mantle that behave elastically in the long term and that can store elastic strain to produce earthquakes.

macroseismic effects The effects of an earthquake on people, human structures, and the natural landscape.

magnitude A measure of the energy released at the source of an earthquake. An increase of one magnitude unit corresponds to an approximately 30 -fold increase in the energy released by the earthquake. Different types of magnitude are determined with different instruments or different seismic wave-types, and for a given earthquake the magnitude numbers may be slightly different for each magnitude type. Seismologists therefore record both the value of a magnitude measurement and the magnitude type.

mantle The region of the Earth's interior below the crust and above the core.

normal faulting Fracture of the Earth's lithosphere involving predominantly vertical motion of the lithosphere next to the fracture, the material on each side of the fracture moving away from the material on the other side of the fracture. Material on the side towards which the fault plane dips is dropped down with respect to that on the other side (contrast with "reverse faulting").

plate A segment of the Earth's lithosphere, commonly having an area of more than one million square kilometers, that moves as a coherent unit with respect to other plates and with respect to the deeper mantle.

reverse faulting Fracture of the Earth's lithosphere involving predominantly vertical motion of the lithosphere next to the fracture, the material on each side of the fracture moving toward 
the material on the other side of the fracture. Material on the side towards which the fault dips is thrust up over the material on the other side (contrast with "normal faulting").

seismic source zone Generic term for a region within which the probability of a strong earthquake may be considered uniform.

shallow-focus earthquake An earthquake having a focal depth of less than $70 \mathrm{~km}$. The vast majority of earthquakes worldwide are shallow-focus earthquakes. Northeastern Afghanistan, however, also has a zone of frequent intermediate-focus earthquakes (see "intermediate-focus earthquake").

strike-slip faulting Fracture of the Earth's lithosphere involving predominantly horizontal motion of the lithosphere next to the fracture, the material on each side of the fracture moving mostly sideways with respect to the material on the other side of the fracture. In "left-lateral" faulting, an observer on one side of the fault would see material on the other side move to his or her left. In "right-lateral" faulting, an observer on one side of the fault would see material on the other side move to his or her right.

subduction The process by which the Earth's lithosphere sinks into the Earth's mantle. When oceanic lithosphere cools it becomes denser than the hotter, more liquid-like, mantle beneath it and can sink into the mantle. The sinking of oceanic lithosphere provides some of the force that moves tectonic plates. In the upper mantle, subducting oceanic lithosphere is commonly manifested by intermediate-focus (see "intermediatefocus earthquake") or deep-focus (focal depths greater than 300 $\mathrm{km}$ ) earthquakes. Continental lithosphere is almost always more buoyant than the mantle beneath it and does not usually subduct. The intermediate-depth earthquakes beneath northeastern Afghanistan mark the site of subducted oceanic lithosphere even though the lithosphere at the Earth's surface is continental. 


\title{
A Comprehensive Earthquake Catalog for the Afghanistan Region
}

\author{
By Eric A. Bergman \\ Contractor, Global Seismological Services \\ Golden, Colorado 80401 \\ bergman@seismo.com \\ $303278-4089$
}

Chapter B of Seismicity of Afghanistan and Vicinity

Edited by James W. Dewey

Prepared under the auspices of the U.S. Agency for International Development

Open-File Report 2006-1185-B

This report is USGS Afghanistan Project Product No. 28B

U.S. Department of the Interior

U.S. Geological Survey 


\section{Contents}

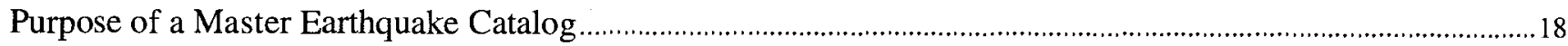

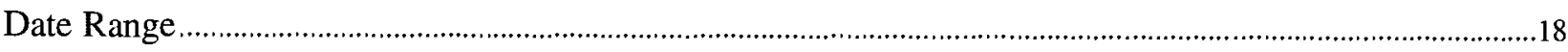

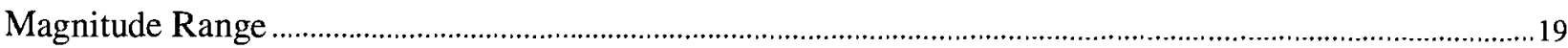

Format and Contents of the "Master Catalog" ...........................................................................................................19

Event Identifier (Source Catalog ID) ........................................................................................................... 19

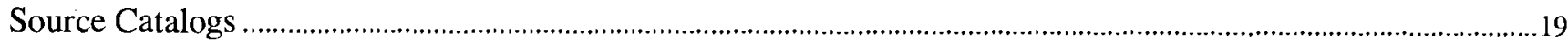

Assembly of the "Master Catalog" of Afghanistan Earthquakes ……......................................................................20

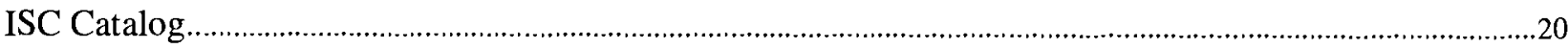

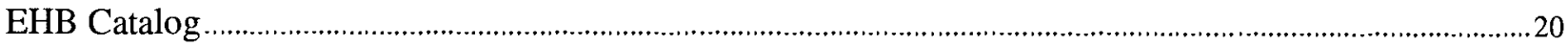

Merging EHB Events into the "Master Catalog" .......................................................................................21

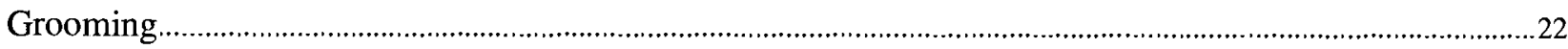

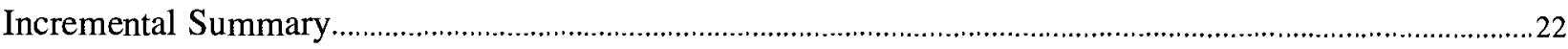

"Master Catalog" after August 2002 ….....................................................................................................23

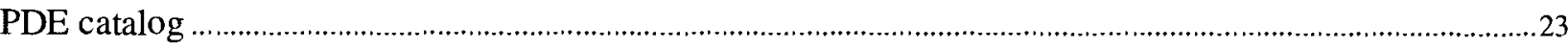

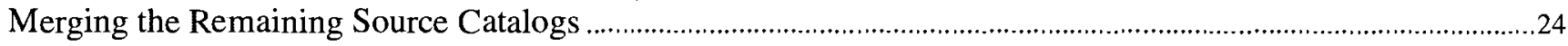

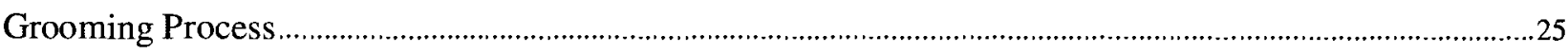

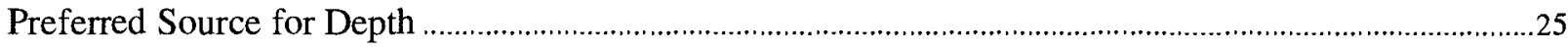

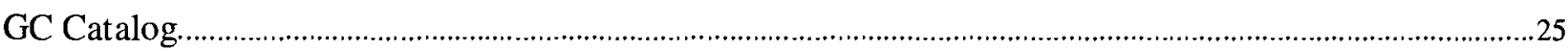

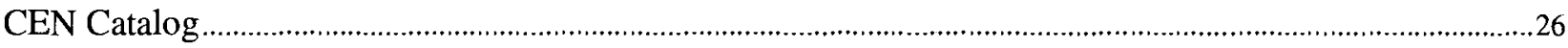

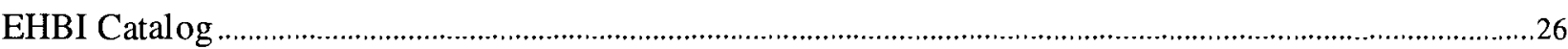

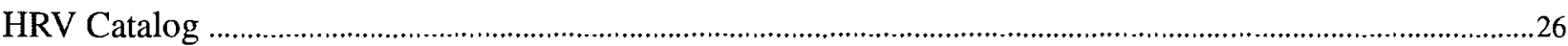

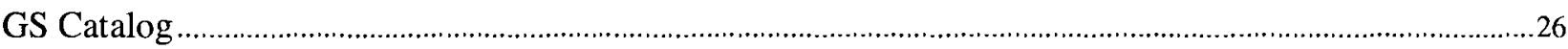

OMT Catalog

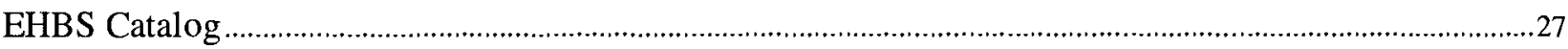

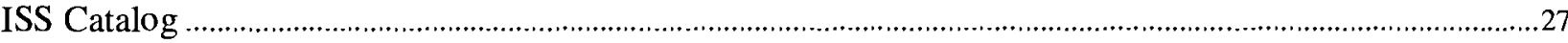

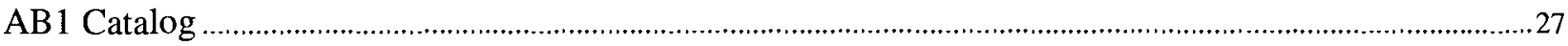

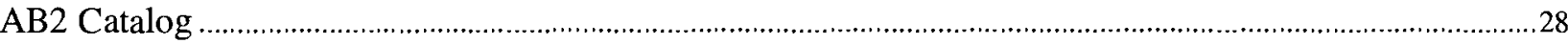

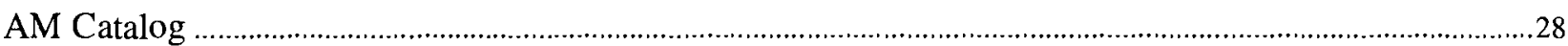

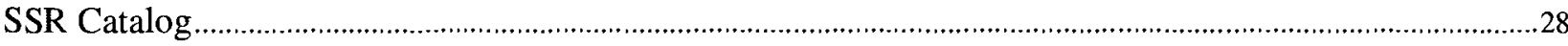

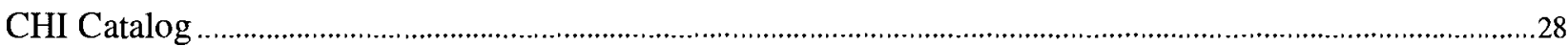

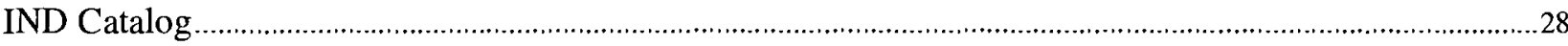

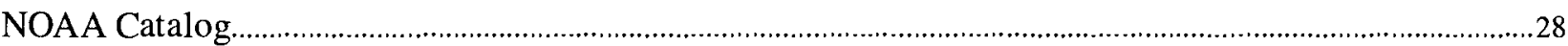

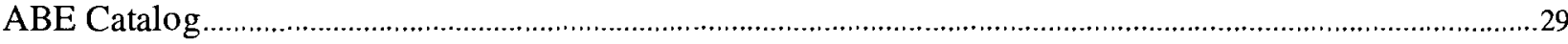

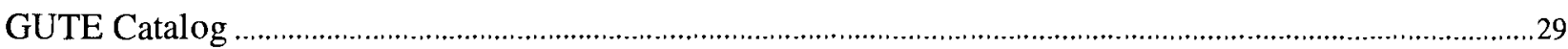

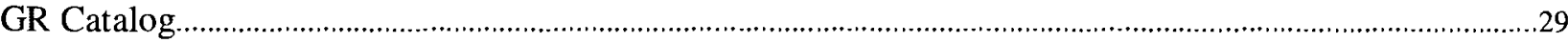

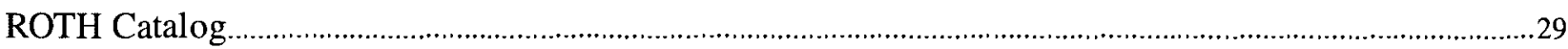

EB Catalog 


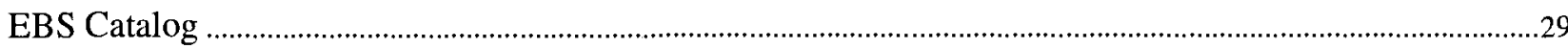

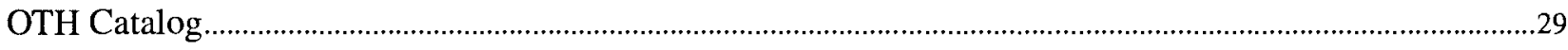

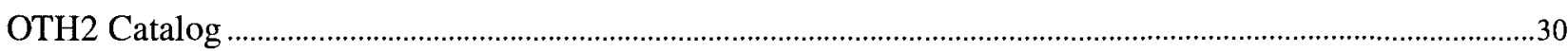

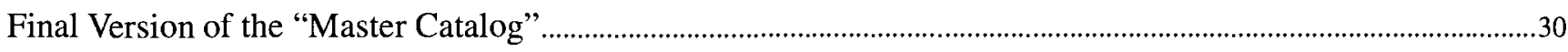

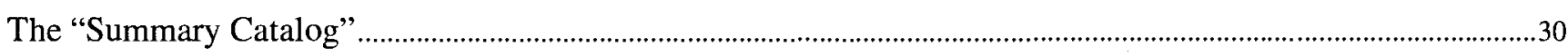

Questionable Historical Events...............................................................................................................................30

Preferred Sources for the "Summary Catalog" ....................................................................................................30

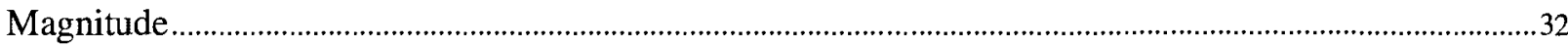

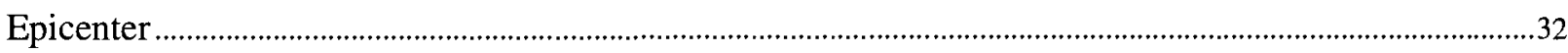

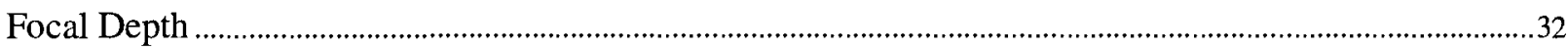

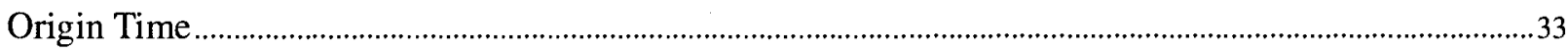

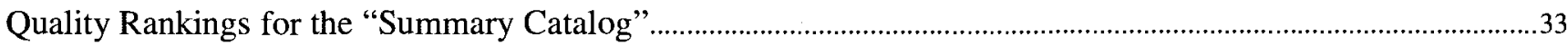

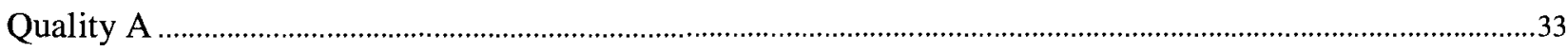

Quality B

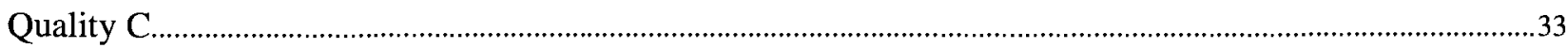

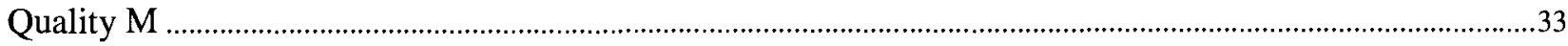

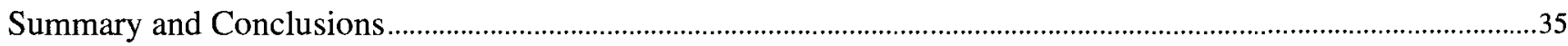

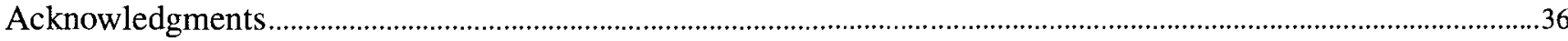

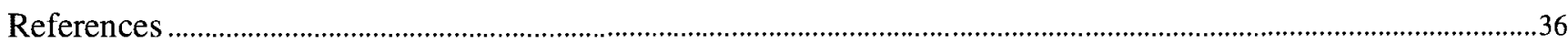

Appendix A. Explosions ........................................................................................................................................38

Appendix B. Format of the "Master Catalog"

Appendix C. The Source Catalogs ....................................................................................................................47

Appendix D. Order of Preferred Sources for Event Parameters ..................................................................................49

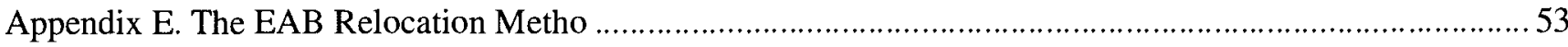

Appendix F. About the "Sub-Threshold Catalog of Afghanistan Earthquakes" ..............................................55

\section{Figures}

Figure 1. Number of earthquakes each year since 1900 in the "Master Catalog"

Figure 2. Map of the region included in the "Master Catalog," showing 24,028 epicenters extracted from the ISC catalog for the period January 1, 1964, through August 31, 2002 ................................................. 20

Figure 3. Map of the region included in the "Master Catalog," showing 5,833 epicenters from the ISC catalog (January 1, 1964, through August 31, 2002) that were "contributed"

Figure 4. Map of the study region, showing 18,226 epicenters in the "Master Catalog" after the initial stages of catalog formation and merging the EHB and ISC catalogs ........................................................ 22

Figure 5. Map of the study region, showing 19,735 epicenters in the "Master Catalog" after merging the PDE catalog with the ISC and EHB catalogs

Figure 6. Map of the study region, showing 116 epicenters in the "Master Catalog" that have only an ISC catalog entry, covering the time period January 1964 through August 2002

Figure 7. Map of the study region, showing 34 epicenters in the "Master Catalog" that have only an EHB catalog entry, covering the time period January 1964 through August 2002 
Figure 8. Map of the study region, showing 54 epicenters in the "Master Catalog" that have only a PDE catalog entry, covering the time period January 1973 through August 2002

Figure 9. Distribution of preferred depths in the Afghanistan "Master Catalog".

Figure 10. Map of Afghanistan earthquake, showing locations, depths, and magnitude scaling based on the "Summary Catalog"

Figure A1. Locations of known explosions in the Afghanistan study region

\section{Tables}

Table 1. Contributions of the different source catalogs to the Afghanistan "Master Catalog," giving the number of cases in which each catalog was the preferred source for epicenter, origin time (OT), depth, and magnitude

Table 2. Contributions of the different source catalogs to the "Summary Catalog," giving the number of cases in which each catalog was the preferred source for epicenter, origin time, depth, and magnitude 34

Table 3. Quality rankings in the Summary Catalog

Table C1. List of earthquake catalogs used in compiling the "Master Catalog of Afghanistan Earthquakes"... 47 


\title{
Comprehensive Earthquake Catalog for the Afghanistan Region
}

\author{
By Eric A. Bergman
}

\section{Purpose of a Master Earthquake Catalog}

"A carefully assembled and documented catalog of seismicity in the Afghanistan region is required to support a variety of projects for infrastructure development and reconstruction of Afghanistan, in particular an assessment of seismic hazards in different parts of the country. This document describes the procedures used to assemble a master earthquake catalog ("Master Catalog") and summary earthquake catalog ("Summary Catalog") for the region $\left(23-45^{\circ} \mathrm{N}\right.$., 53-80 ${ }^{\circ} \mathrm{E}$.) defined for the Afghanistan seismic hazard assessment project. The "Master Catalog" is designed to retain information about each earthquake from a variety of sources and to provide keys to the preferred source for different types of information about each earthquake. The "Summary Catalog" is an abbreviated version of the "Master Catalog" that contains only information on the preferred hypocenter and magnitude for each earthquake.

The "Master Catalog" does not itself contain all available data of interest for each earthquake. In particular, it contains little information about uncertainties in the reported parameters (most of the source catalogs do not contain such information either), and it does not contain any narrative information that may be available. It is the definitive list of seismic events in the region for which information will be compiled. It contains basic event parameters and a unique event identifier to help organize a database containing additional information. The information in the "Master Catalog" is intended to be the primary guide for populating a database of all earthquake-related information for the Afghanistan project.

Because the "Master Catalog" is intended for use in seismic hazard studies, known man-made events (explosions) have been removed. A list of such events is included as Appendix A.

\section{Date Range}

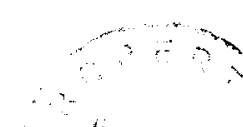

Events in the "Master Catalog" range in date from the second millennium B.C. to December 2004. Most entries fall in the period after 1960 (fig. 1). This partly reflects the difference in magnitude threshold for events cataloged before and after 1964 (see next section), but it mostly reflects a much more thorough global cataloging of small and moderate earthquakes beginning in the 1960s. In the early 1960s, computerized production of the "Preliminary Determination of Epicenters" (PDE) catalog began at the predecessor of the U.S. Geological Survey National Earthquake Information Center (USGSNEIC) and in 1964 the International Seismological Centre (ISC) began publication of its bulletin.

For recent years, the "Master Catalog" includes about 1 event per day, on average. The sharp increase in number of events per year starting in 1964 is partly due to the lower magnitude cutoff used after that date (see below), but even if the same criteria had been used prior to 1964 there would be a significant increase as

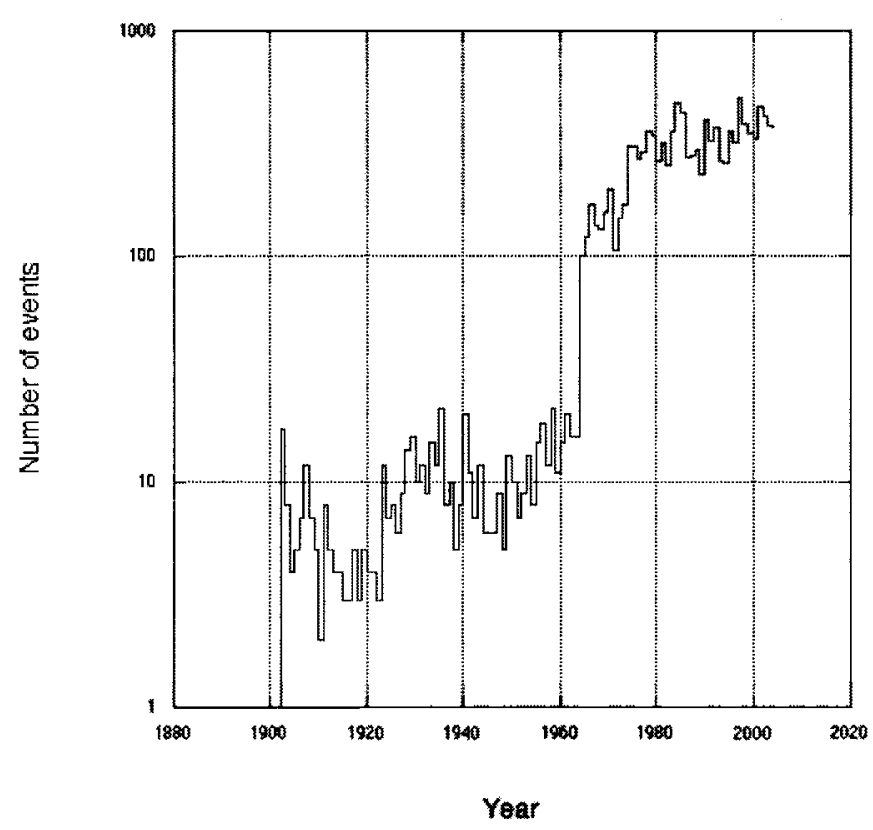

Figure 1. Number of earthquakes each year since 1900 in the "Master Catalog."

\section{${ }^{3}$ Contractor, Global Seismological Services}

Golden, Colorado 80401

bergman@seismo.com

$303278-4089$ 
of that date because of the efficiency of global data collection of the ISC, which began operations then.

\section{Magnitude Range}

An important feature of this catalog is the decision to specify a minimum magnitude for different date ranges:

- 1964-2004: magnitude $\geq 4.0$

- 1900-63: magnitude $\geq 5.5$

There is no minimum magnitude for "historical" events, that is, those occurring prior to 1900 . Events that were dropped from the "Master Catalog" because of these magnitude criteria have been kept for reference in the "Sub-Threshold Catalog of Afghanistan Earthquakes," in the same format as the "Master Catalog."

In general, the magnitude cut was made on the basis of the magnitude(s) reported by the preferred source for magnitude for an event. If any of them exceeded the threshold, the event was retained in the "Master Catalog." In the modern era, since 1964, the ISC is generally taken as the best source of magnitudes for smaller events with magnitudes near the 4.0 threshold. However, there is a case to be made that PDE magnitudes are as authoritative as ISC, or more so for some regions. Therefore, if both ISC and PDE magnitudes were available for an event, both sets of magnitudes were considered for implementing the magnitude criterion. This results in about 1,000 more events being retained in the "Master Catalog" than would be the case if ISC magnitudes alone were used.

The Afghanistan "Master Catalog" contains information on 12,757 earthquakes.

\section{Format and Contents of the "Master Catalog"}

The "Master Catalog" is a plain text flat file in a simple format designed for easy parsing by a computer program. Events are listed in chronological order. In the simplest case (only one source of data) all information for one event is on a single line. Additional lines may be used if information is available from more than one source (referred to here as a "catalog").

A complete format description of the "Master Catalog" is given in Appendix B. For each source catalog, the format of the comment line is different, reflecting the characteristic information that is provided by that catalog.

If there are additional lines for an event to describe information obtained from other catalog sources, then they have the identical fields except for the first field (number of catalog entries).

The sequence of catalog entries for an event is essentially arbitrary, except that the first (or prime) entry always carries the number of catalog entries for that event. The "Master Catalog" has been constructed in such a way that the first entry for most events (at least since 1964) will be the ISC entry. The first entry need not be the authoritative source for any parameter-that is specified by the "use code" for each entry.

\section{Event Identifier (Source Catalog ID)}

A key purpose of the "Master Catalog" is to point unambiguously to other sources of information about a seismic event. Therefore, each entry in the "Master Catalog" includes an identifier that is unique for the source catalog. These identifiers may well not be unique within the "Master Catalog" (that is, different catalog entries for an event in many cases have the same ID), but the identifier in the first entry for each event in the "Master Catalog" is guaranteed to be unique within the "Master Catalog."

As each catalog or source of information is added to the "Master Catalog," a catalog-specific identifier is constructed from the origin time of the event in that source catalog:

\section{YYYYMMDD.HHMMX}

The 14th character $(X)$ of the event identifier is normally blank, but if the 13-character numeric code based on origin time (to the minute) is not unique in the source catalog, a letter ( $a$, $b, c$ ) is added in sequence to make it unique. To handle dates in the B.C. range of dates, of which there are only a handful in the "Master Catalog," a "-" flag is carried in the $14^{\text {th }}$ character position of the event identifier, and the value in the following year field (i5) would also be entered as a negative number. The negative values in the year field and the event identifier are both useful for different aspects of data manipulation.

It is important to understand that different catalog entries for the same earthquake in the "Master Catalog" may not have precisely the same event identifier code, although they should normally be the same within the numeric part, to the nearest hour at least. There are a few cases in the "Master Catalog" in which source catalogs contain typographic errors in event dates and origin times, or gross mislocations, that lead to more extreme differences, especially in the historical (pre-1900) period.

\section{Source Catalogs}

The Afghanistan "Master Catalog" has been assembled with information from 26 source catalogs, which are described in Appendix C. There is great redundancy among the source catalogs, in the sense that many of them carry forward some source parameters from others. For example, the EHB catalog typically carries $m_{b}$ and $M_{s}$ magnitudes from the ISC or PDE and $M_{w}$ magnitudes from the Harvard CMT catalog (catalog codes are defined in Appendix C). The NOAA catalog of large and damaging earthquakes is almost completely composed of parameters from other studies. In assigning preferred source catalogs for earthquake parameters, I have tried to refer to the catalog that is the primary source of that parameter's value.

Nevertheless, each of the source catalogs was judged as a potential source of information that may not be available from any of the others. Even the NOAA catalog can be a useful compilation of results from more obscure studies.

Two source catalogs, the EB and EBS catalogs, were created specifically for this study by relocating a large fraction of all the events in the "Master Catalog" with a consistent method, similar 
to the EHB process, followed by a review process for many (but not all) events. The procedure, referred to here as the "EAB method," is described in Appendix E. These two catalogs are the preferred source for location for about three-fourths of the events in the "Master Catalog," and the preferred source for depth for about one-half of the catalog.

\section{Assembly of the "Master Catalog" of Afghanistan Earthquakes}

The initial stage of assembling the "Master Catalog" was to combine the ISC, EHB, and PDE catalogs, giving a reasonably good catalog for seismicity in the region from 1964 through 2004, and this combination includes the great majority of events that actually ended up in the "Master Catalog."

\section{ISC Catalog}

The first version of the "Master Catalog" was based on the ISC catalog, from which data was available for January 1, 1964, through August 31, 2002. For this purpose, I started with a version of the ISC catalog which had been lightly processed to clean up some common problems with the raw data files obtained from the ISC (E.R. Engdahl, oral commun.) No events or phase reading data were removed or modified. I extracted all events within the geographic area defined for the Afghanistan catalog, 24,028 events in all (fig. 2).

Many events in the ISC catalog have not been located by the ISC; the ISC has simply published a location contributed by another seismological agency, usually a national data center or a local or regional network. The arrivaltime data used by the contributing agency is not always provided, although the ISC sometimes associates some readings with the location. Because many such contributed events are of very poor quality and unverifiable, they have little value for the "Master" Catalog." Inspection showed that many of them are not legitimate events at all, but rather near-duplicates of ISC-located events with a subset of local and regional distance stations assigned to them. Even though these "events" may never appear in the "Master Catalog," they must be assigned an event ID (with respect to the ISC catalog) because they will in some cases cause a different ID (with suffix "a", and so on) to be assigned to a valid ISC event. When one refers back to the ISC catalog from the "Master Catalog," it is important to be able to reconstruct all event IDs exactly as they were done originally. All events contributed from the ISC catalog were assigned a catalog label "OTH," and these events were set aside for later consideration after the "Master Catalog" was fully populated with the other source catalogs. If an OTH entry could be matched with an entry from another catalog, it may have been kept in the "Master Catalog," but rarely as the

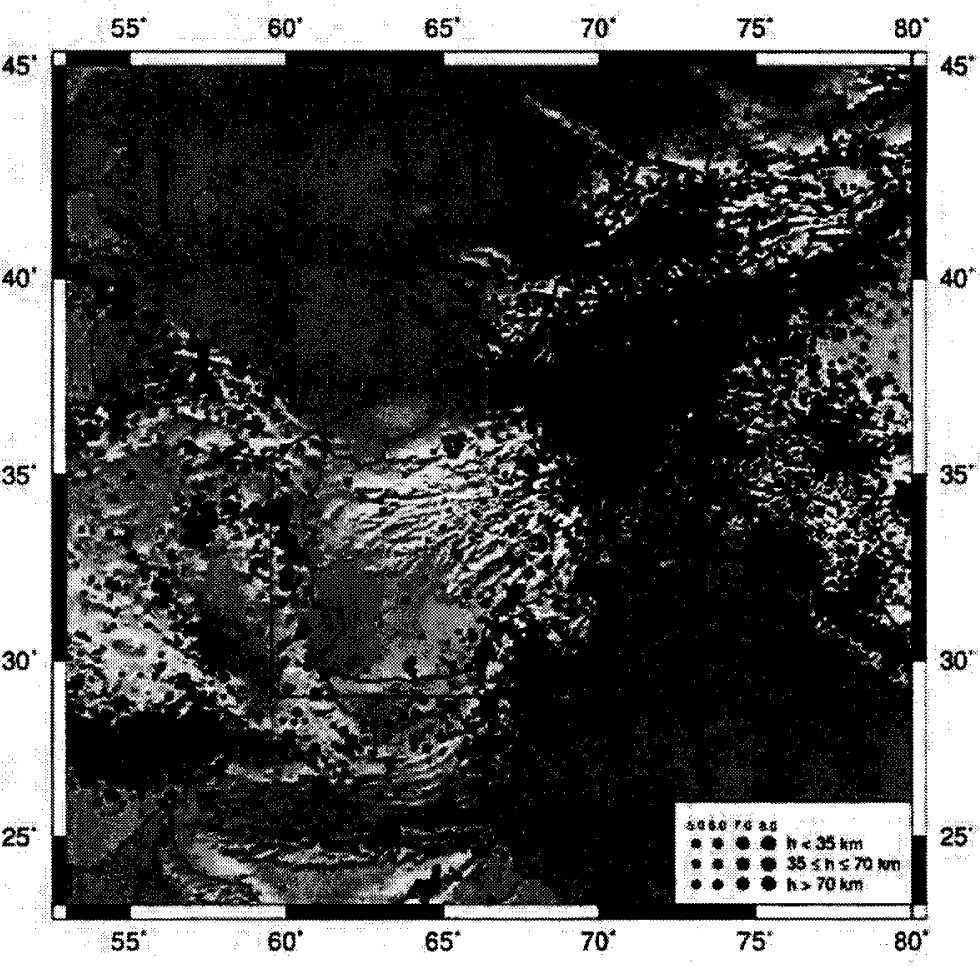

Figure 2. Map of the region included in the "Master Catalog," showing 24,028 epicenters extracted from the ISC catalog for the period January 1 , 1964, through August 31, 2002. Topography from ETOPO2. Symbol size scaled linearly with magnitude and depth range is color coded as shown, with shallower events plotted on top of deeper ones. The polygon roughly approximates the area of Afghanistan and the immediate border regions.

preferred source for any event parameters. For the Afghanistan selection region, there were 5,833 such contributed events (fig. 3 ), leaving 18,195 events for which the ISC computed a location.

\section{EHB Catalog}

The EHB catalog was named after a procedure for systematic, advanced teleseismic location of earthquakes described in Engdahl and others (1998). E.R. Engdahl continues to update the catalog as new data become available, using much the same processing scheme, but minor changes have been implemented over the years. The main features of the method that distinguish it from the ISC method are:

- use of the ak135 travel time model (Kennett and others, 1995 ) and associated tau-p software (Buland and Chapman, 1983)

- careful outlier rejection

- phase- and distance-dependent weighting

- re-association of depth phases to constrain focal depth 


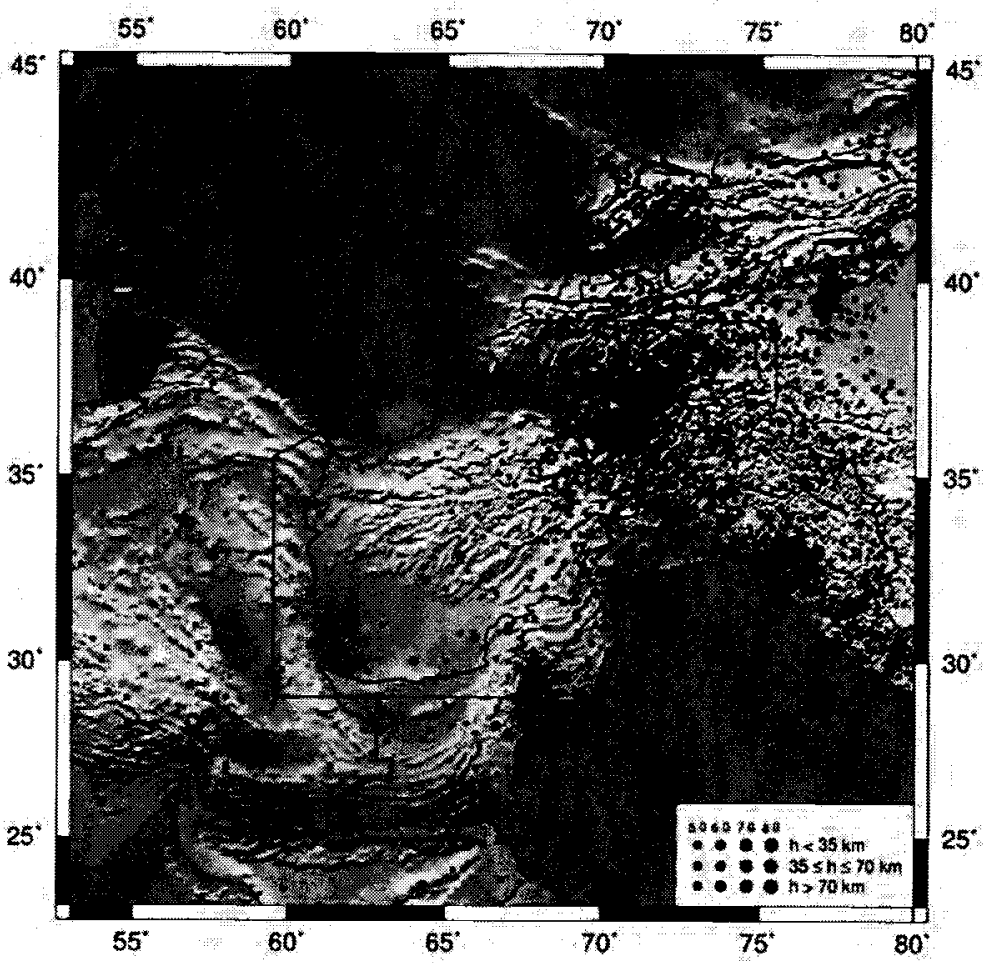

Figure 3. Map of the region included in the "Master Catalog," showing 5,833 epicenters from the ISC catalog (January 1, 1964, through August 31,2002 ) that were "contributed". The ISC did not locate these event, but merely passed on locations computed from another agency. These events have been kept separate from the "Master Catalog." See figure 2 for further description.

- assessment of location accuracy according to azimuthal coverage

In general, the EHB catalog is considerably more accurate than the ISC catalog, but some events are still very poorly located. In fact, the EHB catalog carries forward some events with the ISC location parameters unchanged, or in some cases only resets the origin time and depth according to some standard assumptions. The EHB catalog carries flags to help identify the events for which little or no information has been added. Magnitudes are not recalculated in the EHB process: typically, the ISC magnitudes are carried forward.

For this project the full EHB catalog was processed, first selecting all events within the geographic bounds for the Afghanistan region. A total of $25,25 \mathrm{l}$ events were selected and assigned event IDs as described above. The EHB data set used for this project ends on September 9, 2004, two years later than the latest ISC data. For merging with the ISC data set, I used only the 23,989 EHB events through August 29, 2002. More recent $\mathrm{EHB}$ events were added at a later stage.

\section{Merging EHB Events into the "Master Catalog"}

Each EHB event was processed against the "Master Catalog," which at this point consisted only of the 24,028 ISC events (including contributed events), and matched against as many events as met the criteria:

- origin time (to the year) within 60 seconds

- latitude and longitude within $1.8^{\circ}$

- magnitude difference 0.1 units or less (or no EHB magnitude)

The magnitude criterion reduces the number of multiple matches. The EHB catalog does not always carry the ISC magnitude forward and sometimes confuses the magnitude type. No search criterion on depth is used because one of the strongest differences between ISC and EHB is in hypocentral depth estimates. If the latitude and longitude match exactly and the origin time criterion is met, a match is declared regardless of the magnitude values.

Once the EHB events were matched against the (ISC) events in the "Master Catalog," an updated "Master Catalog" was written. During the updating process, the 7,096 events whose primary entry was identified as "OTH" (and any EHB entry that was matched to them) were written to a separate file for further investigation.

When an EHB entry was added to the "Master Catalog" after matching an ISC entry, it was placed after the ISC entry and the value for the number of entries in the ISC line was incremented.

Of the 23,989 events in the EHB catalog for the region in this period (January 1964 through August 2002), all but 178 could be matched up automatically with at least one event from the ISC catalog. Many of the EHB events for which no match could be found in the automatic matching algorithm are events near the edge of the search region; the corresponding ISC location was just outside the boundary and therefore it was not in the "Master Catalog." These EHB locations were added manually and treated as the prime entry.

Another class of unmatched EHB events arose when the EHB process relocated an event that had been contributed to the ISC (catalog label "OTH"). In most cases the EHB simply carries these contributed hypocenters through unchanged. These events were not added to the "Master Catalog." These are usually poorquality events, with a handful of readings for which the event association is doubtful. In some cases, there are sufficient data in the ISC bulletin for an EHB location, but it differs substantially from the contributed solution and fails to match under the automatic criteria. For these cases, the quantity and quality of arrival-time data were checked in the original ISC data files. If 
the events seemed to be legitimate, they were added manually to the "Master Catalog," with the EHB solution as prime entry.

The remaining cases of unmatched EHB events result from unusually large changes from the starting ISC location, usually associated with large changes in focal depth. The EHB process pays special attention to proper identification of depth phases and uses them directly in the location process, in contrast to the ISC procedure. These are mostly small events with poor azimuthal coverage; minor changes in the phase identification or outlier rejection procedure lead to large changes in the inferred hypocentral parameters. These were easily matched by hand.

In 23 cases an EHB event could be associated with two events in the "Master Catalog." These were manually edited without difficulty. No cases matching more than two events were found.

At this stage, we searched on all EHB events with the flag ("X," in the EHB "iseq" field) set for being a man-made explosion or cavity collapse. Eleven such events were removed from the "Master Catalog," but preserved in Appendix A. They include known nuclear tests by India and Pakistan in 1998 and Soviet "Peaceful Nuclear Explosions" (PNEs) in the former central Asian republics. None was located in Afghanistan itself.

\section{Grooming}

Following the merging of the EHB catalog with the "Master Catalog," the "Master Catalog" was "groomed" to be sure that the EHB entries that were matched to an ISC entry actually added information to the "Master Catalog." The differences between the ISC and EHB entries in origin time, epicenter, and depth were tested to see if they had been changed at all by the EHB location process (which takes ISC locations as its starting point).

In most cases, EHB processing led to new estimates of epicenter, focal depth, and origin time. In this case, the "use code" for the EHB entry was set to show it as the preferred source for these parameters. EHB processing does not involve magnitudes, so the ISC entry remained the preferred source for magnitude.

If all ISC parameters passed through unchanged by EHB, the EHB entry was removed from the "Master Catalog," because no new information was introduced by EHB processing. This result is always the result of poor quality of the arrival-time data in the ISC bulletin: too few readings, poor azimuthal coverage, or inconsistent readings. Unless additional arrivaltime data could be obtained from other sources, there was little chance of any further improvement for such events. There are 79 such cases.

If the epicenter passed through unchanged but the origin time and depth both changed, an EHB entry was kept in the "Master Catalog" with the "use code" set to indicate that the EHB entry was preferred for origin time and depth. The "use code" for the ISC entry was set to show it as the preferred source for epicenter as well as magnitude. There are 84 such cases.

In some cases, the EHB process passed the ISC epicenter through unchanged, but changed either the origin time or the depth (not both). This was treated as though no new information had been added by EHB processing, and the EHB entry was removed from the "Master Catalog." The ISC entry was treated as the preferred source for all parameters.

\section{Incremental Summary}

This stage of the "Master Catalog" consisted of the merged ISC and EHB catalogs for the period January 1964 through August 2002, the period for which ISC bulletin data were available. Beginning with the 18,195 events for which the ISC computed a location, I added 42 events for which the EHB was the primary source and subtracted 11 events that were flagged as explosions in the EHB catalog, yielding a total of 18,226 seismic events (fig. 4).

Of these, 18,052 had an entry from both the ISC and the EHB catalogs. In all these cases, the ISC entry was the prime entry, and it was always the preferred source for magnitude. In most cases $(17,968)$ the EHB entry was the preferred source for the epicenter, focal depth, and origin time. In the remaining 84

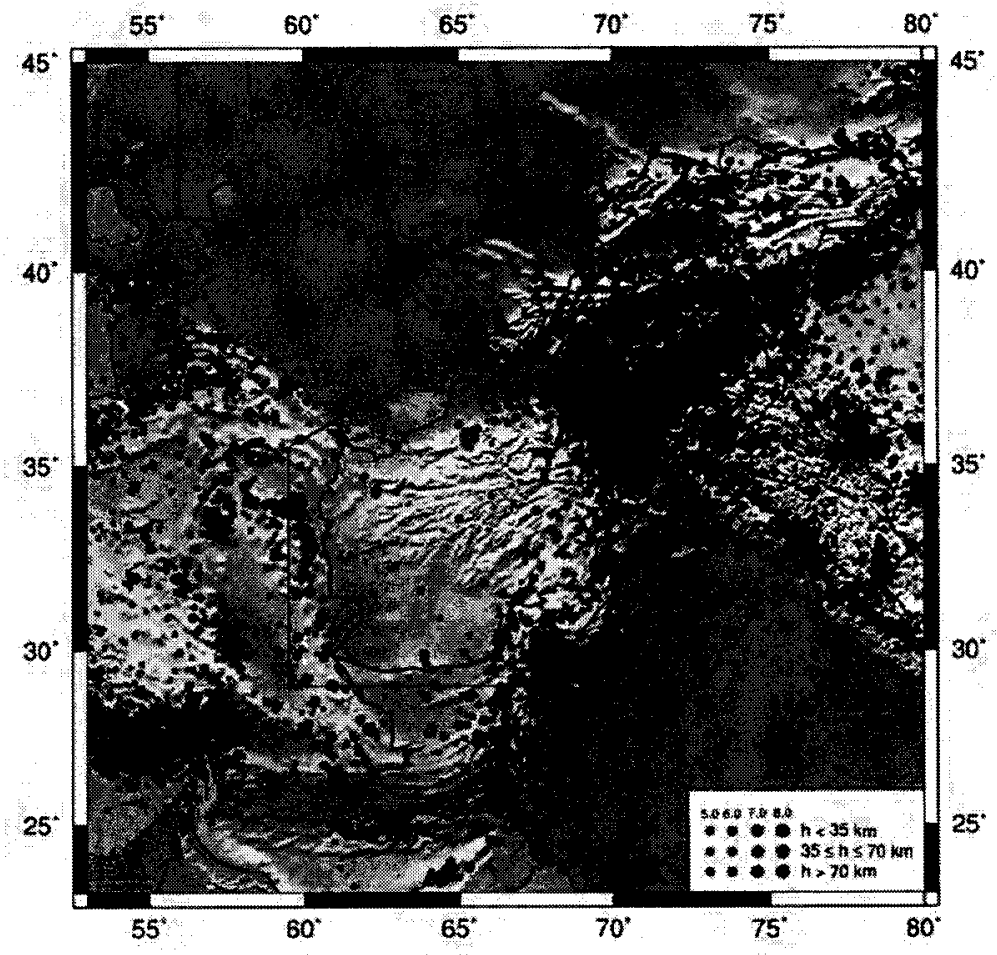

Figure 4. Map of the study region, showing 18,226 epicenters in the "Master Catalog" after the initial stages of catalog formation and merging the EHB and ISC catalogs. At this stage in its preparation, the "Master Catalog" covered the time period January 1964 through August 2002. See figure 2 for further description. 
cases, however, the ISC was retained as the preferred source for epicenter because the EHB process fixed the epicenter at the ISC location and solved only for focal depth and origin time.

The "Master Catalog" at this point contained 174 events having only a single source catalog entry: 133 had only an ISC entry and 41 had only an EHB entry. The EHB-only cases arose almost entirely from situations where the corresponding ISC epicenter fell just outside the boundaries of the region defined for this catalog. The reverse situation accounts for 54 of the ISC-only entries; the other 79 ISC-only entries resulted because the EHB entry added no new information for the event and therefore was not retained.

Eleven events that were flagged as man-made explosions in the EHB catalog were removed from the "Master Catalog" (Appendix A). None was located in Afghanistan itself.

\section{“Master Catalog" after August 2002}

At the time of the work reported here, the ISC catalog ended on August 31, 2002. To extend the "Master Catalog," events in the EHB catalog since that date were added. The EHB catalog available for this project ended on September 9, 2004, and contained 1262 events after August 31,2002. These were added to the "Master Catalog" as the primary entry for all hypocentral parameters and magnitude. The "Master Catalog" at this point contained 19,488 events.

\section{PDE catalog}

The next step in the creation of the "Master Catalog" was merging the PDE (Preliminary Determination of Epicenters) catalog, which is maintained by the National Earthquake Information Center of the U.S. Geological Survey (USGSNEIC).

The on-line version of the PDE catalog begins on January 1, 1973, and contains three versions of the PDE, the "Monthly," the "Weekly," and the QED (Quick Epicenter Determination). The Monthly PDE is considered the final data product from the USGSNEIC and runs about 9 months behind real time. At the time it was accessed for this project, the "Monthly" version ran through February 29, 2004. The "Weekly" version continued through November 24, 2004, and the QED extended through December 18, 2004. The PDE catalog prior to 1973 is available to researchers but is not made generally available to the public because of database issues that may lead to confusion. For this project I merged the 1973-onward PDE data with the existing "Master Catalog."

The PDE catalog for the study region contains 12,049 hypocenters for the period January 1, 1973, through December 18, 2004. Using a procedure similar to that used to merge the EHB catalog with the ISC catalog, all but 260 PDE events were matched with existing events in the "Master Catalog," and there were 41 cases in which a

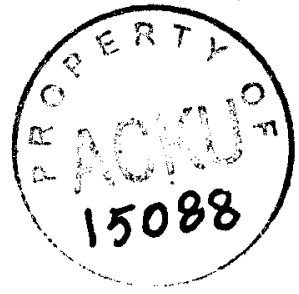

PDE event could be matched to two events in the "Master Catalog." These multiple matches were easily resolved.

Of the unmatched PDE events, six were explosions, which were removed from the "Master Catalog" (see Appendix A). Another 156 unmatched PDE events occurred after the last EHB event in the "Master Catalog," between September 10, 2004, and December 18, 2004. These events were added to the "Master Catalog" with the PDE as prime entry.

In most cases where a PDE event matched an ISC or EHB event, the PDE entry was not used as the source for any event parameters. However, in 353 cases where a PDE event is matched with an ISC or EHB event, the PDE entry is the only entry with a magnitude value. The PDE entry was assigned the use code " $\mathrm{m}$ " for these events.

The "Master Catalog" contained 19,735 events at this stage (fig. 5). Of these, 10,517 had entries from each of the ISC, EHB, and PDE catalogs. Another 8,819 had entries from 2 of the 3 catalogs, and 399 had only a single catalog entry.

Most of the single-entry events were near the borders of the study region, and the matching events from the other catalogs were just outside the region. The distribution of single-entry

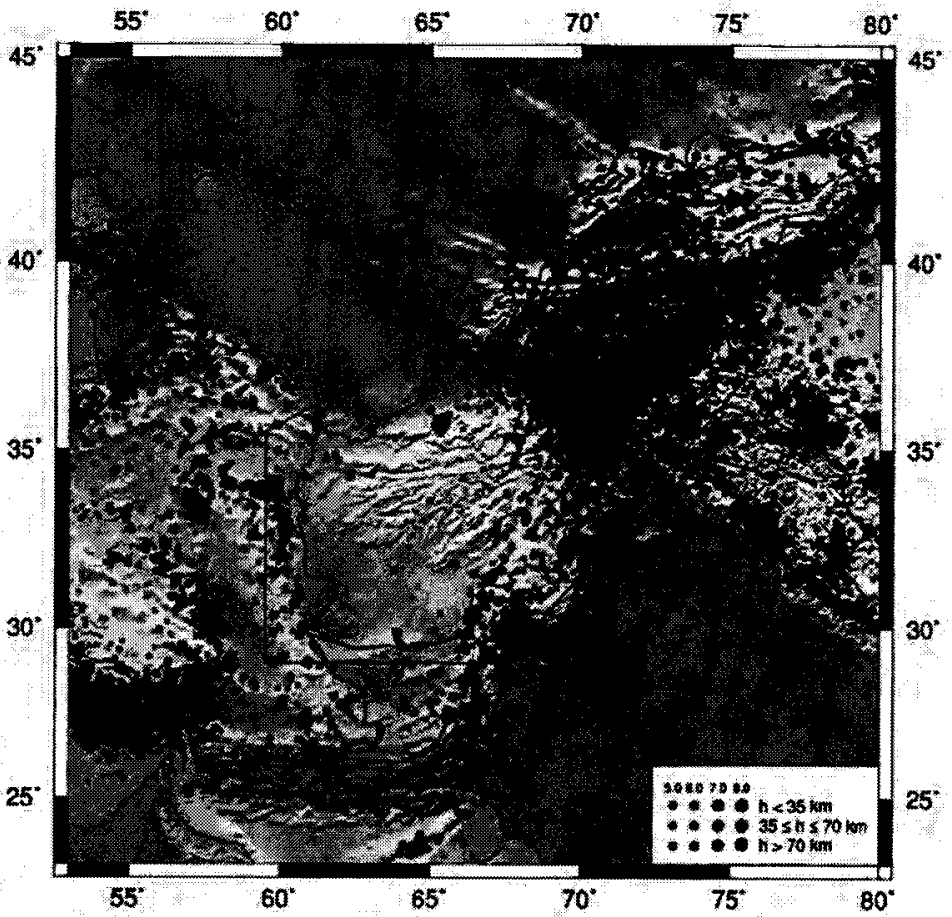

Figure 5. Map of the study region, showing 19,735 epicenters in the "Master Catalog" after merging the PDE catalog with the ISC and EHB catalogs. This stage of the "Master Catalog" covers the time period January 1964 through December 18, 2004. See figure 2 for further description. 
events from the ISC, EHB, and PDE catalogs are shown in figures 6-8, respectively. The EHB and PDE plots are cut off at August 2002 for consistency with the ISC catalog. For the ISC-only events shown in figure 6, in addition to the expected epicenters near the border of the study area, there is shown a group of small, deep events in northeastern Afghanistan. The EHB-only events in figure 7 are all near the border of the study area. This is expected, as the EHB catalog takes the ISC catalog as its basis for relocation. The PDE-only events shown in figure 8 include a few dozen epicenters scattered throughout the study area, including Afghanistan. The fact that they have no corresponding entry in the ISC catalog suggests that they are likely to have been seriously mislocated or perhaps misassociated events that were corrected at the ISC, which collects additional readings for the location study.

\section{Merging the Remaining Source Catalogs}

The interim version of the "Master Catalog" as depicted in figure 5, based on the ISC, EHB, and PDE catalogs, contains most of the events that ultimately appeared in the "Master Catalog." In fact it also contains a large number of events that did not appear in the "Master Catalog" once

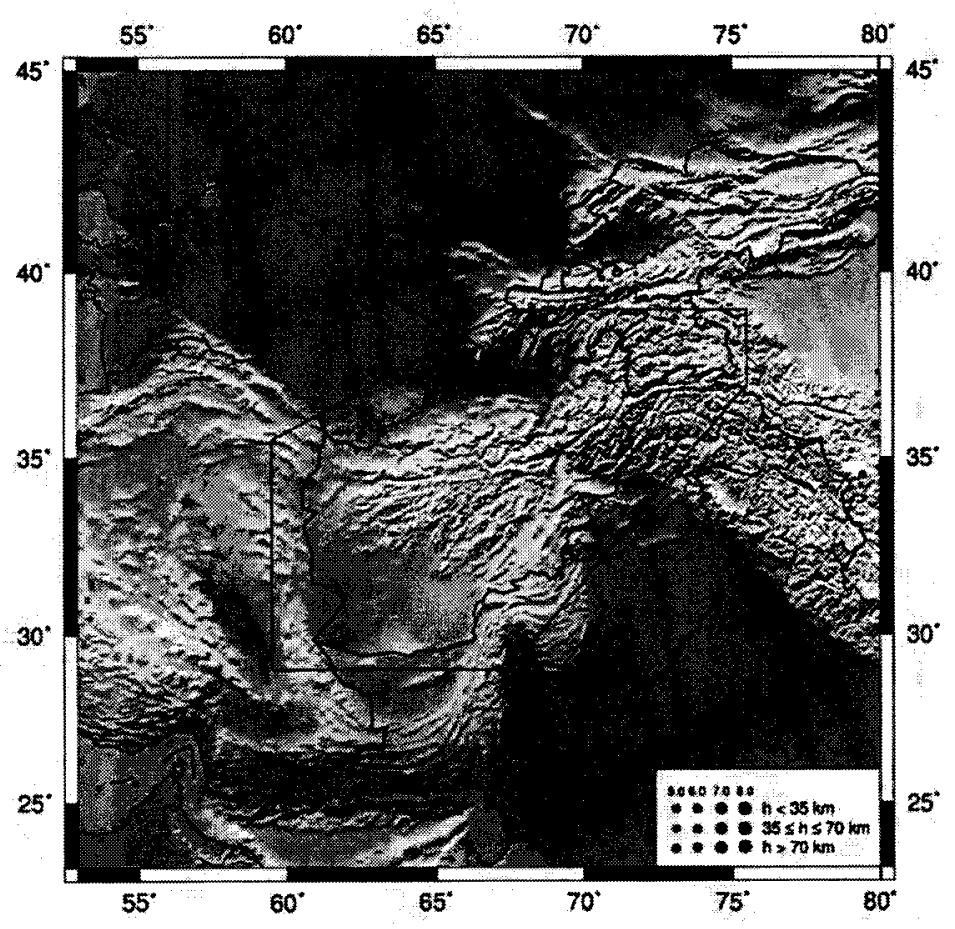

Figure 7. Map of the study region, showing 34 epicenters in the "Master Catalog" that have only an EHB catalog entry, covering the time period January 1964 through August 2002, for comparison with ISC coverage. See figure 2 for further description.

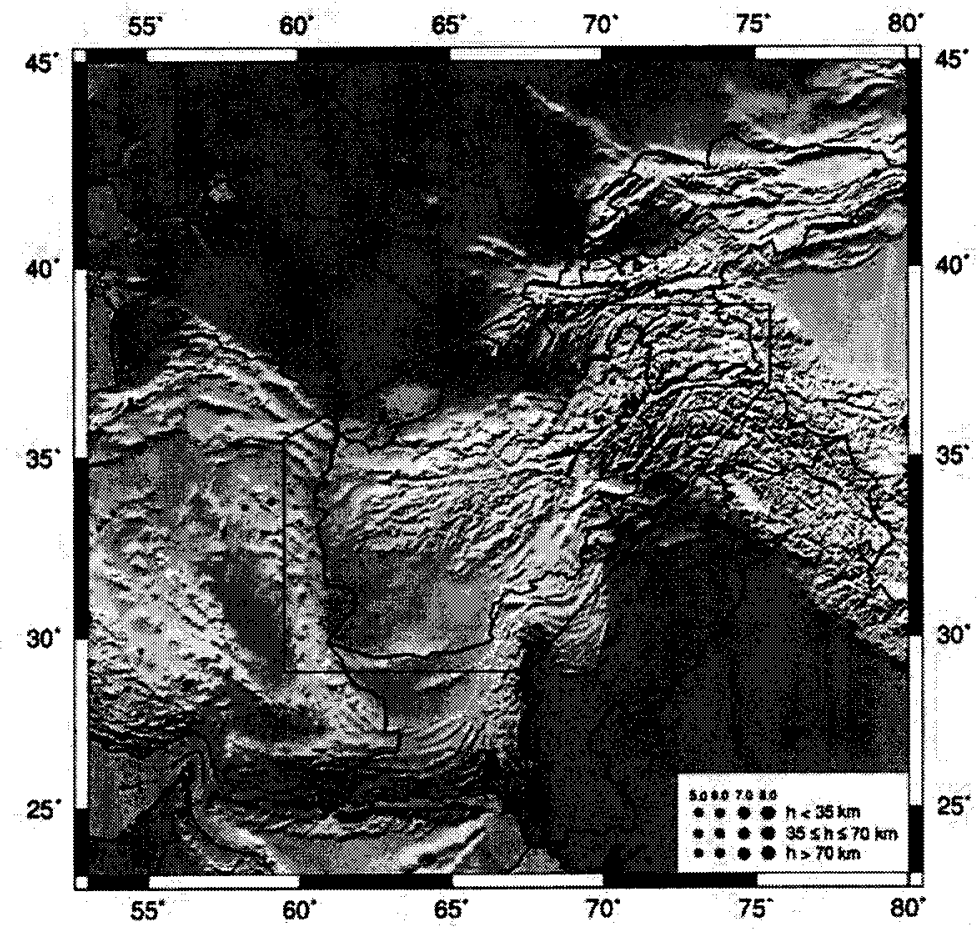

Figure 6. Map of the study region, showing 116 epicenters in the "Master Catalog" that have only an ISC catalog entry, covering the time period January 1964 through August 2002. See figure 2 for further description. the magnitude criteria were applied. However, for the purpose of importing and merging other source catalogs, it was desirable to temporarily retain all these events on the chance that other source catalogs would contain magnitude information that would justify keeping them in the "Master Catalog."

A standard procedure was devised for importing all the remaining source catalogs:

(1) Reformat the source catalog into the "Master Catalog" format, including definition of the event ID from the origin time.

(2) Run a "merge" program that compares the 14character event ID of the reformatted source catalog with that of all "Master Catalog" events. Since the event ID is based on origin time, it provides an easy way to decide if the source catalog entry matches a "Master Catalog" entry in time, which is usually a reliable criterion for matching events. In that case, the new catalog entry is added to that event and the counter for number of catalog entries for that event is incremented. If the source catalog entry does not match any "Master Catalog" entry on the basis of event IDs, it is inserted in the appropriate place 


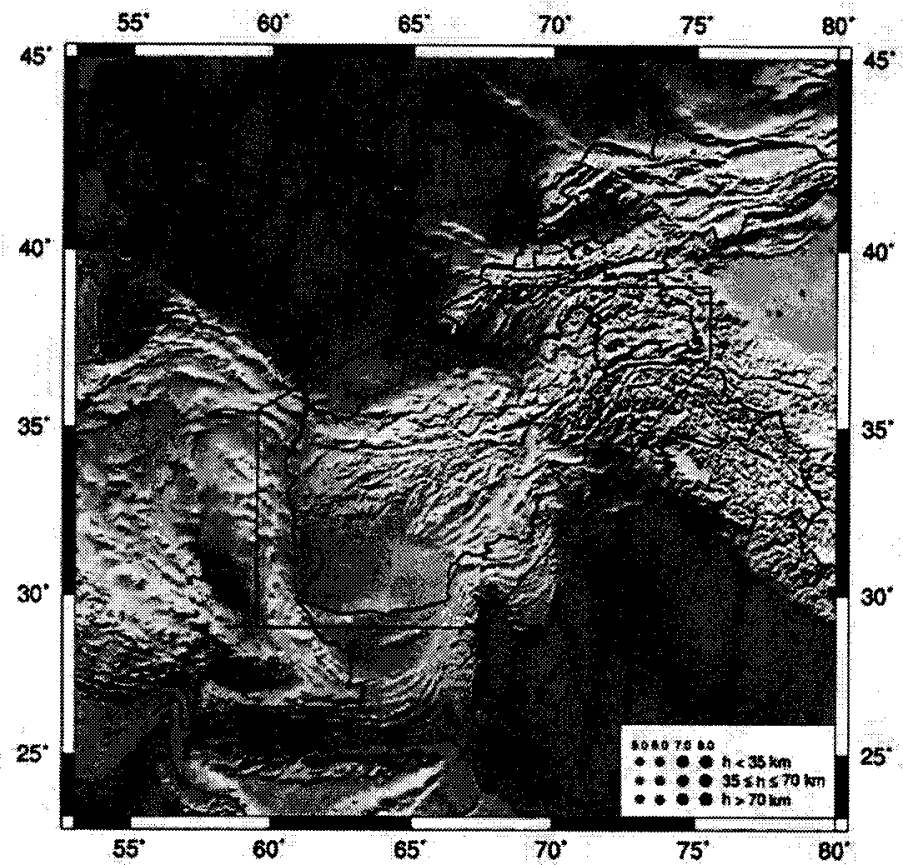

Figure 8. Map of the study region, showing 54 epicenters in the "Master Catalog" that have only a PDE catalog entry, covering the time period January 1973 through August 2002, for comparison with ISC coverage. See figure 2 for further description.

(chronologically) as a new event with the source catalog as prime entry.

(3) Manually inspect, and if necessary edit, the new events with the candidate source catalog as the prime entry, to see if they can be matched with either of the neighboring (in time) "Master Catalog" events. Failures to match often occur because origin times in different catalogs have crossed a minute boundary. Such cases are easy to correct. When dealing with historical events or with some catalogs that are known to carry many typographic errors or unreliable event information, broader criteria were-used to match events.

(4) Run a "groom" program on the new "Master Catalog" to ensure that the "use code" was set correctly in light of the new entries. Some additional minor editing is sometimes done during this step as well.

(5) Spot-check the "Master Catalog" in search of unfortunate consequences of the grooming algorithm when a new catalog is imported.

\section{Grooming Process}

The grooming process (step 4, above) was of critical importance in assembling the "Master Catalog," as it determined the preferred sources for epicenter, origin time, depth, and magnitude that were used to extract the "Summary Catalog of Afghanistan Earthquakes" which will be the basis for much of the seismic hazards study in Afghanistan.

The details of the ordering of source catalogs used to determine preferred source for each parameter are given in Appendix D. One aspect of setting preferred sources deserves discussion here because it had a significant effect on the distribution of depths in the "Master Catalog," and depth is one of the most important parameters to try to resolve for a seismic hazards study. It is also one of the most difficult.

\section{Preferred Source for Depth}

After waveform analysis (as was done, for example, to obtain the depths in the GC catalog and GS catalogs), the most reliable information about earthquake depth comes from a careful analysis of phase-arrival information, especially from depth phases and arrival-times of direct P-waves at stations whose distances from the epicenter are less than the focal-depth. The modern standard for such work is the EHB catalog (Engdahl and others 1998). The EAB process developed for relocation of earthquakes in this study (EB and EBS catalogs) is in many ways very similar to the EHB process (Appendix E). Hypocenters computed by the $\mathrm{EAB}$ and $\mathrm{EHB}$ methods were based on the same data.

For many events, the focal depths computed by the $\mathrm{EAB}$ and $\mathrm{EHB}$ methods agree to within $20 \mathrm{~km}$. In cases of earthquakes for which the EAB and EHB focal-depths differ by more than $20 \mathrm{~km}$, the epicenter and focal-depth were selected from the catalog that reported the shallowest focal depth. In the application of this procedure, poorquality events were not considered from either the $\mathrm{EAB}$ or $\mathrm{EHB}$ solutions, as reflected in an EAB-derived entry showing location as a free parameter and the EHB-derived entry not having the label "XEQ". For the purpose of estimating seismic hazard, this strategy is more conservative than selecting the deeper of two focal-depths reported for the same earthquake, because shallow earthquakes tend to produce more intense shaking in the epicentral region than do deep earthquakes of the same size. For most of Afghanistan (see Chapter A and Maggi and others, 2000), selecting the shallower of two calculated focal-depths is also more consistent with independent knowledge of the depths of seismic sources that is based on well-determined focal-depths.

\section{GC Catalog}

The next stage of compiling the "Master Catalog" brought in the information from the NEIC routine analysis of broadband waveforms for depth determination and other source parameters (Choy and Boatwright, 1995). There are 74 events in the "Master Catalog" for which this information is available; they are given the catalog code "GC" (Appendix C). This procedure leads to the most reliable information on source depth of any available catalog (Appendix D), and this entry is always given the preference for depth. 
Normally, the preferred source for origin time follows the preferred source for depth, but in the case of GC depths, there is no corresponding calculation for a revised origin time. Therefore, in these cases, the preferred origin time is taken from the preferred source for epicenter. For all GC events, there are other sources of magnitude information (such as the HRV $M_{w}$ ) based on long-period information, which is considered preferable to the energy magnitude (which measures high-frequency energy radiation) for this project. Therefore, GC is never the preferred source for magnitude.

The other source parameters of interest in this catalog are the radiated seismic energy (and the associated "energy magnitude" $\mathrm{M}_{\mathrm{E}}$ ), apparent stress, and a focal mechanism derived from the broadband waveforms. This information is carried in the comment field, as described in Appendix B.

\section{CEN Catalog}

The "Centennial Catalog" (Engdahl and Villaseñor, 2002) (catalog code "CEN," Appendix C) summarized and extended knowledge of the largest $(M>7)$ earthquakes during the $20^{\text {th }}$ century. The authors carefully reviewed multiple sources of magnitude information and selected preferred magnitudes. Many of the events were relocated by using the EHB procedures and adding newly available arrival-time data from the ISS Bulletins In those cases, the locations are carried from the EHBS catalog, to which I give preference as the source.

There are two versions of the CEN catalog, one listing all of the various magnitude estimates and another in which the authors listed only the single preferred magnitude, which is carried in the CEN entries in the "Master Catalog," along with references to the source of authority for the location and the magnitude. This information is carried in the comment field for CEN entries (Appendix B).

I made one significant adjustment to the magnitudes carried in CEN entries. In the "Centennial Catalog," 18 earthquakes within the Afghanistan study area have a preferred magnitude on the $M_{w}$ scale, for which the source is Pacheco and Sykes (1992). These values were inferred, in a somewhat controversial way, from a magnitude on the $\mathbf{M}_{\mathrm{s}}$ scale, which is the original direct observation. For the "Master Catalog," I used the $M_{s}$ value from the column labeled " $M_{s}$ original" in the appendix of Pacheco and Sykes (1992).

The "Centennial Catalog" contains 308 events within the study region, but two-thirds of them are during the 1964-99 period for which the CEN catalog mainly repeats magnitude information from other catalog sources, such as the Harvard CMT solutions. The CEN relocations duplicate the "Master Catalog" entries from the EHBS catalog. I did not add CEN entries to the "Master Catalog" unless they carried information that was not otherwise available. A total of $99 \mathrm{CEN}$ entries were added to the "Master Catalog," 78 of them prior to 1964 .

\section{EHBI Catalog}

The EHBI catalog is a special study done by E.R. Engdahl to produce an authoritative earthquake catalog for the Iran region, about half of which is included in the study region for the Afghanistan "Master Catalog." Beginning with the standard EHB catalog, Engdahl conducted a careful review of all events with special attention paid to depth determination to address a known tendency for shallow events to be calculated too deep in routine relocations. He made extensive use of waveform inversion studies to help constrain depths. Engdahl also included pre-1964 events in this catalog by relocating events for which sufficient data could be obtained from the Bulletins of the ISS (Villaseñor and others, 1997).

Therefore, for the 1,030 events in common with the Afghanistan "Master Catalog," the EHBI solutions are considered as the best authority for epicenter, depth, and origin time. In cases where a GC entry is available to constrain depth, Engdahl used that constraint in his relocation, and GC is carried as the original preferred source for depth. In 971 cases for which an event has both an EHB and an EHBI entry, the EHB entry was removed.

The comment field for EHBI entries carries Engdahl's "ahypisol-iseq" code giving information about the quality of the relocation and the nature of the source (Appendix B).

\section{HRV Catalog}

The well-known Harvard CMT catalog (Dziewonski and others, 1980) is widely used as the reference for magnitude (moment magnitude $\mathrm{M}_{\mathrm{w}}$ ) for moderate to large earthquakes worldwide. The epicenter and depth derived in the long-period CMT analysis are of interest for some purposes but are generally considered to be of lower accuracy than locations based on phase arrival times or focal depths determined from waveform analysis at shorter wavelengths (for example, the GS and GC catalogs). The HRV catalog is not even considered as a possible preferred source for any parameter except magnitude because there are always other catalog entries that would be preferred over it.

The 547 events in the CMT catalog that are located within the study region were all easily matched with existing events. CMT origin times are usually 5-6 seconds later than origin times from other catalog sources and sometimes cross a minute mark, preventing a match based on event ID. Hand editing easily corrects such problems. The comment field for HRV entries carries the seismic moment and nine values describing the orientation and scale of the principal axes of the moment tensor (Appendix B).

HRV is the preferred source for magnitude for every event in which there is an HRV entry.

\section{GS Catalog}

This is the USGS catalog of routine moment-tensor solutions using the method of Sipkin (1982). Their greatest potential as preferred source is for depth and magnitude $\left(\mathrm{M}_{\mathrm{w}}\right)$ based on the seismic moment determined in the inversion. In most 
cases, however, HRV entries exist for the same events and HRV is preferred for magnitude because it utilizes longer period waveform data. About one-half of the $148 \mathrm{GS}$ entries in the "Master Catalog" are the preferred source for depth (the only catalog that outranks GS for depth is the GC catalog). The format of the comment field for GS entries is identical to that for the HRV entries (Appendix B).

\section{OMT Catalog}

The "Other Moment Tensor" catalog is carried in the USGSNEIC database. It is very small, containing data on only 15 events in the Afghanistan study region. These solutions are from several sources, mainly Russia and the European Mediterranean Seismological Centre. They would mainly be of use for magnitude determination based on seismic moment, but for every OMT entry there is also an HRV entry that is preferred. No OMT entry is the preferred source for any event parameter. The format of the comment field for OMT entries is identical to that of HRV or GS, except that a short field is added at the end to carry a code for the agency that provided the moment tensor solution (Appendix B).

\section{EHBS Catalog}

E.R. Engdahl applied the EHB algorithm to 160 earthquakes that occurred prior to 1964, using arrival-time data from the Bulletin of the ISS, which has recently been (mostly) scanned, converted to text by optical character recognition, reformatted, and subjected to various quality control tests (Villaseñor and others, 1997). EHBS events that fall within the Iran region are identical to EHBI events, and have not been added to the "Master Catalog." The format of the EHBS comment field is the same as for the EHB, and EHBI catalogs (Appendix B). The EHBS is not the preferred source for any parameter of any event in the "Master Catalog," but it provides a useful consistency check for other sources of information.

\section{ISS Catalog}

The International Seismological Summary (ISS) was a predecessor of the ISC that compiled global readings for earthquakes and issued a regular Bulletin with locations, origin times, and phase readings between 1918 and 1963. These bulletins have recently been (mostly) scanned, converted to text by optical character recognition, reformatted, and subjected to various quality-control tests (Villaseñor and others, 1997), and many of the events have been relocated with modern methods (e.g., the EHBS and EBS catalogs). The source catalog called "ISS" in this study, however, contains the original locations. The catalog contains no magnitude information, and it contains depth information for only a small subset of events. There are 1,516 ISS events within the Afghanistan study area, but many of them were not kept in the "Master Catalog" because of the magnitude criteria $(M \geq 5.5)$. They have been kept only when they can be matched to another catalog that supplies magnitude information, and if that magnitude meets the criteria. The ISS catalog is the preferred source of information for a handful of events in the
"Master Catalog," but the locations cannot be considered at all reliable. The comment field for ISS entries is blank. (Appendix B).

\section{AB1 Catalog}

The source catalog called ABl in this study is based on the data published by Ambraseys and Bilham (2003a) dealing with seismicity of the Afghanistan region. This interesting and valuable publication provides access to original reports of historical earthquake activity. Such a historical-macroseismic approach can yield more accurate estimates of location and magnitude than early instrumental studies. The authors employed a method to convert estimates of felt area and perceived damage, based on historical accounts, into an estimate of $\mathbf{M}_{\mathrm{s}}$ for many historical earthquakes. While they are less reliable than modern digital measurements, such magnitudes do add significantly to the body of knowledge for the pre-instrumental (and even the earlyinstrumental) period. Ambraseys and Bilham went a step further and converted their $M_{s}$ values to $M_{w}$, but we do not carry that information in the "Master Catalog," as use of the $M_{w}$ magnitude type tends to imply a more rigorous methodology than was actually used here.

For many events in the early instrumental period, the authors collected and analyzed analog seismograms to estimate $M_{s}$. This is a great addition to the dataset, because the ISS catalog, which dominates the early instrumental period in terms of the number of events, contains no magnitude information. It should be born in mind, however, that these magnitude values have considerably more uncertainty than modern determinations.

There were 1,299 AB1 events within the Afghanistan study area, most of which were matched up with existing events in the "Master Catalog." Matching required considerable handediting, however, because the AB1 catalog is very irregular about the precision of origin times-some historical events are given only to the nearest year-and therefore the event IDs did not correspond to any other catalog. The ABI catalog is the preferred source of information for the epicenter and magnitude of about 138 events in the "Master Catalog," and the narratives, even when other catalogs are preferred as sources of source parameter information, will be of great interest in the seismic hazard analysis.

During import of the AB1 catalog, I found that there are narratives of four earthquakes (in the electronic supplement to the paper) that do not appear in the data table of Ambraseys and Bilham (2003a) or in any other catalog:

- $1899 / 12 / 31$

- $1909 / 07 / 07$

- 1952

- $1955 / 08 / 29$

These events have not been added to the "Master Catalog," Two other events with narratives that do not appear in the 
associated table were added to the "Master Catalog" because there were other catalog entries to provide the basic source parameters for them.

The comment field for $\mathrm{ABl}$ entries carries, at most, only an indication that a narrative summary of an earthquake's effects is available in the source publication (Appendix B).

\section{AB2 Catalog}

The AB2 catalog comes from Ambraseys and Bilham (2003b), which may be thought of as a companion paper to Ambraseys and Bilham (2003a) that is concerned with the Northern Baluchistan region near the southeastern border of Afghanistan. Most of the earthquake data in $\mathrm{AB} 2$ are duplicated in $\mathrm{AB} 1$, but $\mathrm{AB} 2$ has narratives for additional events. The main role of the 58 $\mathrm{AB} 2$ entries is to note when there is a narrative available (in the comment field).

\section{AM Catalog}

The AM catalog is based on data published in Ambraseys and Melville (1982), on earthquakes in the Iran region, the eastern part of which is included in the present study. As with the $\mathrm{AB} 1$ and $\mathrm{AB} 2$ catalogs, the $\mathrm{AM}$ catalog provides narratives that summarize a wide range of historical, even archeological, information on earthquake activity and felt effects. The presence of such commentaries is noted in the comment field for AM entries (Appendix B).

\section{SSR Catalog}

The SSR catalog is a dataset maintained at the USGSNEIC that is based on Kondorskaya and Shebalin (1982). It presents information on earthquakes, largely based on Russian studies and data, in the region of the U.S.S.R. from "ancient times" through 1977. It is an impressive work in its massiveness and technical detail, yet it is difficult to evaluate for quality. The SSR catalog contains many near-duplicate entries for the same event with the only difference being two-letter "source" codes. Lacking a rationale for choosing between them, I kept the first entry for each event. I also imported only events with magnitude 4.0 or larger. The procedures used to calculate magnitude are exhaustively documented in Kondorskaya and Shebalin (1982), yet it is difficult to state clearly how they relate to modern magnitude scales. It appears that they should be considered comparable to $m_{b}$ and $M_{s}$ for the moderate-sized events of interest here. In the "Master Catalog" they carry no magnitude type.

The SSR catalog runs through 1989, but after 1964 Soviet data began to be integrated routinely with the ISC and it is unlikely that the SSR catalog data would add much new information to the other catalogs available for the modern era. I imported only SSR events prior to 1964,870 entries. A great deal of hand editing was required to match up SSR and ISS entries properly. It was a worthwhile exercise, however, as the SSR entries provide magnitude and depth information for many ISS entries that had none before. The SSR is the preferred source of information for about 300 events in the "Master Catalog." However, it should be remembered that many of the epicenters were calculated using only stations within the U.S.S.R., which means that azimuthal coverage may be very poor. The format of the comment field for the SSR catalog entries is given in Appendix B.

\section{CHI Catalog}

Like the SSR catalog, the China catalog (catalog code CHI) is a dataset carried by the USGSNEIC that is based on Chinese national network locations and reports. Unlike the SSR catalog, there is no companion documentation to help evaluate the quality of the information. Only events prior to 1970 were imported because it was judged that later entries would add little useful information to the other available catalogs. The CHI catalog carries one or two magnitudes, but they are of unknown type. The CHI catalog is the preferred source for about 50 events in the "Master Catalog." As with the SSR locations, these should be treated with caution because many of them may have been done with data from a very limited range of azimuths with respect to the epicenters.

\section{IND Catalog}

The IND catalog is based on the "India" catalog carried by the USGSNEIC. Like the SSR and CHI catalogs, it is a reflection mainly of results determined with Indian national seismic network stations, and therefore any locations for events outside India, or even near its borders, may be seriously biased. Only events through 1973 were imported because more recent events are adequately covered by other available catalogs. Many IND entries had to be matched with existing "Master Catalog" events by hand because the IND catalog does not contain values in the hours or minutes fields of origin time for many events. The IND catalog contains no information on focal depth. The IND catalog is the preferred source for about 60 events in the "Master Catalog."

\section{NOAA Catalog}

The NOAA catalog (Dunbar and others, 1992) is another dataset included within the USGSNEIC database. It is a compilation of information about large and damaging earthquakes throughout history, but it is known to contain gross errors and must be referenced with care. As an example, for the Afghanistan study region, the NOAA catalog contains an event in northeastern Iran on March 31, 1963, that is assigned a magnitude of $7.0 \mathrm{M}_{\mathrm{s}}$. This event appears in no other catalog. The source of the NOAA entry appears to be the U.S. Coast and Geodetic Survey, which had a report of an earthquake in this region on this date, but as a rather small event that did a little damage in a few villages. An intensity value of VII was noted, which a transcription error apparently turned into a magnitude 7 earthquake in the NOAA catalog.

During the hand-editing phase of merging the NOAA catalog with the "Master Catalog," I was extremely liberal in matching events, even with large differences in origin time and location. 
Even so, there are about 30 events in the catalog for which there is only a NOAA entry. These should be treated with caution. The original sources of parameters reported in the NOAA catalog are not included in the NEIC computer file, but they are contained in the associated publication (Dunbar and others, 1992).

\section{ABE Catalog}

The ABE catalog is another dataset maintained by the USGSNEIC, representing a catalog of source parameters for large earthquakes extracted from several publications: Abe (1981, 1984) and Abe and Noguchi (1983a,b). The major contribution of these studies is re-examination of old waveform records from events as early as 1897 and determination of magnitudes. This catalog contributed entries for 48 events in the "Master Catalog," but in only one case is the $\mathrm{ABE}$ entry taken as the preferred source. Nevertheless, the magnitudes should be rather reliable and useful for comparison with other catalog sources.

\section{GUTE Catalog}

The USGSNEIC carries a database in which earthquake information from several studies involving Beno Gutenberg is tabulated. This is known as the GUTE catalog in the USGSNEIC, but for the purposes of the Afghanistan "Master Catalog," I broke it into two parts, one of which also has the code "GUTE" (the other has the code GR). This division is based on the code contained within the USGSNEIC database that associates an entry either with the original Gutenberg catalog (Gutenberg, 1945) or the later catalog of Gutenberg and Richter (1954) which includes many of the same events and which associates revised magnitude estimates with the events. A total of 192 GUTE entries were imported. Only one magnitude is reported, and that is probably most closely associated with the modern $\mathbf{M}_{\mathrm{s}}$ magnitude.

\section{GR Catalog}

Like the GUTE source catalog of the Afghanistan "Master Catalog," this is a subset of the entries included in the USGSNEIC "GUTE" database. The GR catalog represents entries associated with the catalog of Gutenberg and Richter (1954), designated "G-R" in that dataset. Many events have both GUTE and GR entries, but there were three fewer GR entries (189). GR is preferred over GUTE for the source of magnitude information, and it is the preferred source of magnitude for about 100 events in the Master Catalog.

\section{ROTH Catalog}

The ROTH catalog is based on a dataset maintained by the USGSNEIC of the global earthquake catalog of Rothe (1969). It covers the period 1953-65 and is especially important for the period 1953-63, during which the ISS was unable to keep up with the cataloging of small and moderate earthquakes. A total of 179 events from the Rothé catalog were imported, and these entries provide the authoritative source for several dozen events in the "Master Catalog." The magnitude type reported in the ROTH catalog is not specified as to type.

\section{EB Catalog}

The EB catalog is based on relocations of events since 1964 using the $\mathrm{EAB}$ method that is described in Appendix E. The quality of any earthquake catalog is mainly driven by the level of review that individual events receive and by the number of iterations performed in the location process. The level of review of individual earthquakes in the EB catalog is higher than the standard EHB process and somewhat lower than the very careful review done by Engdahl to construct the EHBI dataset. The catalog for the Afghanistan "Master Catalog" is about five times larger than that for the EHBI catalog, so full review would have taken longer than the time allotted for this project.

Nevertheless, the EB catalog is usually preferred as the source for epicenter, origin time and depth over most other catalogs in this study (the EHBI being the main exception). Approximately 10,000 EB entries were imported into the "Master Catalog." The vast majority of them merged easily with existing events in the "Master Catalog," but there were a number of anomalies that required hand editing simply because of the large number of cases being treated.

The EB catalog was created by attempting to relocate every event with a magnitude of 4.0 or greater and for which there were arrival-time readings in the ISC dataset (PDE data after August 2002), whether the location had been determined by the ISC itself or was a contributed solution (OTH). The problematic nature of the OTH entries is discussed elsewhere, and even though it was possible to obtain an acceptable solution in the EB catalog for some of these events, they should be treated with caution because they are still rather likely to carry misassociated readings.

\section{EBS Catalog}

The EBS catalog was created by running the $\mathrm{EAB}$ relocation procedure (Appendix E) on the better-recorded events of the ISS Bulletin, and so it is very comparable to the EHBS catalog. Since none of the ISS entries carries magnitude information, retention in the "Master Catalog" depends on the existence of another catalog entry that carries a magnitude larger than the cutoff of 5.5. About two-thirds of the 160 ISS events relocated for the EBS catalog have such entries. The EBS entries for which the magnitude criterion failed were added to the "Sub-Threshold Catalog of Afghanistan Earthquakes."

\section{OTH Catalog}

The final stage of construction of the Afghanistan "Master Catalog" was an attempt to merge the events from the ISC catalog that were contributed by other agencies and not verified by the ISC. These events belong to the OTH catalog. There are nearly 6,000 such events, but most of them fall below the magnitude cutoff of 4.0. Given very liberal criteria (even more so than with the NOAA catalog), 119 OTH entries could be matched with existing "Master Catalog" events. Many of the associations may be false, but little harm is done since these entries are rarely used as the preferred source for any parameter-in 48 cases an OTH 29 
other information available. Another 391 OTH events would have had to be treated as new events, but after discussion with other project scientists, the decision was made to delete all OTH-only events from the "Master Catalog." They were added to the "SubThreshold Catalog."

Of the 391 OTH-only events, about one-half occurred during the period 1964-76. A number of PDE events seem to have been reported this way in those years. After 1976 the number of such events per year is small until 2001 , when a quarter of the OTH-only events occurred. Most of these are associated with the Independence Day (Bhuj) earthquake in India, and they are either legitimate aftershocks reported by the Indian seismological service or fictitious or badly mislocated events determined by that agency when Bhuj aftershock data were mixed with arrivals from other earthquakes occurring around the world.

\section{TH2 Catalog}

In dealing with the OTH catalog, it became necessary to distinguish between two OTH entries for the same event (from different contributing agencies). No such entries will be found in the "Master Catalog," but a small number of them exist in the Afghanistan "Sub-Threshold Catalog."

\section{Final Version of the "Master Catalog"}

In the final stages of assembly of the "Master Catalog," after all catalogs contributing magnitude information were imported, a condition was added to the part of the code that sets the magnitude preference, to see if the event failed the magnitude cutoff criteria. Such events were not retained in the "Master Catalog" but were written to the Afghanistan "Sub-Threshold Catalog." 'The final version of the Afghanistan master earthquake catalog, published with this report, is version 8.4.

Statistics on the composition of the "Master Catalog of Afghanistan Earthquakes" are given in Table 1.

A preferred source is given for epicenter and origin time for each of the 12,757 events in the "Master Catalog," but a preferred source for magnitude or depth is not always given (if no source catalog provided any useful information on those parameters).

The distribution of preferred depths in the "Master Catalog" is shown in figure 9.

Other than one event with a depth of $370 \mathrm{~km}$ (19710610.0942), the maximum depth of earthquakes in the study region is approximately $250-300 \mathrm{~km}$. A peak at the depth of $33 \mathrm{~km}$ results from the common practice of arbitrarily fixing depths of poorly constrained shallow events at $33 \mathrm{~km}$. In the "Summary Catalog" (discussed in the following section), these events are assigned quality $\mathrm{B}$ or $\mathrm{C}$ because they could not be calculated reliably but had to be assigned a default value.

\section{The "Summary Catalog"}

Although the "Master Catalog" described above is the fundamental dataset for further research on the distribution of seismicity and seismic hazard in the Afghanistan region, for many purposes (such as plotting maps) it is desirable to have a version of the catalog that provides a single "preferred" set of hypocentral parameters. This is provided as a companion dataset, the "Summary Catalog of Afghanistan Earthquakes" ("Summary Catalog").

The selection of a single set of preferred source parameters for each event is not a trivial task. Simply taking the preferred source catalog's value for each parameter from the "Master Catalog" can lead to undesirable inconsistencies, such as the focal depth not being commensurate with the epicenter. Our strategy, therefore, has been to produce a "Summary Catalog" that relaxes the notion of "preferred" sources to a small extent in order to maintain seismological consistency between the hypocentral parameters.

The other major distinguishing feature of the "Summary Catalog" is that we assigned a quality ranking to each event to provide guidance on which events are most reliably located in epicenter and depth. This will help in selecting appropriate datasets for different purposes.

\section{Questionable Historical Events}

The "Summary Catalog" contains all events in the "Master Catalog" except for a handful of questionable events that meet the following conditions:

- The event date is before 1900 .

- The epicenter is in the region $29-38^{\circ} \mathrm{N}, 5^{\circ}-73^{\circ} \mathrm{E}$.

- The epicenter was reported by the SSR or the NOAA catalog.

- The epicenter is not contained in one the "Ambraseys" catalogs (AB1, AB2, or AM).

In their very thorough review of historical sources, Ambraseys and coworkers certainly knew of all events in their study region that had been reported by agencies such as those contributing to the SSR and NOAA catalogs, and a significant purpose of their research was to identify and reject bogus events, which made their way into the literature over time. Such events are understood to be a common element in catalogs of historical seismicity due to a variety of problems.

We have taken the position that if Ambraseys and coworkers did not list an event that was claimed by an earlier catalog to have occurred within their study region, it is probably not a real event. Twenty-nine such events were left out of the "Summary Catalog" for this reason, leaving it with 12,728 events.

\section{Preferred Sources for the "Summary Catalog"}

For the "Summary Catalog," we have added some exceptions to the rules listed in Appendix D for establishing a hierarchy of preferred sources in order to ensure that the "Summary Catalog" can be treated, to the greatest extent possible, as a normal catalog in which depth, origin time, and epicenter can be considered to 
Table 1. Contributions of the different source catalogs to the Afghanistan "Master Catalog," giving the number of cases in which each catalog was the preferred source for epicenter, origin time (OT), depth, and magnitude. The number of entries from each source catalog in the "Master Catalog" may be much larger.

\begin{tabular}{|c|c|c|c|c|}
\hline Catalog & Epicenter & OT & Depth & Magnitude \\
\hline $\mathrm{ABE}$ & 1 & 1 & 0 & 3 \\
\hline $\mathrm{AB} 1$ & 138 & 102 & 18 & 137 \\
\hline $\mathrm{AB} 2$ & 0 & 0 & 0 & 0 \\
\hline $\mathrm{AM}$ & 85 & 72 & 0 & 74 \\
\hline CEN & 42 & 29 & 27 & 99 \\
\hline $\mathrm{CHI}$ & 52 & 49 & 16 & 42 \\
\hline EHB & 2,136 & 5,010 & 5,009 & 13 \\
\hline EHBI & 994 & 638 & 599 & 0 \\
\hline EHBS & 0 & 47 & 47 & 0 \\
\hline $\mathrm{GC}$ & 0 & 0 & 74 & 0 \\
\hline GR & 0 & 2 & 2 & 108 \\
\hline GS & 0 & 0 & 71 & 1 \\
\hline GUTE & 0 & 0 & 0 & 0 \\
\hline HRV & 0 & 0 & 0 & 547 \\
\hline IND & 64 & 63 & 0 & 43 \\
\hline ISC & 8 & 9 & 7 & 10,185 \\
\hline ISS & 15 & 14 & 0 & 0 \\
\hline NOAA & 33 & 45 & 17 & 13 \\
\hline OMT & 0 & 0 & 0 & 0 \\
\hline PDE & 133 & 133 & 133 & 1,078 \\
\hline ROTH & 22 & 34 & 34 & 98 \\
\hline SSR & 293 & 334 & 342 & 198 \\
\hline EB & 8,667 & 6,141 & 6,036 & 0 \\
\hline EBS & 74 & 34 & 34 & 0 \\
\hline OTH & 0 & 0 & 0 & 48 \\
\hline OTH2 & 0 & 0 & 0 & 0 \\
\hline Total & 12,757 & 12,757 & 12,466 & 12,687 \\
\hline
\end{tabular}


Figure 9. Distribution of preferred depths in the Afghanistan "Master Catalog."

have been estimated together in a standard location procedure. The "Summary Catalog" has a single reference to a preferred catalog source for epicenter, origin time, and depth, and a second reference to the preferred catalog source for magnitude.

\section{Magnitude}

The magnitude listed in the "Summary Catalog" was taken from the preferred source for magnitude as indicated in the "Master Catalog" (Appendix D). However, only a single magnitude is listed in the "Summary Catalog." The order of precedence for magnitude types is $M_{w}, M_{S}, M_{B}, m_{b}, M_{E}$, and unknown.

\section{Epicenter}

Next, the preferred source for epicenter was selected from the "Master Catalog." This is normally the epicenter reported by the preferred source (Appendix D). However, the normal order can be modified under these conditions:

- Both an EB-class (EB or EBS) and EHB-class (EHB, EHBI, or EHBS) solution exist for the event
- One solution is "good" and the other is "poor," in the terms appropriate to that catalog type (Appendix B, comment lines). For EB-class solutions, "poor" solutions are those for which epicenter is a fixed parameter ("F" in column 89). For EHB-class solutions, "poor" solutions have the label " $X$ " in column 90.

Under these circumstances, we used the better-rated solution. In some cases the assignment of preferred epicenter was changed during the selection of preferred focal depth, described as follows.

\section{Focal Depth}

In most cases, the focal depth in the "Summary Catalog" was taken from the preferred source for depth for that event in the "Master Catalog." Other factors were considered, however, driven by the fact that we wanted the hypocentral parameters reported in the "Summary Catalog" to be mutually consistent. That is, if we took a certain depth as the preferred estimate, we took the epicenter and origin time that were jointly calculated with that depth or calculated with that depth assumption. 
If the preferred source for depth is one of the "modern waveform analysis" catalogs (GC or GS), and if the event also appears in one of the EHB-class catalogs, we took the EHB-class catalog as the preferred source for depth and epicenter because, in most cases, the EHB solution was calculated with the waveform depth.

\section{Origin Time}

Using the procedures outlined above, we ensured that all entries in the "Summary Catalog" have estimates of depth and epicenter that are consistent, i.e., from the same source catalog. The origin time in the "Summary Catalog" is taken from the same catalog source.

Using the procedures described above, the distribution of preferred sources for the "Summary Catalog" is somewhat different from that of the "Master Catalog."

While we have tried to create the "Summary Catalog" in such a way that the epicenter, origin time, and depth can be considered to have been taken from a single preferred source catalog, there are some discrepancies. There are 82 cases ( 24 prior to 1900 , and 54 between 1900 and 1963, none since 1964) in which the single preferred source catalog code for epicenter, origin time, and depth does not accurately reflect the catalog sources actually used for the entry. These events are flagged in the "Summary Catalog" with a "+" after the single preferred source catalog code for epicenter, origin time, and depth. The nature of the discrepancy can easily be determined by referring to the Master Catalog.

\section{Quality Rankings for the "Summary Catalog"}

The "Summary Catalog" has a letter code that provides a convenient ranking of the events according to "quality," which is related to the likely uncertainties of epicentral location and depth:

- A: High-quality epicenter and focal depth.

- B: High-quality epicenter, but depth is less well determined.

- C: Less reliable epicenter and depth, in the period $1900-$ 2004.

- M: Earthquakes prior to 1900. Epicenters and depths subject to large uncertainty.

Our basic strategy for judging the quality of locations was to look for agreement between two modern, independent location studies, one from the EB-class catalogs, and one from the EHBclass catalogs.

\section{Quality A}

The conditions to be met for a quality-A ranking are

- Listing of the event in both an EB-class and an EHBclass catalog.
- Difference between the two solutions in epicenter and focal depth less than $10 \mathrm{~km}$

- AHYP parameter is blank or "I" and the ISOL parameter is "DEQ," "WEQ," or "BEQ" in the EHB-class catalog.

- Epicenter and depth are free parameters, the length of the semi-major axis for epicenter is $\leq 10 \mathrm{~km}$, and the standard error in focal depth is $\leq 10 \mathrm{~km}$ in the EB-class catalog,

Quality-A events can be considered uncertain in location and depth by less than $15 \mathrm{~km}$, not considering any systematic location bias due to the use of an average global model for the location analysis. For any study in which focal depth is of special interest, it would be advisable to use quality-A events only.

\section{Quality B}

If an event fails to meet the A criteria, it is checked against the following criteria for quality-B ranking:

- Event is listed in both an EB-class and an EHB-class catalog.

- Difference between the two solutions in epicenter is less than $10 \mathrm{~km}$.

- In the EHB-class catalog, the AHYP parameter is blank or "I" and the ISOL parameter is "DEQ," "WEQ," "BEQ," or "FEQ."

- In the EB-class catalog epicenter is a free parameter and the length of the semi-major axis for epicenter is $\leq 10$ $\mathrm{km}$.

Quality-B events can be considered to have uncertainty in location similar to quality-A events, but there is greater uncertainty in their depths, perhaps several tens of kilometers. These events should be used with caution in any study for which focal depth is an important parameter.

\section{Quality C}

If an event fails to meet the criteria for quality B and occurred in the year 1900 or later, it is assigned quality C. These events were all located instrumentally but with uncertain accuracy. Mislocation of these events may reach $50 \mathrm{~km}$ or more, and many of them have virtually no constraint on focal depth. The usefulness of quality-C events is mainly in obtaining a clearer image of long-term seismicity patterns in different areas.

\section{Quality $M$}

All events that occurred before 1900 are assigned quality $M$. These events were located by using reports of damage and felt effects from historical sources. The epicenters may be considerably in error, by as much as several hundred kilometers, and there is almost no constraint on depth beyond the rule of 33 
Table 2. Contributions of the different source catalogs to the "Summary Catalog," giving the number of cases in which each catalog was the preferred source for epicenter, origin time, depth, and magnitude.

\begin{tabular}{|c|c|c|c|c|}
\hline Catalog & Epicenter & Origin Time & Depth & Magnitude \\
\hline $\mathrm{ABE}$ & 1 & 1 & 0 & 3 \\
\hline $\mathrm{AB} 1$ & 138 & 102 & 18 & 137 \\
\hline $\mathrm{AB} 2$ & 0 & 0 & 0 & 0 \\
\hline $\mathrm{AM}$ & 85 & 72 & 0 & 74 \\
\hline CEN & 42 & 29 & 27 & 99 \\
\hline $\mathrm{CHI}$ & 52 & 49 & 16 & 42 \\
\hline EHB & 2,733 & 2,733 & 2,733 & 13 \\
\hline EHBI & 977 & 978 & 978 & 0 \\
\hline EHBS & 6 & 6 & 6 & 0 \\
\hline GC & 0 & 0 & 0 & 0 \\
\hline GR & 0 & 2 & 2 & 108 \\
\hline GS & 0 & 0 & 0 & 1 \\
\hline GUTE & 0 & 0 & 0 & 0 \\
\hline HRV & 0 & 0 & 0 & 547 \\
\hline IND & 64 & 63 & 0 & 43 \\
\hline ISC & 8 & 8 & 6 & 10184 \\
\hline ISS & 15 & 14 & 0 & 0 \\
\hline NOAA & 20 & 31 & 13 & 9 \\
\hline OMT & 0 & 0 & 0 & 0 \\
\hline PDE & 134 & 134 & 134 & 1079 \\
\hline ROTH & 22 & 34 & 34 & 98 \\
\hline SSR & 277 & 319 & 326 & 182 \\
\hline EB & 8,086 & 8,086 & 8,086 & 0 \\
\hline EBS & 68 & 67 & 67 & 0 \\
\hline OTH & 0 & 0 & 0 & 48 \\
\hline OTH2 & 0 & 0 & 0 & 0 \\
\hline Total & 12,728 & 12,728 & 12.446 & 12,667 \\
\hline
\end{tabular}


events, but cause less damage in the immediate epicentral area. Many of these events are of extraordinary interest in terms of seismic hazards in the region.

Table 3. Quality rankings in the Summary Catalog.

\begin{tabular}{cr}
\hline Quality & Number \\
\hline A & 1,433 \\
B & 2,024 \\
C & 9,053 \\
M & 218 \\
\hline
\end{tabular}

A map of the final "Summary Catalog of Afghanistan Earthquakes," based on the preferred source parameters for each event, is shown in figure 10 . event. Thus, the researcher is able to quickly compare the parameters reported in different source catalogs. For each of the main parameters (epicenter, origin time, depth, and magnitude) one of the source catalogs is designated as the preferred source for that parameter.

- The "Summary Catalog of Afghanistan Earthquakes " ("Summary Catalog") is based on the "Master Catalog" and contains a single entry for each event in the "Master Catalog" except for 29 events (all occurring before 1964) that were judged to be duplicate entries corresponding to other events in the "Master Catalog." The source parameters reported in the "Summary Catalog" were selected in such a way that the epicenter, origin time, and depth are internally consistent, that is, they can be considered to have come from a single location procedure. To achieve this goal, some of the criteria for selecting a preferred source in the "Master Catalog" were relaxed. The "Summary Catalog" also

\section{Summary and Conclusions}

A "Master Catalog" of information about earthquake activity in the Afghanistan study region $\left(23^{\circ} 45^{\circ} \mathrm{N}, 53^{\circ} 80^{\circ} \mathrm{E}\right)$ was prepared from 26 source catalogs. The "Master Catalog" contains information about 12,728 earthquakes from the second century B.C. into December 2004. A minimum magnitude threshold was applied for events since 1899: magnitude 5.5 or greater from 1900 to 1963 and 4.0 or greater in the period 1964 to 2004 .

From the source catalogs containing information on an event, preferred sources were determined for epicenter, origin time, depth, and magnitude. In a few cases, no preferred source was available for depth or magnitude.

The catalog of earthquakes is presented in two forms:

- The "Master Catalog of Afghanistan Earthquakes" ("Master Catalog") contains an entry for every source catalog that includes the

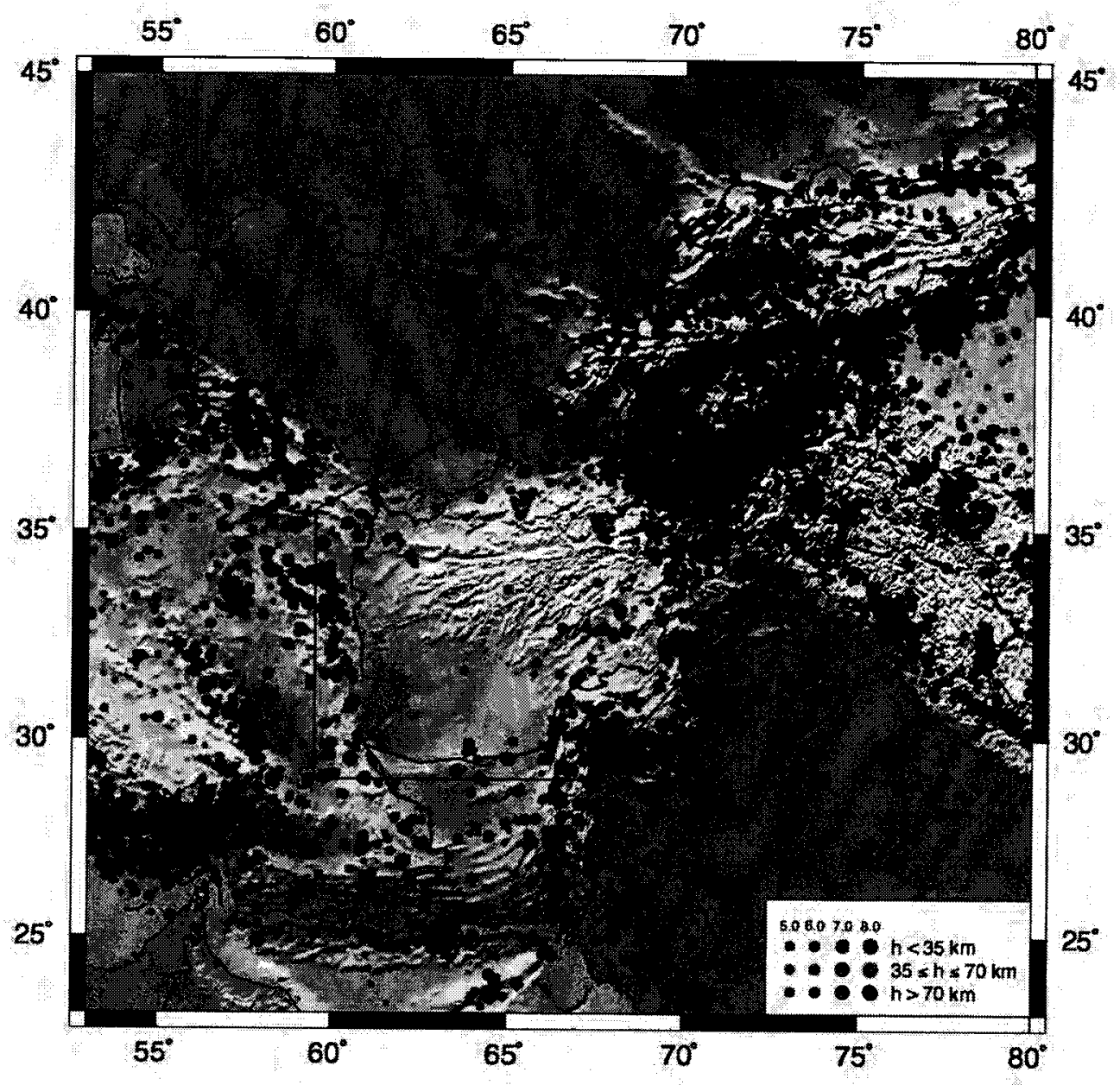

Figure 10. Map of Afghanistan earthquake, showing locations, depths, and magnitude scaling based on the "Summary Catalog." 
includes a quality ranking for each event that allows easy discrimination between the events on the basis of the likely uncertainties in location and depth.

Approximately 10,000 of the "Master Catalog" events were relocated specifically for this study using a method ("EAB") similar to, but independent of, the EHB method (Engdahl and others, 1998). Depth information was extensively (but not universally) reviewed in the EAB process prior to full location. Some EHB-derived catalogs were also reviewed at various levels, and such review contributed substantially to their accuracy. Comparisons between the results in the two catalogs were a useful means of controlling the quality of this very large dataset. In most cases, either the EAB- or EHB-derived solutions are the preferred source for epicenter, origin time, and depth.

Further improvements to this catalog are most likely needed in two areas:

- Additional review of the relocation results of individual earthquakes of interest may lead to greatly improved confidence about their location and, especially, depth. It is impractical to do this for every event in the "Master Catalog," and such review should be based on questions that arise during the subsequent hazard analysis.

- Substantial improvements in epicentral locations can be obtained by application of a multiple-event relocation procedure (see, for example, Jordan and Sverdrup, 1981). The improvements are both in absolute location and in relative locations that may be useful in associating clusters of events with geological features of interest. Clusters of events for this kind of study should have a maximum dimension of less than about $100 \mathrm{~km}$ to avoid biasing effects of intra-cluster structural heterogeneity. They should be limited in depth range for the same reason. Such studies provide relatively little improvement in depth estimates, which are most likely to come from detailed analysis of waveforms or depth phases for individual events.

\section{Acknowledgments}

Thanks are due to Margaret Hopper for entering by hand a large amount of earthquake data from printed sources for computer processing, and for retrieving many datasets from the archives of the USGSNEIC. James Dewey and Stuart Sipkin offered very helpful scientific advice at critical junctions during this project. Bob Engdahl was extremely generous with important datasets, software, and vast knowledge of how to compile earthquake catalogs.

This report is based on research conducted under Interagency Agreement 306-P-00-04-00566-00 between the U.S. Agency for International Development (USAID) and the USGS.

\section{References}

Abe, Katsuyuki, 1981, Magnitudes of large shallow earthquakes from 1904 to 1980: Physics of the Earth and Planetary Interiors, v. 27, p. 72-92.

Abe, Katsuyuki, 1984, Complements to "magnitudes of large shallow earthquakes from 1904 to 1980": Physics of the Earth and Planetary Interiors, v. 34, p. 17-23.

Abe, Katsuyuki, and Noguchi, Shin'ichi, 1983a, Determination of magnitude for large shallow earthquakes, 1898-1917: Physics of the Earth and Planetary Interiors, v. 32, p. 45-59.

Abe, Katsuyuki, and Noguchi, Shin'ichi, 1983b, Revision of magnitudes of large shallow earthquakes, 1897-1912: Physics of the Earth and Planetary Interiors, v. 33, p. 1-11.

Ambraseys, Nicholas, and Bilham, Roger, 2003a, Earthquakes in Afghanistan: Seismological Research Letters, v. 74, p. 107 123 (includes electronic supplement on the web site of the Seismological Society of America, http://www.seismosoc. org/publications/SRL/SRL_74/srl_74-2_ambraseys_esupp1. html; last accessed September 19, 2005).

Ambraseys, Nicholas, and Bilham, Roger, 2003b, Earthquakes and associated deformation in northern Baluchistan: Bulletin Seismological Society America, v. 93, p. 1573-1605.

Ambraseys, N. N., and Melville, C. P., 1982, A History of Persian Earthquakes: Cambridge, Cambridge University Press, $219 \mathrm{p}$.

Buland, R.P., and Chapman, C.H., 1983, The computation of seismic travel times: Bulletin of the Seismological Society of America, v. 73, p. 1271-1302.

Choy, G.L., and Boatwright, J.L., 1995, Global patterns of radiated seismic energy and apparent stress: Journal of Geophysical Research, v. 100, p. 18205-18228.

Choy, G.L., and Dewey, J.W., 1988, Rupture process of an extended earthquake sequence-Teleseismic analysis of the Chilean earthquake of 3 March 1985: Journal of Geophysical Research, v. 93, p. 1103-1118.

Dunbar, P.K., Lockridge, P.A., and Whiteside, L.S., 1992, Catalog of significant earthquakes, including quantitative casualties and damage: National Oceanic and Atmospheric Administration, National Environment Satellite Data and Information Service, National Geophysical Data Center, Report SE-49, 320 p.

Dziewonski, A.M., Chou, T.A., and Woodhouse, J.H., 1980, Determination of earthquake source parameters from waveform data for studies of global and regional seismicity: Journal of Geophysical Research, v. 86, p. 2825-2852.

Engdahl, E. R., Van der Hilst, R.D., and Buland, R.P., 1998, Global teleseismic earthquake location with improved travel times and procedures for depth determination: Bulletin Seismological Society of America, v. 88, p. 722-743.

Engdahl, E. R., and Villaseñor, Antonio, 2002, Global Seismicity: 1900-1999, in Lee, W.H.K., Kanamori, Hiroo, Jennings, P.C., and Kisslinger, Carl, eds., International handbook of earthquake and engineering seismology, pt. A: Amsterdam, Academic Press, p. 665-690. 
Gutenberg, Beno, 1945, Amplitudes of surface waves and magnitudes of shallow earthquakes: Bulletin of the Seismological Society of America, v. 35, p. 3-12.

Gutenberg, Beno, and Richter, C.F., 1954, Seismicity of the Earth and Associated Phenomena: Princeton, N.J., Princeton University Press, $310 \mathrm{p}$.

Gutenberg, Beno, and Richter, C.F., 1956, Magnitude and energy of earthquakes: Annali di Geofisica, v. 9, p. 1-15.

Jordan, T.H., and Sverdrup, K.A., 1981, Teleseismic location techniques and their application to earthquake clusters in the south-central Pacific: Bulletin of the Seismological Society of America, v. 71, p. 1105-1130.

Kennett, B.L.N., Engdahl, E.R., and Buland, R.P., 1995, Constraints on seismic velocities in the Earth from traveltimes: Geophysical Journal International, v. 122, p. 108-124.

Kondorskaya, N.V. and Shebalin, N.V., eds., 1982, New Catalog of Strong Earthquakes in the U.S.S.R. from Ancient Times through 1977: National Oceanic and Atmospheric Administration, National Environment Satellite Data and Information Service, National Geophysical Data Center, Report SE-31, 601 p.
Maggi, A., Jackson, J.A., Priestly, K., and Baker, C., 2000, A reassessment of focal depth distributions in southern Iran, the Tien Shan and northern India Do earthquakes really occur in the continental mantle?: Geophysical Joumal International, v. 143, p. $629-661$

Pacheco, J.F., and Sykes, L.R., 1992, Seismic moment catalog of large shallow earthquakes, 1900 to 1989: Bulletin of the Seismological Society of America, v. 82, p. 1306-1349.

Rothé, J. P., 1969, The seismicity of the Earth, 1953-1965: Paris, United Nations Educational, Scientific, and Cultural Organization (UNESCO), $336 \mathrm{p}$

Sipkin, S.A., 1982, Estimation of earthquake source parameters by the inversion of waveform data Synthetic seismograms: Physics of Earth and Planetary Interiors, v. 30, p. 242-259.

U.S. Geological Survey, 2001, Preliminary determination of epicenters, Monthly Listing, January 2001; U.S. Geological Survey, $56 \mathrm{p}$.

Villaseñor, Antonio, Bergman, E.A., Boyd, T.M., EngdahI, E.R., Frazier, D.W., Harden, M.M., Orth, J.L., Parkes, R.L., and Shedlock, K.M., 1997, Toward a comprehensive catalog of global seismicity: Eos AGU, v. 78, p. 581-588.

\section{Appendix A. Explosions}

Following is a list of the events in the study region of the Afghanistan project that are known to be explosions. The 
format is the standard "Master Catalog" form (Appendix B), but truncated after the second magnitude field and with a blank line between events.

\begin{tabular}{|c|c|c|c|c|c|c|c|c|c|c|}
\hline ISC & m 19660930.0559 & 1966 & 9 & 30 & 559 & 52.80 & 38.950 & 64.540 & 33.0 & $5.1 \mathrm{~B}$ \\
\hline EHB eod & 19660930.0559 & 1966 & 9 & 30 & 559 & 51.00 & 38.968 & 64.517 & 1.5 & $5.1 \mathrm{~B}$ \\
\hline EB & 19660930.0559 & 1966 & 9 & 30 & 559 & 52.31 & 39.003 & 64.563 & 13.7 & $5.1 \mathrm{~b}$ \\
\hline ISC & m 19680521.0359 & 1968 & 5 & 21 & 359 & 10.00 & 38.890 & 65.100 & 1.0 & $5.4 \mathrm{~B}$ \\
\hline EHB eod & 19680521.0359 & 1968 & 5 & 21 & 359 & 11.98 & 38.918 & 65.032 & 2.4 & $5.4 \mathrm{~B}$ \\
\hline EB & 19680521.0359 & 1968 & 5 & 21 & 359 & 13.28 & 38.895 & 65.092 & 14.4 & $5.4 \mathrm{~b}$ \\
\hline
\end{tabular}

3 ISC m 19691206.0702 EHB eod $\quad 19691206.0702$ EB $\quad 19691206.0703$

$1 \quad$ EHB codm 19701223.0700

$\begin{array}{lllllll}\text { ISC } \mathrm{m} & 19720411.0600 & 1972 & 4 & 11 & 6 & 0 \\ \text { EHB eod } & 19720411.0600 & 1972 & 4 & 11 & 6 & 0 \\ \text { AB1 } & 19720411.0600 & 1972 & 4 & 11 & 6 & 0 \\ \text { EB } & 19720411.0600 & 1972 & 4 & 11 & 6 & 0\end{array}$

$\begin{array}{llllllll}4 & \text { ISC } & \mathrm{m} 19730815.0159 & 1973 & 8 & 15 & 1 & 59\end{array}$ $\begin{array}{lllllll}\text { EHB cod } & 19730815.0200 & 1973 & 8 & 15 & 2 & 0\end{array}$ $\begin{array}{lllllll}\text { PDE } & 19730815.0159 & 1973 & 8 & 15 & 1 & 59\end{array}$

$\begin{array}{llllllll}\text { EB } & 19730815.0200 & 1973 & 8 & 15 & 2 & 0\end{array}$

$\begin{array}{llllllll}4 & \text { ISC } & \mathrm{m} 19740518.0234 & 1974 & 5 & 18 & 2 & 34\end{array}$ $\begin{array}{lllllll}\text { EHB eod } & 19740518.0234 & 1974 & 5 & 18 & 2 & 34\end{array}$ $\begin{array}{lllllll}\text { PDE } & 19740518.0234 & 1974 & 5 & 18 & 2 & 34\end{array}$ $\begin{array}{lllllll}\text { EB } & 19740518.0234 & 1974 & 5 & 18 & 2 & 34\end{array}$

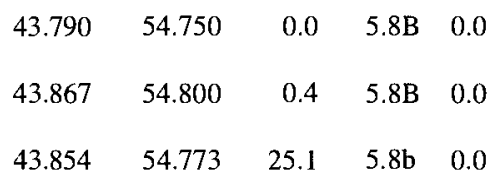




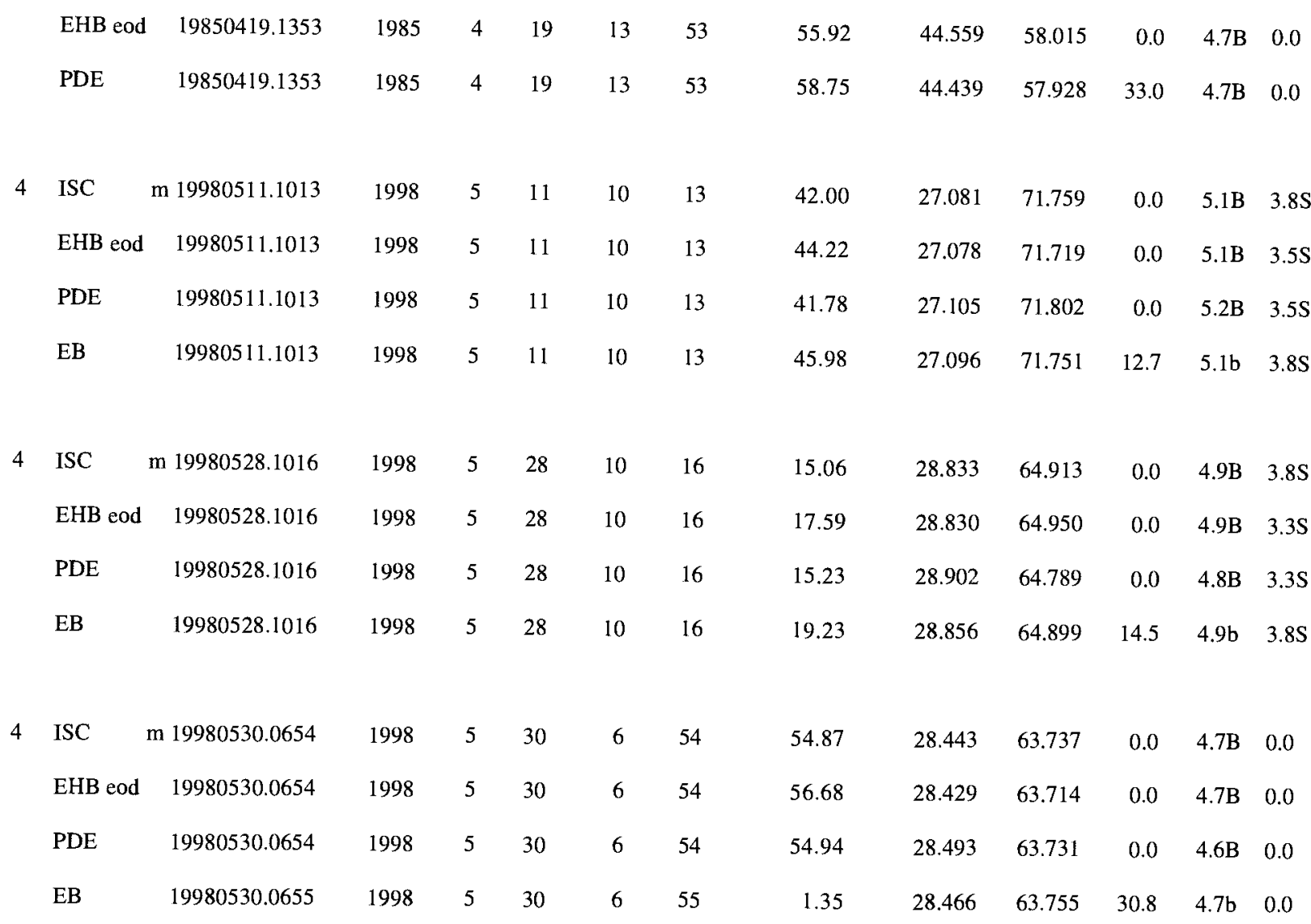

These locations are shown in figure A1. 


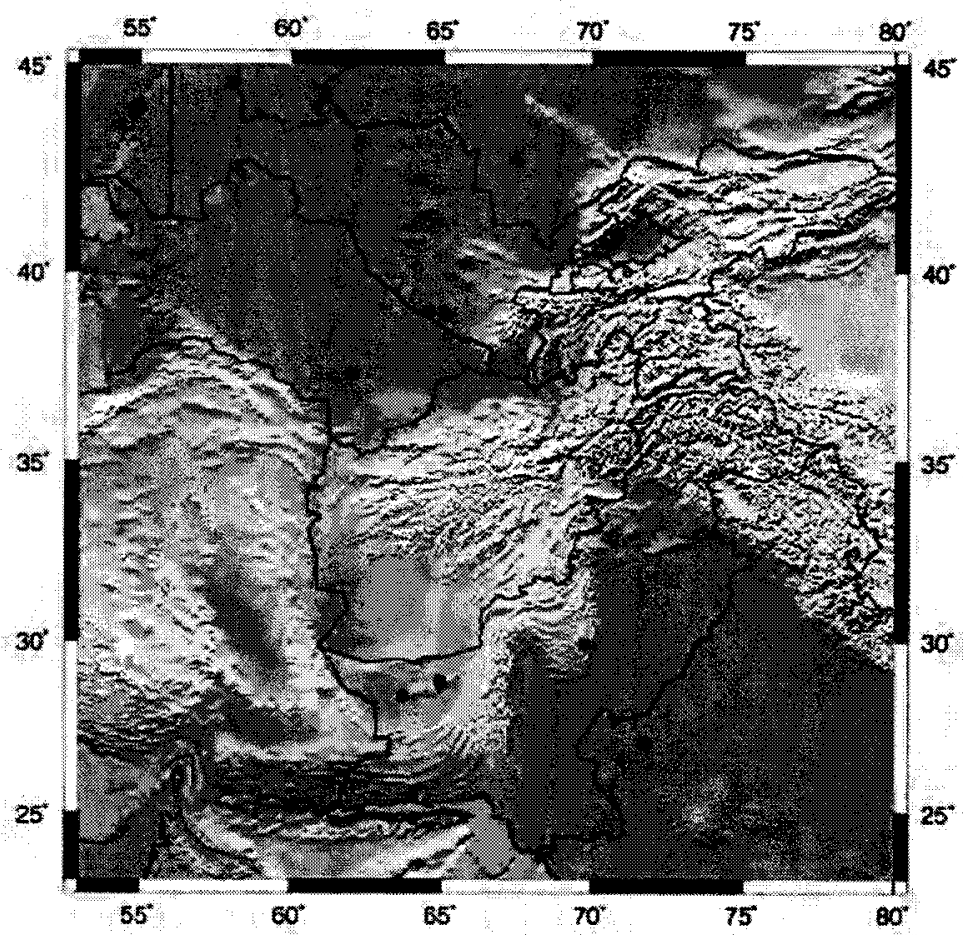

Figure A1. Locations of known explosions in the Afghanistan study region.

\section{Appendix B. Format of the "Master Catalog"}

The "Master Catalog of Afghanistan Earthquakes" is a plain text flat file, with lines of 140 characters length. It consists of catalog groups that hold one or more one-line entries from different source catalogs containing information on a given event. The source catalogs used for the "Master Catalog" are listed in table 1 of this chapter. The "Master Catalog" is compiled from 26 source catalogs, but the maximum number of entries for any event is 11. Most events in the "Master Catalog" have at least two entries.

Most of the fields in the "Master Catalog" are the same for all source catalog entries, but the last 53 characters of each line are catalogspecific comment fields containing information that is particular to that catalog. Knowing the catalog code, which is given at the beginning of each line, one can reliably parse the comment line for that catalog for the supplied parameters.

\section{Fields Unique to the Prime Entry}

The first catalog entry for any event is considered the prime entry. Its source catalog code (event ID, columns 13:26) is taken as the "Master Catalog" event ID. It is identical to other catalog entries for an event in all ways except one: the first two places are reserved for an integer counter for the number of catalog entries for the current event:

\begin{tabular}{ccl}
\hline Columns & Format & Description \\
\hline $1: 2$ & $\mathrm{i} 2$ & Number of catalog entries for this event \\
\hline
\end{tabular}




\section{Fields Common to All Catalog Entries}

The prime entry and any additional entries from other source catalogs have the following fields:

\begin{tabular}{|c|c|c|}
\hline Columns & Format & Description \\
\hline $4: 7$ & $\mathrm{a} 4$ & Catalog code \\
\hline 8 & a1 & Use code for epicenter ('e' or blank) \\
\hline 9 & al & Use code for origin time ('o', or blank) \\
\hline 10 & a1 & Use code for depth ('d' or blank) \\
\hline 11 & a1 & Use code for magnitude (' $\mathrm{m}$ ' or blank) \\
\hline $13: 26$ & a14 & $\begin{array}{l}\text { Event ID, YYYYMMDD.HHMMX where ' } \mathrm{X} \text { ' is ' } a \text { ', ' } b \text { ', } \\
\text { and so on, to resolve non-uniqueness. '- ' can be used for } \\
\mathrm{BC} \text { events }\end{array}$ \\
\hline $27: 31$ & I5 & Year (negative for B.C.) \\
\hline $33: 34$ & $\mathrm{i} 2$ & Month \\
\hline $36: 37$ & $\mathrm{i} 2$ & Day \\
\hline $39: 40$ & $\mathrm{i} 2$ & Hour \\
\hline $42: 43$ & i2 & Minute \\
\hline $45: 49$ & f5.2 & Second \\
\hline $51: 57$ & f7.3 & Latitude (North positive) \\
\hline $58: 65$ & f8.3 & Longitude (East positive) \\
\hline $67: 71$ & f5.1 & Focal depth \\
\hline $73: 75$ & f3.1 & Magnitude 1 \\
\hline 76 & al & Magnitude 1 type \\
\hline $78: 80$ & f 3.1 & Magnitude 2 \\
\hline 81 & a1 & Magnitude 2 type \\
\hline $83: 85$ & f 3.1 & Magnitude 3 \\
\hline 86 & $\mathrm{a} 1$ & Magnitude 3 type \\
\hline
\end{tabular}




\section{Magnitude Types}

The following codes are used for magnitude types:

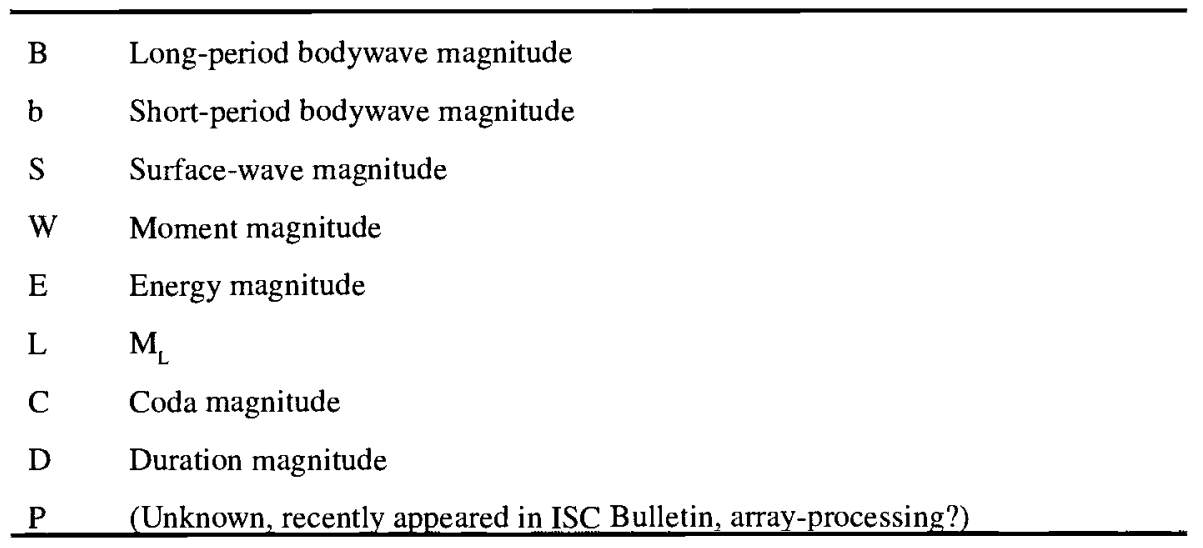

If the magnitude-type field is blank, the magnitude type is unknown.

\section{Comment Fields}

The format of the comment field (columns 88:140) is different for each source catalog. In some cases it is always blank and in others it contains important information that does not fit into the standard format. See Appendix $C$ for descriptions of the catalogs.

\section{ABE}

The comment field for the ABE catalog is composed of three elements of the source file:

\begin{tabular}{ll}
\hline Columns & Description \\
\hline $91: 94$ & Donor of first magnitude entry: \\
& ABE1 = Abe(1981) \\
& ABE3 = Abe(1984) \\
& AN2 = Abe and Noguchi (1983b) \\
& Donor of second magnitude entry: \\
$96: 99$ & (abbreviations as immediately above) \\
\hline
\end{tabular}

\section{AB1}

The comment field for $\mathrm{AB} 1$ entries is either blank or contains the word "Narrative" in columns 88:96 to indicate that a narrative summary of an earthquake's effects is available in the source catalog (Ambraseys and Bilham, 2003a).

\section{AB2}

The comment field for $\mathrm{AB} 2$ entries is either blank or contains the word "Narrative" in columns 88:96 to indicate that a narrative summary of an earthquake's effects is available in the source catalog (Ambraseys and Bilham, 2003b). All AB2 entries in the "Master Catalog" have a narrative. 


\section{AM}

The comment field for AM entries is either blank, or contains the word "Narrative" in columns 88:96 to indicate that a narrative summary of an earthquake's effects is available in the source catalog (Ambraseys and Melville, 1982).

\section{CEN}

The comment field for CEN entries contains six elements from the source file:

\begin{tabular}{ll}
\hline Columns & Description \\
\hline $88: 90$ & Catalog source \\
92 & AHYP (Engdahl code for open azimuth) \\
$93: 96$ & ISOL (Engdahl code for solution type) \\
97 & ISEQ (Engdahl code for other info) \\
$99: 100$ & Magnitude scale \\
102:106 & Magnitude source \\
\hline
\end{tabular}

See the section on the EHB comment-field format for explanations of "Engdahl" codes. Other fields are described by Engdahl and Villaseñor (2002).

\section{CHI}

The comment field for $\mathrm{CHI}$ entries is always blank.

\section{EB}

The comment field for EB entries carries the following information:

\begin{tabular}{ll}
\hline Columns & Description \\
\hline 88 & "P" for origin time as free parameter (always free in this catalog) \\
89 & "P" for cpicenter (lat-lon) as frce paramcter, " $F$ " for fixed \\
90 & "P" for depth as free parameter, " $F$ " for fixed. \\
$91: 95$ & Standard error of origin time (f5.2) \\
$96: 100$ & Standard error in depth (f5.1) \\
$101: 106$ & Azimuth (degrees clockwise from north) of minor semi-axis of $90 \%$ confidence ellipse for \\
$107: 111$ & epicenter (f6.1) \\
$112: 116$ & Length (km) of minor semi-axis of $90 \%$ confidence ellipse for epicenter (f5.1) \\
\hline
\end{tabular}

\section{EBS}

Same as EB catalog. 


\section{EHB}

The comment line for EHB entries contains the following information:

\begin{tabular}{ll}
\hline Columns & Description \\
\hline 88 & AHYP (secondary azimuth gap) \\
$89: 91$ & ISOL (solution type \\
$92: 93$ & ISEQ (other info) \\
\hline
\end{tabular}

The meanings of these flags are:

- AHYP -- secondary teleseismic azimuth gap (a1)

o $\quad$ Blank $=$ secondary azimuth gap $\leq 180 \mathrm{deg}$

o $\quad Z=$ secondary azimuth gap $>180 \mathrm{deg}$

- ISOL solution type (a3)

o $\quad$ HEQ $=$ origin time and hypocenter fixed

o $\quad$ DEQ $=$ depth free $($ sedep $\leq 15 \mathrm{~km})$

o WEQ = depth fixed at waveform depth

o $\quad B E Q=$ depth fixed at BB depth

o $\quad F E Q=$ depth fixed by Engdahl

o LEQ $=$ depth fixed by program (sedep $>15 \mathrm{~km}$ )

o $\quad \mathrm{XEQ}=$ poor solution $(\mathrm{ser}>35 \mathrm{~km})$

- ISEQ -- other info (a2)
o $\quad \mathrm{X}=$ explosion/cavity collapse
o $\quad \mathrm{Xx}=$ location known to $\mathrm{xm}$
o $\quad \mathbf{M}=\mathrm{CMT}$ solution available
o $\quad \mathrm{Mx}=$ location known to $\mathrm{x} \mathrm{km}$

\section{EHBI}

Same as EHB catalog.

\section{EHBS}

Same as EHB catalog. 


\section{GC}

The comment field for GC entries contains the following information:

\begin{tabular}{ll}
\hline Columns & Description \\
\hline $88: 95$ & Radiated seismic energy (e8.2) \\
$97: 104$ & Seismic moment (e8.2) \\
$106: 109$ & Apparent stress (f4.1) \\
$111: 120$ & Focal mechanism (strike/dip/slip) \\
\hline
\end{tabular}

\section{GR}

The comment field for GR entries is always blank.

\section{GS}

The comment line for GS entries has the following information:

\begin{tabular}{ll}
\hline Columns & Description \\
\hline $88: 93$ & Seismic moment \\
$96: 132$ & Principal axes and eigenvalues of the moment tensor \\
\hline
\end{tabular}

Principal axes and eigenvalues are given in the same format as on the USGS NEIC website (http://neic.usgs.gov/neis/FM/)

\section{GUTE}

The comment field for GUTE entries is always blank.

\section{HRV}

Same format as GS catalog.

\section{IND}

The comment field for IND entries is always blank.

\section{ISC}

The comment field for ISC entries is always blank.

\section{ISS}

The comment field for ISS entries is always blank.

\section{NOAA}

The comment field for NOAA entries is always blank.

\section{OMT}

Same format as GS catalog, except that a code for the source of the moment tensor is appended in columns 133:136. 


\section{OTH}

The conment field for OTH entries is always blank.

\section{OTH2}

The comment field for OTH2 entries is always blank.

\section{PDE}

The comment field for PDE entries contains the following information:

\begin{tabular}{|c|c|}
\hline Columns & Description \\
\hline \multirow[t]{5}{*}{88} & NEIC code for noteworthy characteristics of epicenter and origin time: \\
\hline & $\begin{array}{l}\mathrm{R} \text { Parameters of the hypocenter were supplied to the USGSNEIC by another } \\
\text { agency. }\end{array}$ \\
\hline & $\begin{array}{l}\text { \% Single network solution. A non-furnished hypocenter was computed by } \\
\text { using data reported by single network of stations for which the date and(or) } \\
\text { origin time cannot be confirmed from seismograms available to a USGSNEIC } \\
\text { analyst. }\end{array}$ \\
\hline & $\begin{array}{l}\text { * Less reliable solution. The geometric mean of the semi-major and semi- } \\
\text { minor axes of the horizontal } 90 \% \text { confidence ellipse is greater than } 8.5 \mathrm{~km} \text { and } \\
\text { less than or equal to } 16.0 \mathrm{~km} \text {. }\end{array}$ \\
\hline & $\begin{array}{l}\text { ? Poor solution, published for completeness of the catalog. The geometric } \\
\text { mean of the semi-major and semi-minor axes of the horizontal } 90 \% \\
\text { confidence ellipse is greater than } 16.0 \mathrm{~km} \text {. }\end{array}$ \\
\hline \multirow[t]{6}{*}{90} & USGSNEIC code for noteworthy characteristics of focal-depth: \\
\hline & $\mathrm{N}$ Focal-depth was constrained at $33 \mathrm{~km}$. \\
\hline & D Focal-depth was constrained by depth-phases. \\
\hline & G Focal-depth was constrained by a geophysicist. \\
\hline & $\begin{array}{l}\text { * Less well-constrained free depth. The } 90 \% \text { marginal confidence interval for } \\
\text { depth is greater than } 16.0 \mathrm{~km} \text { and less than or equal to } 30.0 \mathrm{~km} \text {. }\end{array}$ \\
\hline & $\begin{array}{l}\text { ? A poorly constrained free depth. The } 90 \% \text { marginal confidence interval for } \\
\text { depth is greater than } 30.0 \mathrm{~km} \text {. }\end{array}$ \\
\hline $91: 98$ & $\begin{array}{l}\text { Combined magnitude-scale-source for additional magnitudes beyond those } \\
\text { listed in columns 73:86.(see U.S. Geological Survey, 2001) }\end{array}$ \\
\hline 99 & Modified Mercalli Intensity \\
\hline \multirow[t]{4}{*}{100} & Macroseismic summary code: \\
\hline & $F-$ felt \\
\hline & $\mathrm{D}$ - damage reported \\
\hline & $\mathrm{C}$ - casualties reported \\
\hline
\end{tabular}

\section{ROTH}

The comment field for ROTH entries is always blank.

\section{SSR}

The comment field for SSR entries is always blank. 


\section{Appendix C. The Source Catalogs}

The "Master Catalog of Afghanistan Earthquakes" has been assembled with information from 26 source catalogs, which are briefly described in Table C1, in alphabetical order according to their catalog code in the "Master Catalog." More extensive descriptions of each catalog are in the body of this report.

Table C1. List of earthquake catalogs used in compiling the "Master Catalog of Afghanistan Earthquakes." "Catalog code" is used in the "Master Catalog" to identify source catalogs. "Number of entries" refers to the number of events in the "Master Catalog" that contain an entry from that source catalog. "Date range" is the range of years spanned by those entries.

\begin{tabular}{|c|c|c|c|}
\hline Code & Description & $\begin{array}{l}\text { Number of } \\
\text { entries }\end{array}$ & Date range \\
\hline $\mathrm{ABE}$ & $\begin{array}{l}\text { Catalog of large earthquakes, derived from Abe }(1981,1984) \text { and Abe and } \\
\text { Noguchi }(1983 a, b) \text { and obtained by us from the NEIC-HDF catalog "Abe." } \\
\text { Useful mainly for magnitude estimates. }\end{array}$ & 47 & $1897-1978$ \\
\hline $\mathrm{AB} 1$ & $\begin{array}{l}\text { Study of Afghanistan earthquakes by Ambraseys and Bilham (2003a). } \\
\text { Especially valuable for work on historical events and calculation of Ms for } \\
\text { many older events, either from macroseismic data or early instrumental } \\
\text { records. Valuable historical narratives for many events. }\end{array}$ & 823 & $734-2002$ \\
\hline $\mathrm{AB} 2$ & $\begin{array}{l}\text { Study of earthquakes in Northern Baluchistan (southeastern Afghanistan) } \\
\text { by Ambraseys and Bilham ( } 2003 \mathrm{~b} \text { ). Most events repeated from AB1 but } \\
\text { contains important historical narratives of many events not covered in } \\
\text { AB1. }\end{array}$ & 44 & $1852-1997$ \\
\hline AM & $\begin{array}{l}\text { Study of historical earthquakes in the Iran region by Ambraseys and } \\
\text { Melville (1982). }\end{array}$ & 125 & $\begin{array}{l}2000 \text { B.C. } \\
-1979\end{array}$ \\
\hline CEN & $\begin{array}{l}\text { "Centennial Catalog" by Engdahl and Villaseñor (2002). Careful review of } \\
\text { different magnitude estimates for events with magnitude } 7 \text {. }\end{array}$ & 99 & $1902-1974$ \\
\hline CHI & "China" catalog from the hypocenter data files of the USGSNEIC. & 347 & $1895-1970$ \\
\hline EB & $\begin{array}{l}\text { Relocations by this author, using EAB method similar to EHB on phase- } \\
\text { arrival data from the ISC and PDE. }\end{array}$ & 10,007 & $1964-2004$ \\
\hline EBS & $\begin{array}{l}\text { Relocations by this author, using EAB method similar to EHB (Engdahl } \\
\text { and others, 1998) on phase-arrival data from the ISS. }\end{array}$ & 102 & $1921-1963$ \\
\hline EHB & $\begin{array}{l}\text { Standard catalog of global seismicity by Engdahl, using the EHB method } \\
\text { (Engdahl and others, 1998). }\end{array}$ & 10,712 & 1964-2004 \\
\hline EHBI & $\begin{array}{l}\text { Special catalog of Iranian earthquakes based on the EHB catalog but with } \\
\text { careful review of all events for proper depth determination. Includes pre- } \\
1964 \text { events relocated using ISS data. }\end{array}$ & 995 & $1923-2004$ \\
\hline EHBS & $\begin{array}{l}\text { Standard application by Engdahl of the EHB method (Engdahl and others, } \\
\text { 1998) to larger events in the ISS bulletins. }\end{array}$ & 73 & $1921-1963$ \\
\hline GC & $\begin{array}{l}\text { USGSNEIC analysis of broadband waveforms for larger events, obtained } \\
\text { from G.L. Choy. Especially useful for depth (Choy and Dewey, 1988) } \\
\text { but also for energy magnitude and radiated seismic energy (Choy and } \\
\text { Boatwright, 1995). }\end{array}$ & 74 & $1987-2003$ \\
\hline GR & $\begin{array}{l}\text { USGSNEIC-HDF catalog "G-R," based on Gutenberg and Richter (1954). } \\
\text { Important source of magnitudes for large events. }\end{array}$ & 178 & 1905-1949 \\
\hline GS & $\begin{array}{l}\text { USGSNEIC moment tensor determinations (Sipkin, 1982). Useful } \\
\text { estimates of depth, moment, and mechanism. }\end{array}$ & 148 & $1981-2004$ \\
\hline GUTE & $\begin{array}{l}\text { USGSNEIC-HDF catalog "GUTE," based on Gutenberg (1945). Important } \\
\text { source of magnitudes for large events, but mostly superceded by GR. }\end{array}$ & 181 & 1905-1949 \\
\hline
\end{tabular}


HRV Harvard CMT solutions (Dziewonski and others, 1980) obtained from the USGSNEIC database. Especially useful for systematic estimates of moment magnitude.

$\begin{array}{ll}\text { IND USGSNEIC-HDF "India" catalog. } & 107\end{array}$

$1668-1973$

ISC "Bulletin of the International Seismological Centre," considered the most complete global archive of earthquake phase readings and parameter data.

ISS "Bulletin of the International Seismological Service," scanned, optical character recognition, reformatting and quality control by Antonio Villaseñor (Villaseñor and others, 1997).

NOAA Catalog of Dunbar and others (1992).

OMT Other moment tensor solutions besides HRV and GS, obtained from the USGSNEIC-HDF database. Mostly from Russia or CSEM.

OTH Events listed in the ISC Bulletin but not located by the ISC. Locations and magnitudes from a contributing agency. Use with caution! Mostly in the "Sub-Threshold Catalog of Afghanistan Earthquakes." .

OTH2 Same as OTH, but for an event that has contributed solutions from more than one agency. "Sub-Threshold Catalog of Afghanistan Earthquakes.".

PDE USGS "Prelininary Determination of Epicenters." Some Weekly and QED locations were used for the very latest events in the "Master Catalog." Pre1973 events not used.

ROTH Rothé (1969) global catalog; useful coverage during the 1950s. 


\section{Appendix D. Order of Preferred Sources for Event Parameters}

For each event in the "Master Catalog of Afghanistan Earthquakes," the preferred sources for event parameters were taken in the following order:

1) Magnitude

2) Epicenter

3) Depth

4) Origin time (normally follows whatever source is preferred for depth, but there are some exceptions)

The preferences are shown in the "use code" (see Appendix B) for each catalog entry in the "Master Catalog." See Appendix C for more information about the individual catalogs. For each event, only one catalog entry can be designated as preferred for each of the four parameters.

For magnitude, epicenter, and depth, the same basic algorithm was used, but the order of candidates for preferred source naturally varies. The algorithm starts with the most "respected" source. If that is available for the event in question, it is used and the search stops. If not, it moves down the list until it finds a catalog that supplied the appropriate parameter for this event.

There will be a preferred source for epicenter and origin time (even if it is only a year) for every catalog event but not for depth and magnitude (in the case where no non-zero depth or magnitude was supplied by any source catalog). Only events prior to 1900 can have no preferred source for magnitude (that is, no magnitude information).

Not all source catalogs were tested for each parameter. Because of the other catalogs that are always available for this dataset, some catalogs would never be cited as the source for some parameters. For example, the Harvard CMT catalog was never tested as the preferred source for epicenter because there are always other sources (for example, ISC or PDE) that are preferred over it.

If the preferred source for depth is GC or GS, the origin time preference follows the preferred source for epicenter because these two catalogs do not give an origin time that is strictly coupled to the depth in a location algorithm.

On the following pages, the order of preferred catalog sources is listed for magnitude, epicenter, and depth.

\section{Magnitude}

\section{Modern waveform analysis}

- HRV--Harvard CMT

- GS--NEIC body waveform inversion

- OMT--Other moment tensor studies

\section{Special studies}

- CEN--Centennial catalog, careful survey of all reported magnitudes

- $\quad$ AB1--Ambraseys and Bilham (2003a), if Ms was measured

- AM--Ambraseys and Melville (1982), if Ms was measured

- ABE--USGSNEIC-Abe, Abe $(1981,1984)$ and Abe and Noguchi $(1983 a, b)$ papers

\section{Modern standard global catalogs}

- ISC--ISC-determined original magnitudes, not contributed

- PDE--USGSNEIC original magnitudes, mostly from the monthly bulletin, some from the weekly bulletin or the QED

\section{Modern standard regional catalogs}

- OTH--Listed by ISC, some early ones are PDE solutions 
- $\quad$ OTH2--Listed by ISC, some early ones are PDE solutions

\section{Early instrumental standard global catalogs}

- GR--USGSNEIC-Gutenberg and Richter, often listed in CEN catalog

- GUTE--USGSNEIC-Gutenberg

- ROTH--USGSNEIC-Rothé; unknown magnitude type

\section{Early instrumental regional catalogs}

- SSR--USGSNEIC-USSR catalog; unknown procedures

- CHI--USGSNEIC-China catalog; unknown procedures

- IND--USGSNEIC-India catalog; unknown procedures

\section{No original magnitude determination}

- EB-- EAB relocations; contains ISC or PDE magnitudes

- AB1--Ambraseys and Bilham (2003a); no special Ms study was made

- AM--Ambraseys and Melville (1982); no special Ms study was made

- EHBI--EHB reviewed Iran catalog; contains ISC, PDE, and HRV magnitudes

- EHBS--EHB ISS relocations; unknown magnitude source

- EHB--Standard EHB catalog; no special review, contains ISC, PDE or HRV magnitudes

- NOAA--USGSNEIC-NOAA; highly doubtful quality

\section{Epicenter}

\section{Special instrumental studies}

- EHBI--EHB reviewed Iran catalog; ISC or PDE starting point

- $\quad$ EB--EAB relocations; usually from ISC or EHB starting point

- $\quad$ EBS--EAB relocations; usually from ISS or EHBS starting point

- EHBS--EHB ISS relocations; ISS starting point

- EHB--Standard catalog; no special review; ISC or PDE starting point

- CEN--Centennial catalog; some relocations; some from literature

\section{Modern instrumental global catalogs}

- ISC--ISC-determined original locations; not contributed

- PDE--USGSNEIC original locations; mostly from the monthly bulletin, some from the weekly bulletin or the QED 


\section{Modern instrumental regional catalogs}

- OTH--Listed by ISC; some are PDE locations from early ISC

- OTH2--Listed by ISC; some are PDE locations from early ISC

\section{Special macroseismic studies}

- AB1--Ambraseys and Bilham (2003a); macroseismic locations, but not always

- $\mathrm{AB} 2-$-Ambraseys and Bilham (2003b); mostly in AB1; no new location info

- AM-Ambraseys and Melville (1982); macroseismic locations

\section{Early instrumental regional catalogs}

- SSR--USGSNEIC-USSR catalog; instrumental locations; doubtful quality

- CHI--USGSNEIC-China catalog; instrumental locations; doubtful quality

- IND--USGSNEIC-India catalog; instrumental locations; doubtful quality

\section{Early instrumental standard global catalogs}

- ROTH--USGSNEIC-Rothé; instrumental locations; doubtful quality

- ISS--USGSNEIC-ISS; instrumental locations; doubtful quality

- GR-- USGSNEIC-Gutenberg and Richter; original locations; poor quality

- GUTE--USGSNEIC-Gutenberg; original locations; poor quality

\section{Compilations, not original locations}

- ABE--USGSNEIC-Abe; unknown source of locations

- NOAA--USGSNEIC-NOAA; highly doubtful quality

Note: If EAB- or EHB-derived solutions were flagged as poor solutions (fixed epicenter in the case of EB, "XEQ" flag in the case of EHB), they are not selected as preferred source for epicenter.

\section{Depth}

\section{Modern waveform analysis}

- GC--USGSNEIC BB depths

- GS--USGSNEIC body waveform inversion 


\section{Special analysis of depth phases in relocation}

- $\quad$ EHBI--EHB-reviewed catalog for Iran; special attention to depth

- EB--EAB relocations; ISC and PDE

- EBS--EAB relocations of ISS

- EHBS EHB ISS relocations

- EHB--Standard EHB catalog; unreviewed

- CEN--Centennial catalog; some relocations

\section{Modern instrumental global catalogs}

- ISC--ISC-determined original locations; not contributed

- PDE--USGSNEIC original locations; mostly from the monthly bulletin, some from the weekly bulletin or the QED

\section{Modern instrumental regional catalogs}

- OTH--Carried by ISC; some early ones are PDE solutions

- OTH2--Carried by ISC; some early ones are PDE solutions

\section{Early instrumental regional catalogs}

- SSR--USGSNEIC-USSR catalog; instrumental locations; doubtful quality

- CHI--USGSNEIC-China catalog; instrumental locations; doubtful quality

\section{Early instrumental standard global catalogs}

- ROTH--USGSNEIC-Rothé; instrumental locations; doubtful quality

- ISS--USGSNEIC-ISS; instrumental locations; doubtful quality

- GR--USGSNEIC-Gutenberg and Richter; original locations; poor quality

- GUTE--USGSNEIC-Gutenberg; original locations; poor quality

\section{Compilations (unknown source of depth information)}

- AB1--Ambraseys and Bilham (2003a)

- ABE--USGSNEIC-Abe

- NOAA--USGSNEIC-NOAA; highly doubtful quality

Note: As discussed in the main text, when EB-class and EHB-class entries are available for the same event, the catalog that reported the shallowest depth is preferred. 


\section{Appendix E. The EAB Relocation Method}

The EB and EBS catalogs in this study were prepared with a newly developed set of programs and procedures that implement a method very similar to the well-known EHB methodology (Engdahl and others, 1998) for relocating large numbers of earthquakes in a highly automated but seismologically sophisticated manner. This method will be referred to here as the "EAB method."

The basis of the EAB method is a highly developed program for multiple-event relocation based on the Hypocentroidal Decomposition, or HDC, method (Jordan and Sverdrup, 1981). The HDC code has been developed extensively in recent years for research on ground-truth events in collaboration with E.R. Engdahl, and the code has been thoroughly tested in regular comparisons with output from the EHB method. The EAB and EHB codes have a few subroutines in common but otherwise have been developed completely independently and have almost completely distinct code bases. The HDC code began development in 1985 and had no interaction with the EHB code until 2000. Both codes have subsequently benefited from constant comparison of results.

The EAB method uses the HDC algorithm in a single-event mode, which is a special case of the more general multiple-event mode for which the algorithm was constructed. In its most general, multiple-event, usage, the HDC algorithm calculates the locations of each of a multi-event cluster of earthquakes with respect to the centroid ("hypocentroid") of the cluster as a whole. In single-event mode, the HDC algorithm treats each individual event as a cluster having only one member, and the computation of the hypocenter for the event is treated computationally as the estimation of an improved hypocentroid for the cluster. The handling of a single-event computation as a special case of the more general HDC procedure enables us to take advantage of the thorough testing to which the general HDC procedure has been subjected.

\section{Data Formats}

The EAB code takes as input the 96-byte fixed format records of the ISC. The EAB process has adopted the same extension of this format as EHB to carry reading flags that can be set for any phase reading to exclude it from a relocation computation. This flagging feature is used extensively during the cleaning and review process. The input data file for the relocations in this study, for about 20,000 events, is $130 \mathrm{Mb}$ in size.

\section{Calculation of travel times}

As with EHB, travel times and derivatives for all phases in the EAB method are calculated with the ak135 travel time model (Kennett and others, 1995) and tau-p software (Buland and Chapman, 1983). Corrections are made for station elevation and ellipticity, in a manner functionally identical to the EHB code.

\section{Weighting}

Like EHB, phases are weighted on the basis of estimates of the spread of actual data around the theoretical travel times, as a function of phase and epicentral distance. While this is clearly the right strategy, the proper values to use with most phases are still very poorly known. Also, like EHB, the EAB method employs variable estimates of reading error for different phases, and these translate into different weights. The weighting schemes in the EHB and EAB methods are not identical and will lead to slightly different results, even with identical datasets.

\section{Phase Association}

The EAB method takes the "probability density function" approach used by the EHB method to conduct phase association (or identification) for depth phases and extends it to all phases. This work is still in the early stages of development, and, for the time being, the same PDF is used for most phases. Phase association is done simultaneously on all readings from a single station, and a complex layer of program logic is used to enforce some seismologically reasonable rules. Phase association is done when data are first read (based on the input file's starting hypocenter and origin time) and again after the first iteration to account for any large changes from the starting location that may have occurred. Additional phase re-association mainly serves to prevent convergence. The phase association algorithm is able to associate secondary phases as $\mathrm{Lg}$, and they can be used in the location.

In contrast to the EHB method (which does use some secondary phases), the EAB method attempts to use all available phase readings, regardless of phase ID. This philosophy has been driven by the experience of our ground-truth work with multiple-event location procedures, but it may require some revision in large-scale single-event location work such as the Afghanistan catalog. Further research is needed on this issue.

\section{The Cleaning Process}

The main problem in earthquake location is always the same: to find a starting location that is close enough to the global minimum so that the linearized inversion does not settle into one of the many local minima that usually exist. ISC locations are often good for 
this purpose, but not always, and when one is dealing with ISS data or the contributed solutions carried in the ISC, there are frequent problems. One approach to this problem is to do multiple runs of a full location process with different trial depths, study the output files, edit the input files, and rerun. For a dataset of 10,000 events this is not practical. Instead, the EAB process employs a separate "minimal" location program that makes it somewhat practical to

- Interactively test different starting depths for an event until one is satisfied

- Hold the depth fixed or leave it free

- Do phase reassociation whenever depth or origin time changes

- Set a new starting origin time if necessary or let the inversion calculate it for the new depth

- Finally, write a new data file with preferred starting depth and corresponding phase associations, and with large outliers flagged

Note that this process does not involve any free parameters in latitude or longitude, only depth and origin time. Therefore, it is still prone to trouble when the starting epicenter is badly in error.

As part of the process, the open azimuth (largest azimuthal gap between two stations) is calculated on the basis of the stations that are actually being used (i.e., not flagged stations). If the open azimuth is greater than $180^{\circ}$ the event is set to have a fixed epicenter in the full relocation because there is too much risk of such an event becoming completely unstable during relocation.

To process 10,000 events this way would still take too much time, so the program runs semi-automatically. It first tries to solve for a free depth from the depth and origin time given in the input file. Based on the number of data in the dataset that are fitted by this solution (arrivals with very large residuals are kicked out for several iterations) and by the squared residual error, the program decides if a solution requires interactive review. On average about one in five events are presented for review. It is a continuous process, with rarely more than a few seconds elapsing before the next event that needs interactive review. It is possible to force interactive review for every event, but the time allotted for this project would not have sufficed.

Interactive review can be as simple as fixing the depth and writing the event out, or as laborious as making dozens of inversions with different starting depths. No direct editing of phase arrivals is possible, and some events are best classified as pathological: nothing short of intense scrutiny will sort them out.

During the cleaning process for the Afghanistan project, a large number of events fell into the category of fitting a rather large range of crustal depths, typically from about $10 \mathrm{~km}$ to $40 \mathrm{~km}$. These events usually have no depth phase reports, or perhaps a small number of secondary phase reports, some of which could be depth phases, but rarely are they consistent. This is normally dealt with by setting an arbitrary $(10,30,33,35 \mathrm{~km})$ depth for shallow events that fail to converge cleanly. For the Afghanistan project, a somewhat different, and certainly more time consuming, strategy was implemented. Using fixed depths and solving only for origin time and new phase associations, we were commonly able to define a range of acceptable depths over which the number of data that are fitted and the residual squared error were approximately constant. The minimum depth of this range of depths was used as the default for crustal events that have been reviewed. It is typically in the $10-20 \mathrm{~km}$ range, but for many events the range of acceptable depths extends to depths shallower than $10 \mathrm{~km}$. The shallowest events have normally been fixed at $5 \mathrm{~km}$, even if they seem to converge to a free depth of a few kilometers, to avoid the possibility of negative focal-depths during the full relocation. On average, the default depths set in the EAB process are shallower than those used in the EHB process.

This cleaning process had no logic to identify shallow-focus events for which errors in arrival-time data or velocity model result in an apparent range of acceptable depths that is substantially too deep. The "Grooming" section of this chapter contains a discussion of the procedure (choosing the shallower of the depths reported by EAB- and EHB-derived solutions) used to try to reduce contamination of the "Master Catalog" by events with severely overestimated focal-depths.

Even with the modest (in terms of percentage of events) amount of review done in the cleaning phase, two conclusions are reached:

- It still takes a huge amount of time to process a dataset the size of the Afghanistan catalog: approximately a month of fulltime work.

- It is well worth doing. Any form of review, before or after relocation, makes a significant difference in the quality of the dataset.

The actual relocations are rather anticlimactic (once one has found all the pathological situations that break the code), requiring about 8 hours on a Macintosh computer of modest speed.

It is regrettable that there was insufficient time to carry out a more careful review of the EAB relocations afterwards. Even so, these locations should be at least as good as the standard EHB catalog, and the ability to make comparisons between two equivalent but 
independent location procedures gives the researchers who follow a better chance at unraveling the complex story of Afghanistan earthquake activity.

\section{Appendix F. About the "Sub-Threshold Catalog of Afghanistan Earthquakes"}

Earthquakes in the "Master Catalog" that were removed due to failure to meet the minimum magnitude requirements were collected in the "Sub-Threshold Catalog of Afghanistan Earthquakes" catalog in "Master Catalog" format (see Appendix B). Their date range is 1911 through 2004. Many of these events have reasonably well determined hypocenters, and it is likely that they would have been included in the "Master Catalog" if their magnitudes had exceeded the minimum magnitude thresholds. Another large subset of the "Sub-Threshold Catalog" consists of earthquakes for which no magnitudes were computed. Again, many of these have reasonably well determined hypocenters. During much of the $20^{\text {th }}$ century, events in the mid-5 magnitude range could easily have failed to be assigned a magnitude. The "Sub-Threshold Catalog" also includes OTH-only (Appendix C) events that were solutions contributed to the ISC. Many of these may be legitimate events, and some of them may even be fairly well located, but only careful inspection of the phasearrival data can begin to confirm that. There are 9,736 earthquakes listed in the "Sub-Threshold Catalog."

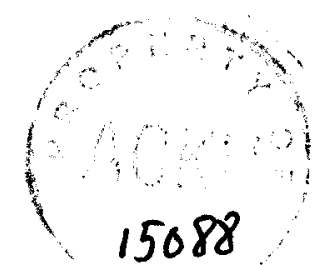

